\title{
EVALUATING NON-PROFIT INTRAORGANIZATIONAL TWITTER USE OF UNICEF
} AND MSF

by

Kimberley Fortin

Bachelor of Arts, International Development, African Studies, McGill University, 2010-2013

Graduate Certificate in Professional Communications Management, Royal Roads University, 2020

\begin{abstract}
A MRP
presented to Ryerson University

in partial fulfillment of the requirements of the degree of Master of Professional Communication
\end{abstract}

Toronto, Ontario, Canada, 2021

(C) Kimberley Fortin, 2021 


\section{AUTHOR'S DECLARATION FOR ELECTRONIC SUBMISSION OF AN MRP}

I hereby declare that I am the sole author of this Major Research Paper. This is a true copy of the MRP, including any required final revisions.

I authorize Ryerson University to lend this MRP to other institutions or individuals for the purpose of scholarly research.

I further authorize Ryerson University to reproduce this MRP by photocopying or by other means, in total or in part, at the request of other institutions or individuals for the purpose of scholarly research.

I understand that my MRP may be made electronically available to the public. 
Evaluating Non-profit Intraorganizational Twitter Use of UNICEF and MSF

Kimberley Fortin

Master of Professional Communication, 2021

Ryerson University

\begin{abstract}
Non-profit organizations (NPOs) have used Twitter as a platform to communicate with their stakeholders since its launch in 2006, yet numerous studies show that there is no consistent strategy among organizations on how they communicate on the platform (Java et al., 2009). While these studies showcase some strategies employed by non-profits on Twitter, there is a lack of research on how non-profit organizations (NPOs) communicate on Twitter across branches of their organization in different regions. This pilot study evaluates 163 Tweets across Médecins Sans Frontières (MSF) and UNICEF Twitter accounts in Canada and South Africa to determine how NPOs frame their communications content on Twitter. Through an analysis of functional and rhetorical framing, the study discovers that some NPOs have consistent strategies in functional and rhetorical framing, while others are inconsistent between intraorganizational channels on Twitter. The findings also showcase the importance of critically looking at previous studies on NPO Twitter use, as studies that generalize how NPOs communicate on the platform may not match how NPOs communicate across their intraorganizational channels.
\end{abstract}




\section{Acknowledgement}

I would like to thank my MRP supervisor Dr. Gregory Levey for his constructive feedback, guidance, and encouragement throughout my work on my MRP. I also would like to thank my second reader Dr. Greg Elmer for his valuable review and comments in preparation for final submission. Lastly, I would also like to thank my partner and family for their continuous motivation and support during the year and throughout the writing process of my MRP. 


\section{Table of Contents}

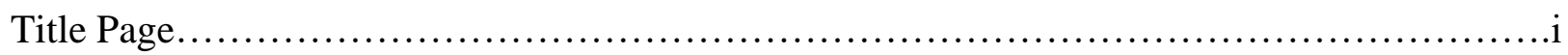

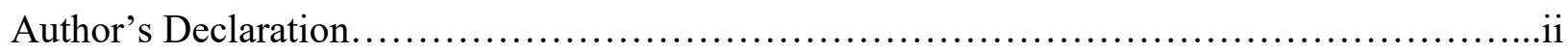

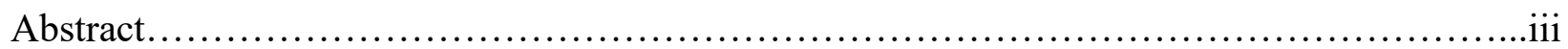

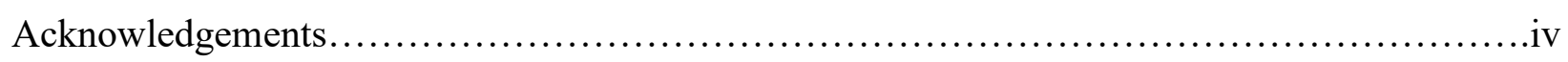

Table of Contents..................................................................

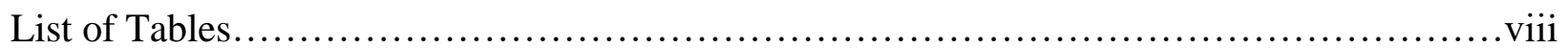

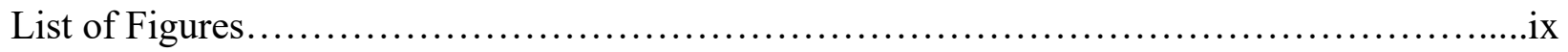

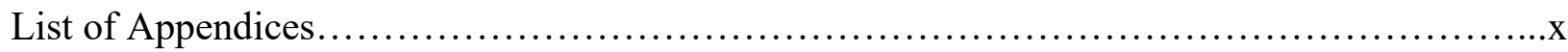

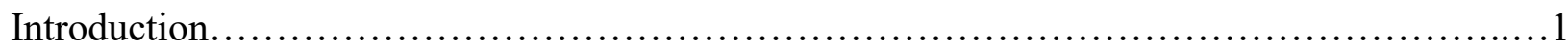

Research Questions.......................................................2

Background Information..................................................

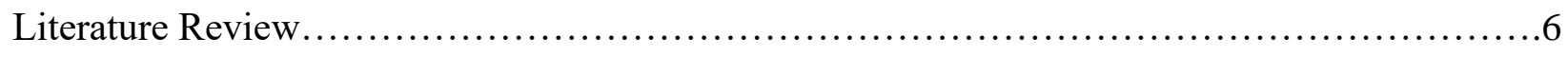

Dialogic Communication....................................................6

Functional Communication................................................

Content Strategy and Engagement on Twitter.................................. 10

Rhetorical Framing on Twitter............................................... 12

Advocacy and Hashtag Use................................................. 13

Twitter Communication During Health Crises.................................. 14

Geographic Considerations............................................... 16

Social Media Use in Canada.................................................. 17

Social Media Use in South Africa.............................................. 18

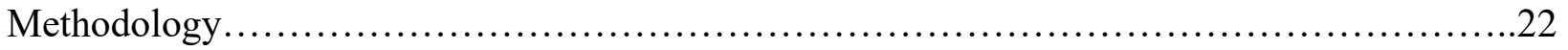




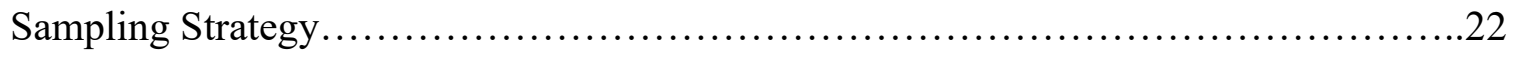

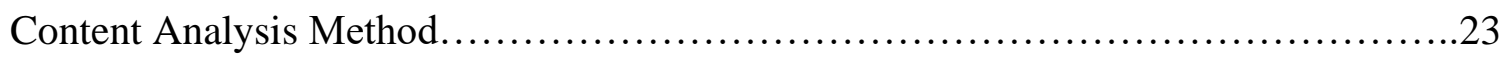

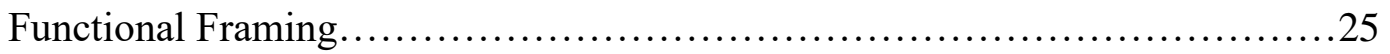

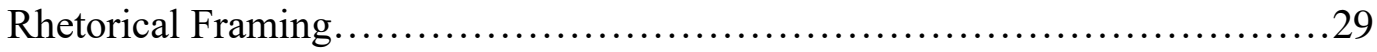

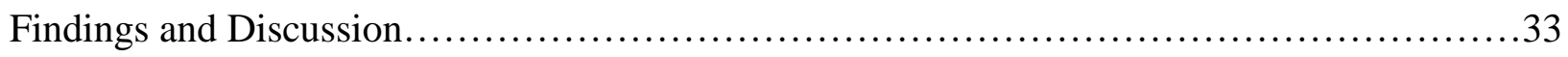

Functional Frame Use by NPOs................................................

MSF Canada......................................................................

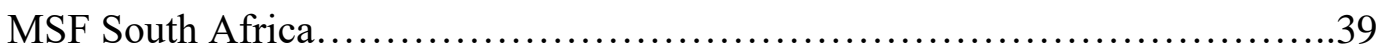

MSF’s Intraorganizational Channels................................................

UNICEF Canada......................................................... 42

UNICEF South Africa.................................................... 44

UNICEF's Intraorganizational Channels....................................46

Rhetorical Frame Use by NPOs.................................................47

MSF Canada and MSF South Africa..........................................50

UNICEF Canada and UNICEF South Africa.................................52

MSF and UNICEF Rhetorical Framing ....................................54

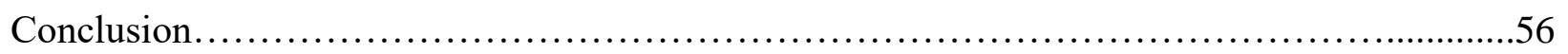

Considerations for Future Research and Limitations.................................56

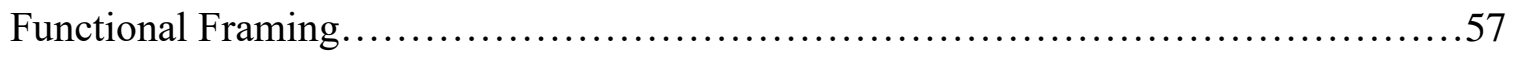

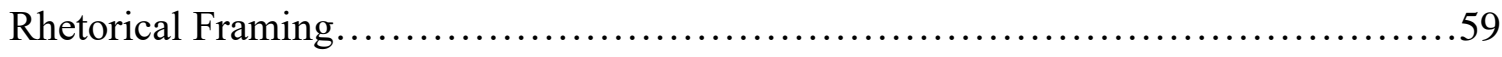

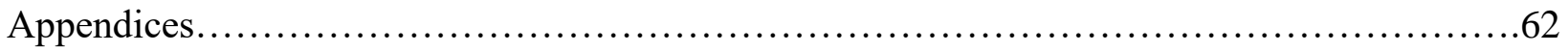

Appendix A: Coding Results................................................62

Appendix B: Screenshots of Select Sampled Tweets................................63 


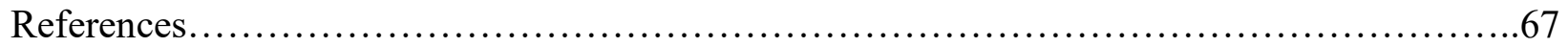




\section{List of Tables}

Table 1. Functional Frames Prominence Across Sample

Table 1.2. Examples of Tweets with the Appeal Frame

Table 2. Rhetorical Frames Prominence Across Sample 


\section{List of Figures}

Figure 1. Use of Functional Frames by Organization

Figure 2. Use of Functional Frames by Twitter Account

Figure 3. Functional Frame Use in MSF Canada Tweets

Figure 4. Functional Frame Use in MSF South Africa Tweets

Figure 5. UNICEF Canada Use of Functional Frames

Figure 6. UNICEF South Africa Use of Functional Frames

Figure 7. Quote Use versus Storytelling Frame Use

Figure 8. Use of Rhetorical Frames by Organization

Figure 9. Use of Rhetorical Frames by Twitter Account

Figure 10. Rhetorical Frame Use by MSF Canada and MSF South Africa

Figure 11. Rhetorical Frame Use by UNICEF Canada and UNICEF South Africa 


\section{List of Appendices}

Appendix A: Coding Results

Table A1. Coding Results: Functional Frames by Twitter Account

Table A2. Coding Results: Functional Frames by Organization

Table A3. Coding Results: Rhetorical Frames by Twitter Account

Table A4. Coding Results: Rhetorical Frames by Organization

Appendix B: Screenshots of Selected Sampled Tweets

Figure B1. MSF Canada Tweet with Informational, Promotional and Appeal Frames

Figure B2. MSF Canada Tweet with Functional Frame

Figure B3. MSF South Africa Tweet with News Dissemination Frame

Figure B4: MSF South Africa Tweet with News Dissemination, Promotion, and Appeal Frames

Figure B5: MSF Canada Tweet with Conversation and Informational Frames

Figure B6: UNICEF Canada Tweet with Informational, Promotion, Conversation and Appeal Frames

Figure B7: UNICEF Canada Tweet with Promotion and Appeal Frames

Figure B8: UNICEF South Africa Tweet with Storytelling Frame using Quotations

Figure B9: UNICEF South Africa Tweet with Storytelling Frame using Quotations

Figure B10: MSF Canada Tweet using Logos

Figure B11: MSF South Africa Tweet using Logos

Figure B12: MSF Canada Tweet using Logos and Ethos

Figure B13: MSF Canada Tweet using Pathos

Figure B14: MSF South Africa Tweet using Pathos 
Figure B15: UNICEF Canada Tweet using Ethos

Figure B16: UNICEF South Africa Tweet using Pathos

Figure B17: UNICEF Canada Tweet without Rhetorical Device Use 


\section{Introduction}

Non-profit organizations (NPOs) have used Twitter as a platform to communicate with their stakeholders since its launch in 2006 (Java et al., 2009). However, numerous studies show that there is no consistent strategy among organizations as to how they communicate on the platform. These studies cover organizations' use of public relations tactics on Twitter, user engagement, as well as how international organizations or NPOs utilize the platform for social advocacy (Guo \& Saxton, 2014, 2018; Li \& Li, 2014; Lovejoy, Waters \& Saxton, 2012; Messner et al., 2013). The reviewed literature suggests that NPOs prefer to publish one-way communication on Twitter, provide mostly information-based content to stakeholders, as well as utilize pathos rhetorical framing to build community using emotion (Waters \& Jamal, 2011, Lovejoy \& Saxon, 2012, Auger, 2014). An organization's strategic choice on whether to engage with partners, include hashtags, or publish about social issues is also found to impact NPOs ability to reach their stakeholders (Dong \& Rim, 2019; Guo \& Saxton, 2014, 2018; Saxton et al., 2015). While these findings and existing literature focus mainly on the interorganizational comparison of Twitter use, there is a lack of research on how NPOs communicate on Twitter across branches of their organizations in different regions. This pilot study explores this gap by evaluating the intraorganizational Twitter use of two international humanitarian organizations: Médecins Sans Frontières (MSF), also referred to as Doctors Without Borders, and UNICEF, also known as the United Nations Children's Fund. These two organizations utilize the platform on a global scale with numerous Twitter accounts in different locations under the umbrella of each organization. 


\section{Research Questions}

The study employs a qualitative content analysis through coding to analyze 163 Tweets from MSF Canada, MSF South Africa, UNICEF Canada, and UNICEF South Africa Twitter accounts. In order to determine any variations in how these organizations communicate on Twitter, the research questions guiding this pilot study are: What is the difference between MSF's and UNICEF's use of functional frames within text communication across intraorganizational channels on Twitter?, and What rhetorical framing strategies are presented in MSF's and UNICEF's Canada and South Africa channels? Given these research questions, the study aims to determine how NPOs frame their communications content on Twitter, and identify differences or similarities between their inclusion of six functional frames and three rhetorical frames. The functional frames discussed in this study include informational, news dissemination, conversation, appeal, storytelling, and promotion, and the rhetorical frames include ethos, logos, and pathos. Overall, the study seeks to explore how MSF and UNICEF communicate to stakeholders through their respective Canada and South Africa accounts, while considering content and framing strategies.

\section{Background Information}

MSF was founded in 1971 and is an international medical humanitarian organization operating in over 70 countries across the Americas, Africa, Europe, Central Asia, the Middle East, Asia and the Pacific (MSF, n.d.). Specifically, MSF "provide[s] medical assistance to people affected by conflict, epidemics, disasters, or exclusion from healthcare” (MSF, n.d.). MSF's social media channels include Twitter, Facebook, Instagram, LinkedIn, YouTube and TikTok, with the most followers present on MSF's Twitter and Instagram accounts. While MSF operates on a global scale, its medical projects are focused on responding to international 
humanitarian emergencies, "working largely in countries unable to provide the necessary medical response" (Doctors Without Borders, 2020, p. 3). For example, MSF South Africa implements projects "to prevent and treat HIV and tuberculosis (TB) and provide comprehensive care for victims of sexual violence" (MSF South Africa, n.d.). MSF's operations in Canada do not focus on medical projects due to a lower need, given Canada's high-functioning healthcare system (Doctors Without Borders, 2020). Further, MSF's operations in Canada focus more on fundraising and knowledge dissemination, by running education and awareness campaigns, planning events, as well as mobilizing funding, volunteers, and staff for its projects overseas (MSF, n.d.). The second NPO evaluated in this study is UNICEF.

As an agency of the United Nations since 1953, UNICEF operates in over 190 countries and territories to protect the rights of children and families, while supporting projects in "child health and nutrition, safe water and sanitation, quality education and skill building, HIV prevention and treatment for mothers and babies, and the protection of children and adolescents from violence and exploitation" (UNICEF, n.d.). UNICEF is also active on Twitter, Facebook, Instagram, YouTube, and LinkedIn, with the highest number of followers present on their global Facebook and LinkedIn pages. While MSF's field work is mainly conducted in countries that are affected by conflict, UNICEF's field projects focus on responding to the needs of vulnerable children.

UNICEF South Africa implements projects with support from the "South African Government, families and communities [to reduce] child poverty and [improve] education, health care and child protection for every child" (UNICEF, n.d.). Through its field projects on health, education, and safety, UNICEF South Africa delivers health programs to vulnerable populations, conducts evidence-based research to support policymaking, delivers capacity- 
building workshops and pedagogical skills training for early childhood educators, as well as establishes programming to provide safe and inclusive environments for children experiencing violence in South Africa (UNICEF, n.d.). UNICEF South Africa also works with donors, field staff, volunteers, and suppliers in order to fulfill its programing. Similar to MSF Canada, UNICEF Canada does not implement medical projects in Canada. UNICEF Canada instead focuses on fundraising, and encourages community engagement through the organization of fundraisers, UNICEF campus clubs, as well as an annual Halloween-themed walkathon fundraiser to raise money for UNICEF projects abroad (UNICEF Canada, n.d.). Fundraising efforts in Canada support "UNICEF's highest priorities, and [UNICEF staff work] neutrally with governments and the private sector in Canada and internationally to advance the rights and wellbeing of children and youth" (UNICEF Canada, n.d.).

As international NPOs, MSF and UNICEF each utilize a central Twitter channel for their organization, while also employing numerous country-specific Twitter channels with both duplicated, as well as unique content based on location and language. Both MSF and UNICEF began using Twitter a couple of years following the platform's launch, and currently their Canada and South Africa pages publish content daily. As this study only focuses on the Tweet content of MSF and UNICEF's Twitter channels, the engagement rates and different follower counts of MSF Canada (24k followers), UNICEF Canada (49.5k followers), MSF South Africa (25.6.k followers), and UNICEF South Africa (22.1k followers) are not considered in the study. Instead, the study examines the framing strategies of MSF's and UNICEF's Tweet content to provide a deeper analysis of their intraorganizational communication and tactics on Twitter. Using Canada and South Africa accounts for each organization, it also seeks to discover if there are any differences or similarities in the discourse used to communicate to the same two groups 
by each organization. The following literature review provides a framework for this study as well as for future research, including insights on NPO use of dialogic and functional communications, and rhetorical framing, among other themes. 


\section{Literature Review}

Twitter is utilized by NPOs to achieve organizational goals, connect with stakeholders, and disseminate information about their mission and programming. Since the inception of Twitter, various researchers have explored how the platform is used by for-profit and non-profit organizations. This literature review begins by exploring dialogic communication trends on Twitter, and how organizations use the platform to foster one or two-way communications with their audience. The second segment discusses how organizations build strategies around the functional aspects of Twitter messaging. The third segment explores how organizations use varying levels of tags, hashtags, Tweet replies and Retweets as part of their content and engagement strategy on Twitter. The fourth segment examines how NPOs utilize rhetorical framing to persuade audiences, and is followed by a look into how NPOs promote their advocacy efforts online using hashtags and links. Literature on how organizations employ Twitter during health crises is also reviewed given that this study analyzes content published during a global pandemic. The final three segments cover geographic considerations of Twitter use, as well as how social media platforms are used in Canada and South Africa more generally.

\section{Dialogic Communication}

Existing research argues that while dialogic communication strategies on Twitter differ by organization type, NPOs are not fully taking advantage of the dialogic potential of Twitter and prefer to publish one-way communication messages on the platform (Lovejoy \& Saxton, 2012; Wang \& Yang, 2020). Many organizations use Twitter to connect with their audiences and build relationships; however, several studies reveal that non-profits are more likely to utilize Twitter to broadcast one-way messages to their stakeholders (Lai et al., 2017; Lovejoy, Waters \& Saxton, 2012; Waters \& Jamal, 2011). A study by Li and Li (2014) evaluates two different 
communication strategies and observes that messages conveyed on Twitter should also be oriented towards building communal and expectation-free relationships, rather than exchange relationships, which focus on a transfer of goods or services for a returned benefit.

Previous research has distinguished dialogic communication strategies by organization type on Twitter. Wang and Yang (2020) find that NPOs focus on providing useful information, and encouraging return visits on Twitter, whereas for-profit organizations are prioritizing twoway communication with their potential customers online. Their study codes Tweet content to evaluate public engagement and establish usage patterns, finding that the application of dialogic principles depends on an organization's audience, and that "interactive conversations may not be vital to organizations' use of social media" (Wang \& Yang, 2020, p. 6). Lovejoy and Saxton (2012) counter the popular assumption that "non-profits have not been living up to their interactive, dialogic potential," (p. 349) and argue that dialogue should be considered as only "one piece of the communication puzzle" (Lovejoy \& Saxton, 2012, p. 349). Waters and Jamal (2011) conversely argue that by mainly disseminating one-way messages, NPOs are demonstrating their unwillingness to engage.

These existing studies ultimately point to an overall inconsistency between theory and practice. Theories from academic literature suggest two-way communication as a key strategy on Twitter while studies show that non-profits are more inclined to utilize the platform to broadcast information through one-way communication tactics (Lovejoy, Waters \& Saxton, 2012; Waters \& Jamal, 2011). While one-way communication is employed to share information, and two-way communication promotes dialogic communications, there are several other functions of Twitter communications that are used by NPOs. The next segment covers how organizations are 
publishing content based on a series of functions that encourage users to engage in different ways.

\section{Functional Communication}

Twitter communications are strategic and fulfill different functions. Numerous studies follow the hierarchy of engagement theoretical framework to define Tweet content. This framework classifies Twitter content as either sharing information, building community, or soliciting action, while another study has developed sub-categories of these functions to provide a deeper analysis of functional communications on Twitter (Lovejoy \& Saxton, 2012; Campbell \& Lambright, 2020). According to Lovejoy and Saxton (2012), non-profit communications on Twitter can be categorized into three functions, including sharing information, building community through interactivity, and providing a call to action. These three functions are part of Lovejoy and Saxton's hierarchy of engagement, which is a theoretical framework that identifies ways that social media messages engage with stakeholders (Campbell \& Lambright, 2020). Information Tweets are defined as "content about organizational activities, consistent with what other researchers [describe] as one-way communication" (Campbell \& Lambright, 2020, p. 547); community building Tweets "emphasize interactivity and dialogue" (Campbell \& Lambright, 2020, p. 547); and action-oriented Tweets "prompt stakeholders to do something, such as donate, attend an event, or protest” (Campbell \& Lambright, 2020, p. 547). Lovejoy and Saxton's (2012) study reviews 4,655 Tweets across 73 organizations and finds that $58.6 \%$ of Tweets are information-based, followed by $25.8 \%$ community-oriented, and $15.6 \%$ action-based. These results are consistent with nine other studies evaluating how NPOs apply Lovejoy and Saxton's hierarchy of engagement between 2012 and 2016, which find that "a majority or near majority of the message content is informational in nature" (Campbell \& Lambright, 2020, p. 247). 
Another study by Campbell and Lambright (2020) refines this framework by developing sub-categories within the hierarchy of engagement functions such as "organizational information, mission-related information, general information, profile updates, and live tweeting" (p. 554) in order to analyze Tweet content of 98 NPO Twitter channels. The study finds that the most prevalent sub-categories in NPO Tweet content include organizational information, acknowledgment of current news to "demonstrate the organization is part of the larger community" (Campbell \& Lambright, 2020, p. 557), recognition or thanks to supporters, as well as the promotion of non-fundraising events through action Tweets. Notably, organizational information is present in $16 \%$ of Tweets, and promotion of non-fundraising events is present in $17 \%$ of Tweets (Campbell \& Lambright, 2020). These results demonstrate that while information-oriented content is dominant overall, certain sub-categories may have equal or higher prevalence across the information, communication, and action functions.

The majority of reviewed studies apply Lovejoy and Saxton's hierarchy of engagement framework to analyze Tweet type; however, Campbell and Lambright's (2020) more recent study highlights the importance of expanding these categories to develop more in-depth analyses of Twitter use and engagement with stakeholders. These earlier studies present the functional intent of Twitter communications of NPOs more generally. However, for organizations that choose to engage and use two-way communications as their primary function, the hierarchy of engagement framework does not provide further insight into how organizations are strategically using the functionalities of Twitter to engage with their stakeholders. The next segment examines how organizations utilize the different features of Twitter, such as Retweets and hashtags, as part of their content strategy. 


\section{Content Strategy and Engagement on Twitter}

Determining the frequency of Tweets, Retweets, and the inclusion of tags and hashtags is important when developing content and engagement strategies on Twitter. Studies suggest, however, that there is no consistent strategy utilized by organizations, and the level of engagement on Twitter depends on organizational resources (Galvez-Rodriguez et al., 2016; Shahin \& Dai, 2019). The decision to engage business partners online can also have both positive and negative implications for an organization (Dong \& Rim, 2019).

It is increasingly a challenge for organizations to draw the attention of their stakeholders, as the rising number of digital platforms has accelerated information sharing online (Guo \& Saxton, 2014, 2018). Studies show that organizations should be strategic when communicating on Twitter (Saffer et al., 2013). Messner et al. (2013) analyze Tweets across 20 health sector NPOs across a two-week period and discover "broad differences in frequency and use of audience engagement" (p. 129). These include varying levels of Tweet frequency, Retweets, high hashtag use, as well as minimal direct communication with stakeholders, suggesting that there is no consistent Twitter strategy among NPOs (Messner et al., 2013). In a study by Shahin and Dai (2019), Tweet replies and Retweet strategies differ across the Twitter channels of three aid agencies including the United States Agency for International Development (USAID), the Swedish International Development Cooperation Agency (SIDA), and the International Committee of the Red Cross (ICRC). The study reveals SIDA to have the highest number of Retweets (72.7\%) and replies (8.6\%); USAID to have the lowest number of Retweets (26.6\%); and ICRC to have the lowest number of replies (0.1\%) (Shahin \& Dai, 2019). Shahin and Dai (2019) conclude that aid agencies with higher Tweet replies or Retweets have greater participation from the public. Further, the authors argue that Tweet replies and Retweets should 
be a central part of NPO strategy on Twitter, "as opposed to just transmitting information about their programs or instrumentally attempting to use Twitter to change public behaviour" (Shahin \& Dai, 2019, p. 1701).

Contributing to this strategy gap is the assumption that smaller NPOs have lower capacity than larger organizations to implement communication strategies on Twitter (Galvez-Rodriguez et al., 2016). However, a study by Galvez-Rodriguez et al. (2016) concludes that small NPOs, who often have lower financial and human resources, are "the most vulnerable to pressures of organizations and groups in its environment," (p. 1065). These NPOs thus increasingly use Twitter as a key platform to interact with and disseminate regular information to their stakeholders (Galvez-Rodriguez et al., 2016). The study also examines several external factors that can affect the willingness and ability of NPOs to engage strategically, finding that high donor dependence, and online community size encourages greater two-way communication strategies on Twitter (Galvez-Rodriguez et al., 2016). These studies outline how NPOs and aid agencies have inconsistent strategies and engagement on Twitter. However, organizations that more frequently publish Tweet replies and Retweets are found to have more audience engagement, and smaller organizations with limited budgets utilize these functions to disseminate more regular updates to their stakeholders (Galvez-Rodriguez et al., 2016; Shahin \& Dai, 2019). While generally Tweet replies and Retweets promote engagement, some NPOs are specifically using the platform to engage with partners.

Dong and Rim (2019) consider this alternative strategy to achieve organizational goals by looking at NPO use of business partnerships on Twitter. Their study analyzes the frequency of Retweets, partner mentions, and link sharing on non-profit Twitter accounts (Dong \& Rim, 2019). The authors find that while "both partnered organizations can benefit from such 
partnerships," (Dong \& Rim, 2019, p. 104) it could result in greater competition among NPOs who also work with businesses, or could also have negative implications for the NPO if the partnership is controversial. The scope of Dong and Rim's (2019) study is limited to NPOs addressing specific social issues. Further exploration of non-profit to business (N2B) communications in different NPO types could help determine if the study's findings expand to all sectors of N2B partnerships (Dong \& Rim, 2019). As these studies showcase how NPOs choose to engage and circulate content using hashtags, replies, Retweets, and tagging partners, the next segment expands on how Twitter engagement is framed rhetorically.

\section{Rhetorical Framing on Twitter}

As many NPOs employ Twitter to solicit an action, such as signing up for an event or donating to a cause, studies show that the inclusion of rhetorical and persuasive framing is prominent in NPOs online messaging, although inconsistent between types of rhetorical framing (Auger, 2014; Lovejoy \& Saxton, 2012; Smitko, 2012). Instead of looking at the ways in which NPOs foster one or two-way communications, and disseminate information, Auger (2014) examines the message structure of Tweets across eight NPOs in difference spheres. The study analyzes NPO use of rhetorical framing techniques including ethos, building trust and credibility; pathos, using emotions and promoting values; and logos, using logic and reason (Auger, 2014). The researcher concludes that most Tweets (60\%) employ at least one of these three rhetorical strategies, while "pathos [is] used more often, particularly in messages structured to provide

motivation or a sense of community" (Auger, 2014, p. 246). McNeill and Briggs (2014) add that different organizations are producing different rhetorical frames for similar issues, which can have an impact on how the messages are received. 
Another study by Smitko (2012) evaluates the textual discourse of two NPOs, United Way of Toronto and Care2, and conversely finds that ethos is the most prominent rhetorical framing device followed by logos. Additionally, over " $90 \%$ of the Tweets showed evidence of [at least] one of the elements of persuasive appeal," (Smitko, 2012, p. 634). While rhetorical framing overall appears to be prominent, the types of persuasive appeal are used inconsistently by the studied NPOs. While ethos and pathos are observed by Auger (2014) and Smitko (2012) as the dominant rhetorical frames used by NPOs, these concepts of building trust, credibility, and using emotions to promote values can also be considered when communicating on Twitter about advocacy.

\section{Advocacy and Hashtag Use}

Studies reveal that advocacy-oriented organizations include more hyperlinks and hashtags in their Tweets and incorporate hashtags that follow a theme or existing trend, focus on public education, or promote organizational values (Guo \& Saxton, 2014, 2018; Saxton et al. 2015). NPOs that are engaged in advocacy activities often employ social media to reinforce their key messages and core organizational mission (Guo \& Saxton, 2014). Guo and Saxton (2014) examine NPO use of Twitter for advocacy, observing that organizations with advocacy-related content have a larger number of daily Tweets, and more significant hyperlink and hashtag use compared to organizations not engaged in advocacy. The study also finds that due to the broad and public audience on Twitter, advocacy efforts are largely indirect and focus on encouraging public education and grassroots lobbying, rather than targeting specific individuals with actionspecific goals (Guo \& Saxton, 2014).

In the framework of advocacy, hashtags are utilized by organizations and individuals to mark a theme or topic on a Tweet, and encourage participation from other users (Saxton et al., 
2015). In a study that analyzes the inclusion of hashtags across 105 member accounts of the National Health Council in the United States, Saxton et al. (2015) finds that most hashtags are related to public education advocacy, followed by hashtags representing an organization's values and brand to help "strengthen understanding of the organization" (p. 19). The researchers conclude that using specific and unique hashtags makes a bigger impact, although popularizing the hashtags, and encouraging participation is needed in the organization's strategy to promote stronger engagement (Saxton et al., 2015). A later study by Guo and Saxton (2018) alternatively argues that to garner attention for a cause, NPOs "should seek to join conversations (by employing existing hashtags), speak often, and grow their follower base" (Guo \& Saxton, 2018, p. 21). While these studies showcase that organizations engaged in advocacy activities focus on encouraging public education on Twitter, what follows covers how NPOs educate the public on Twitter during health crises.

\section{Twitter Communication During Health Crises}

Disseminating timely, accurate and regular online messaging is vital in any crisis, and NPOs working in the medical sphere play a particularly important role during health crises (Vafeiadis et al., 2019). As this paper evaluates Twitter content published during the COVID-19 pandemic, previous studies provide insight into how NPOs communicated on Twitter during another health crisis, the Ebola epidemic in 2014-2016. Studies on the Ebola epidemic reveal that NPOs garner higher engagement when they publish more positive and solution-focused content (Guidry et al., 2017; Tully et al., 2019). Further, NPOs are found by researchers to have comparable link sharing tactics, including publishing links mostly related to their work and achievements (Guidry et al., 2017; Tully et al., 2019). 
Guidry et al. (2017) employ a content analysis of 779 Tweets and 107 Instagram posts between September and December 2014 from three NPOs, including the World Health Organization (WHO), the Center for Disease Control and Prevention (CDC) and MSF to examine the type, content, and context of social media communications during the Ebola epidemic. The study finds that NPOs who disseminate a balance of risk-based information and solution-based messages on social media, rather than mostly positive messages, generate more engagement online (Guidry et al., 2017). The authors conclude that NPOs should thus "be mindful to send out more positive/solution-based messages rather than negative/problem-based messages" (Guidry et al., 2017, p. 485) to facilitate clearer audience understanding and engagement. While comparing CDC, WHO and MSF communication on Twitter, Guidry et al. (2017) also observes that CDC and WHO publish the greatest number of Retweets, and that "mentions, hyperlinks, and photos [are] used most frequently by MSF" (p. 481). These findings showcase the importance for NPOs to consider the tone of messages during health crises, and may point to continued inconsistencies in social media strategies regarding Tweet frequency and type.

Another study by Tully et al. (2019) evaluates how NPOs used hyperlinks within Tweets during the Ebola health crisis, finding that increased inclusion of links helps build trust, establish credibility, and raise more awareness. The study examines how 12 NPOs shared links on Twitter between March and December 2014, finding that "organizations [follow] similar patterns in type of links shared" (Tully et al., 2019, p. 320). The authors also observe that organizations mostly publish links to owned and earned media, such as the organization's website, or links to local news stories about the work of the NPOs (Tully et al., 2019). The study also highlights the tendency for NPOs to favour using links as part of their Twitter communications strategy, 
"particularly when informational and promotional purposes are combined in sharing earned media" (Tully et al., 2019, p. 326). As these studies evaluate NPO Twitter strategies from the Ebola epidemic, they provide insights into how NPOs may communicate in similar health crises such as the COVID-19 pandemic. Given that the Ebola epidemic impacted several countries in Western Africa and Europe, and that the COVID-19 pandemic is a global health crisis, geographic considerations on Twitter are discussed in the subsequent segment.

\section{Geographic Considerations}

The rise of internet access around the world has broken down physical geographic barriers and fostered increased cross-cultural communications through social media (Kulshrestha et al., 2012). Studies show that organizations should always be aware of cultural differences and potential audiences on Twitter, as followers do not always originate from their national boundaries, and may engage on Twitter differently between individualistic and collectivist cultures (Garcia-Gavilanes et al., 2014; Kulshrestha et al., 2012; Park et al., 2014).

In a study that evaluates the geographic breakdown of Twitter, Kulshrestha et al. (2012) discovers that globally most users follow accounts that are within their national boundaries, but in countries with the largest number of users, trans-national connections are more prevalent. The researchers also argue that audience breakdowns and geography should always be considered when disseminating information on Twitter (Kulshrestha et al., 2012). In a complimentary study, Garcia-Gavilanes et al. (2014) add that "awareness of these boundaries is prerequisite in our understanding of the kinds of information residents of these countries are likely to consume" (p. $10)$.

Beyond geographic distinctions lies fundamental cultural differences among audiences, specifically cultural individualism versus collectivism (Park et al., 2014). In a study evaluating 
the cross-cultural use of emoticons on Twitter, Park et al. (2014) find that audiences from individualistic cultures are more expressive than collectivistic cultures in their choice of emoticons, and use more emoticons focused on mouth expressions than eye expressions, which are more subtle. While the study is limited to user-generated content, it points to the consideration that organizations may receive different engagement levels depending on how NPOs or other organizations utilize emoticons in their Twitter content strategy. While these studies highlight the importance of organizations to consider audiences and potential cultural differences on Twitter, the next segment examines how social media is used in Canada.

\section{Social Media Use in Canada}

Social media use in Canada is popular among adults, and studies reveal that NPOs based in Canada are increasingly using Facebook and Twitter, despite some organizations facing financial and human resource challenges to maintain their social presence (Greenberg \& MacAulay, 2009; Gruzd \& Mai, 2020; Obar, 2014). In a report by Gruzd and Mai (2020), 94\% of surveyed Canadian adults have at least one social media account, with $42 \%$ of respondents on Twitter, and $50 \%$ of Twitter users using the platform daily. Additionally, the study reports that most Twitter users fall within the 18-24 age group, and that individuals with higher levels of education, excluding individuals with doctorates, are more likely to be on the platform (Gruzd \& Mai, 2020). A couple of studies have outlined how non-profit organizations in Canada have utilized social media in the early onset of the platforms.

Greenberg and MacAulay (2009) analyze the web presence of 43 environmental nonprofit organizations in Canada and discover that while "NPOs should be leaders in using social technologies to grow and strengthen their networks, (...) the data reported in this study suggest that this potential remains mostly untapped" (p. 74). The authors argue that financial barriers 
may contribute to this gap, and "for some, the dialogical orientation of these media may create new administrative demands that outstrip an organization's communicative capacity" (Greenberg \& MacAulay, 2009, p. 74).

A later study by Obar (2014) further analyzes how advocacy organizations in Canada use social media and finds that 54 of 56 surveyed organizations are on social media, with the majority using Facebook (96\%) and Twitter (89\%). The two organizations that reported to not use social media note that they did not have financial or staff resources to maintain effective and regular communication with their stakeholders on these platforms (Obar, 2014). While many of the Canadian organizations use Twitter everyday (57\%), the platform is consistently ranked as the third most preferred platform for advocacy related tasks, following email and Facebook (Obar, 2014). The study also surveys 157 individuals from 63 Canadian advocacy organizations, and identifies that social media is viewed as a way to "strengthen outreach efforts, enable engaging feedback loops, and increase speed of communication” (Obar, 2014, p. 221).

While these two studies demonstrate that Canadian NPOs are increasingly using social media, "Canadian groups are concerned about the resources required to maintain a broad and deep social media presence" (Obar, 2014, p. 226). Limited research evaluates Canadian-specific social media use, and additional study is required to evaluate more recent social media trends in Canada, specifically related to NPO use. As social media use in Canada is on the rise; other studies showcase that a similar increase is observed in South Africa. Social media in South Africa is further explored in the next segment.

\section{Social Media Use in South Africa}

Previous research on social media use in South Africa demonstrates that while Facebook is the most popular platform in the country, Twitter has high credibility, and plays an important 
role in health promotion, as well as socio-political advocacy (Budree et al., 2019; Viljoen et al., 2016; Kubheka et al., 2020). According to a study by the Pew Research Centre, up to $60 \%$ of South Africa's adult population own a smartphone as of 2018, up 23\% since 2015, and in the same year, $52 \%$ of adults in South Africa report using social media, with more activity among higher educated citizens (Taylor \& Silver, 2019). Considering the rise of smartphone users in South Africa, Twitter use has also grown. According to Budree et al. (2019), its adoption in South Africa "rose by 129\% in a year, as registered [users] more than doubled" (p. 318) between 2012 and 2013, and Twitter use continues to see growth in the country today.

A study by Budree et al. (2019) evaluates social media usage in South Africa and finds that Facebook is the dominant social media platform in the country. The researchers also uncover that Twitter is consistently used across different age groups, with the highest preference among younger age groups (Budree et al., 2019). Another study by Viljoen et al. (2016) analyzes Facebook and Twitter in the context of South Africa. Following a survey to 446 respondents from South Africa, the authors conclude that Twitter is more credible than Facebook, therefore showcasing its importance in advertising and promotion by organizations in the country (Viljoen et al., 2016). Social media in South Africa is heavily utilized by individuals to "promote various activist movements in an effort to create awareness and gather support," (Budree et al., 2019, p. 319) while for organizations, it "has become one of the most influential ways to get products or messages across to their customers" (Budree et al., 2019, p. 319).

Social media is also an important tool in health promotion. A study by Kubheka et al. (2020) proposes using social media as an opportunity to scale health promotion programs, create virtual communities, and reduce geographical barriers of access in South Africa. Based on a secondary analysis of health promotion articles, Kubheka et al. (2020) demonstrate that Twitter 
is emerging as a platform "to engage in contentious socio-political engagement in real-time" (p. 2-3), as well as to receive breaking news in South Africa. Despite the purported importance of social media to the South African population, it is not included in the country's National Digital Health strategy for 2019-2024 (Kubheka et al., 2020). However, social media is suggested by the authors to be considered in the future to combat misinformation campaigns, and share health information more effectively (Kubheka et al., 2020). These studies point to the rising importance of social media in South Africa, particularly related to health promotion and advocacy.

The existing academic literature surrounding NPOs on Twitter point out several areas for further research. Research suggests that Twitter is primarily employed by NPOs to foster oneway, information-oriented communication despite the dialogic potential of the platform (Lovejoy \& Saxton, 2012; Wang \& Yang, 2020). Studies also show that while NPOs have no consistent Twitter strategy, they prominently utilize rhetorical framing, and frequently include hyperlinks and hashtags focusing on public education and organizational values (Auger, 2014; Shahin \& Dai, 2019; Smitko, 2012). Based on studies from the Ebola epidemic, positive and solutionfocused content is recommended when communicating during health crises (Guidry et al., 2017). Geography is another key consideration, and previous research suggests that organizations should be mindful of potential cultural and audience differences when communicating on Twitter (Kulshrestha et al., 2012; Park et al., 2014).

The scope of this pilot study considers some of these aspects, including the rhetorical framing, dialogic, and functional communications in order to compare how two NPOs communicate across intraorganizational channels in Canada and South Africa. The study's use of functional frames is based on Lovejoy and Saxon's (2012) hierarchy of engagement and Campbell and Lambright's (2020) sub-categories of how content is framed to determine how 
organizations choose to publish content and promote engagement. It also analyzes how organizations use rhetorical frames. As existing studies each point to comparable findings when framing social media content across NPOs, this study evaluates if there are similar findings applicable to content published to intraorganizational channels on Twitter. Overall, this study provides an in-depth analysis of framing across sampled Tweet content from UNICEF Canada, UNICEF South Africa, MSF Canada, and MSF South Africa pages, while considering if this matches or counters findings from previous studies. 


\section{Methodology}

This pilot study employs a qualitative content analysis through coding to determine whether there are any differences or similarities between intraorganizational communication throughout MSF and UNICEF Twitter accounts in Canada and South Africa. This section covers the sampling strategy used to develop the corpus, including timeframe considerations, and is followed by an explanation of the study's content analysis method, as well as how the corpus is examined using functional frames and rhetorical frames.

\section{Sampling Strategy}

The corpus includes the text within 163 general Tweets posted between January 1 and 31 , 2021 from the UNICEF Canada, UNICEF South Africa, MSF Canada and MSF South Africa Twitter channels. General Tweets are defined as "a message posted to Twitter containing text, photos, a GIF, and/or video", which appear on the sender's profile page ("About different types of Tweets", n.d.). The corpus includes 34 Tweets from UNICEF Canada, 45 from UNICEF South Africa, 54 from MSF Canada, and 30 from MSF South Africa. Due to the inconsistent number of Tweets published to each channel across January 2021, analyses are conducted using ratio scales to present a comparable evaluation. This paper uses the terms accounts, channels, and pages interchangeably to reference the four Twitter accounts examined in this study.

Retweets, Quote Tweets, and Replies are not included in the corpus in order to evaluate only the primary information circulated by each channel. An additional consideration in the sampling strategy is to only select Tweets written in English. This excludes French language Tweets in the sample as English is the dominant Tweet language used by each organization, and French-language Tweets are minimally present in only one of the channels. A thread on Twitter is "a series of connected Tweets from one person, [which] can provide additional context, an 
update, or an extended point by connecting multiple Tweets together" ("How to create a thread on Twitter", n.d.). Since not all Twitter channels utilize the thread function, only the first Tweet of each thread is included in the corpus to ensure consistency in the analysis. Tweets that include duplicated content from a previous post in January 2021 are also excluded from the sample to focus on evaluating the framing, and content of the different communications messages rather than the frequency of Tweets.

The timeframe of this study falls during the COVID-19 pandemic, but January is selected as a more neutral month, avoiding major milestones related to the pandemic, such as the 1-year anniversary of the pandemic in March, and national vaccine approvals in Canada and South Africa. The sampled Tweets are also not limited to only COVID-19 related content and incorporate all general content regardless of theme or topic. There are no country-specific or celebrated holidays occurring in Canada or South Africa in January except New Years, which is observed by both countries. January also avoids a significant protest campaign related to patent reforms that was held in South Africa in February. This consideration is made to ensure that the selected Tweets are not influenced by an outside event. A one-month duration is chosen to provide a more representative sample of Twitter communications. Due to Twitter's archiving limitations, the study is not able to be conducted using a pre-COVID-19 timeframe.

\section{Content Analysis Method}

To examine MSF and UNICEFs Tweet content, a codebook is used to provide a deeper analysis of each channel's communication tactics on Twitter. Each Tweet from the UNICEF Canada, UNICEF South Africa, MSF Canada and MSF South Africa Twitter channels is first categorized into six functional frames: informational, news dissemination, conversation, appeal, storytelling and promotion. The Tweets are then evaluated based on three rhetorical frames: 
ethos, pathos, and logos to assess how organizations are using persuasive appeal as part of their communications strategy on Twitter.

The concept of framing is derived from the idea that "content is constructed through particular features that provide clues about the interpretation of the text and the news event itself” (Valenzuela et al., 2017, p. 806). When content is published on Twitter, authors write in a way that communicates key messages or disseminates information based on their organizational goals. To do this, authors are framing the content in ways that either persuade, guide the viewers interpretation, or promote action. The technique of framing content based on their function is considered 'functional framing,' whereas rhetorical framing is based on different modes of persuasion. These rhetorical frames showcase how ethos, pathos and logos are used by organizations to communicate messages to their audience.

In this study, each of the six identified functional frames denote a perceived Tweet function in terms of its type of engagement, such as whether the Tweet is aimed at starting a conversation, or at providing information to the audience. The chosen breakdown of functional frames is developed based on Lovejoy and Saxon's (2012) hierarchy of engagement of defining Tweets as informational, community building or eliciting call-to-action. It also considers several sub-categories outlined by Campbell and Lambright's (2020) study including organizational information and acknowledgement of current news. While the hierarchy of engagement has a broad focus, Campbell and Lambright (2020) develop sub-categories within Lovejoy and Saxon's (2012) mold of information, community and action-based content to create more specific functional frames for analysis.

Overall this study takes a more thematic approach to how Tweet content is framed and considers that NPOs may have more refined strategies on how they engage beyond simply 
providing information, building community, or promoting action. Since each Tweet is found to have multiple frames, they are also coded to include all relevant frames, rather than being limited to one general frame. By using six functional frames including informational, news dissemination, conversation, appeal, storytelling and promotion, the study aims to identify how NPOs engage on Twitter, beyond the information, community and action framework that has previously been studied by Lovejoy and Saxon (2012), among others. Through an evaluation of rhetorical frames, the study also aims to determine if there are any patterns or trends in how each organization is choosing to structure their content on Twitter. The next two segments define each of the functional and rhetorical frames used in this study.

\section{Functional Framing}

Coding guidelines are developed for each of the functional frames to provide clear direction, and reduce subjectivity when coding each Tweet. The first frame is informational and is defined as providing facts, numbers or statistics related to the context in which each organization is working. This can be statistics related to the number of deaths, injured or displaced people, as well as facts that are aimed at educating the audience, or are pulled from research studies. For example, an informational Tweet by UNICEF South Africa explained that "washing hands with soap and water is one of the best defences against \#COVID19SA" (UNICEF Southern Africa, 2021, 3:00 ET), while another by MSF Canada reported that "the \#COVID19 pandemic [amplifies] uncertainty and instability affecting \#mentalhealth" (MSF Canada, 2021, 11:00 ET) and communicated a rise in suicide attempts. While the informational frame focuses on sharing facts, numbers, and statistics, it is also considered one-way communication as it focuses on sharing information, rather than promoting engagement. Another functional frame that utilizes one-way communication is news dissemination. 
News dissemination is the second frame and includes content conveying breaking or recent news and contains references to a recent date or time, and language such as "an evolving crisis", "last week", "for the past weeks", "on Friday". For example, one Tweet notes that "following violent attacks in \#Bouar in the previous two weeks, about 8,000 \#IDPs took refuge in different makeshift camps across the city and live in extremely precarious conditions" (MSF Canada, 2021, 13:15 ET). Since this Tweet includes both a statistic, and reference to a recent breaking news event, it is categorized as both informational and news dissemination. While informational and new dissemination frames are both identified as one-way communication to audiences, informational is defined by the inclusion of facts, numbers and statistics, whereas news dissemination conveys information about breaking or recent news, and includes references to a date or time. The promotion frame also denotes one-way communication, although it centers more towards organizational updates, rather than information about the context in which the organization works.

The third frame is promotion, and Tweets categorized with this frame share information related to the self-promotion of the organization's achievements. This consists of any promotion of the organization's work, including programming such as water deliveries, food kit support, consultations, educational campaigns, among others. This is differentiated from informational and news dissemination, as it focuses on sharing information about UNICEF and MSF programs, as well as what their employees are doing, rather than providing information to educate or announce recent world news. An example of promotion highlights a new UNICEF partnership:

"To address issues of access to essential services and information during \#COVID_19 UNICEF \#India partnered with the NSS to create the 'Blue Brigade' - a team of community volunteers who assist with immunization efforts, remote learning and 
provide key messaging around COVID-19”(UNICEF Canada, 2021, 14:30 ET).

While posts with the promotion frame may include statistics and news related to the organization, it differs from informational and news dissemination, as the content shared relates specifically to the achievements and work of the organization. In the next segment, functional frames that employ two-way communication tactics are defined including the conversation and appeal frames.

The fourth functional frame is conversation, where posts promote audience interaction on Twitter and contain a request to Retweet to answer a specific question or include an open-ended question to promote discussion. This category is distinguished from the fifth frame, appeal, which includes content containing a call-to-action. Posts with a conversation frame intend to get a response from the audience through Twitter, while appeal or call-to-action posts are defined as leading users off Twitter to other pages such as the organization's website, a petition, report, video, social media post or page, or an event registration page. An example of a conversation Tweet is one that includes a question such as: "If you were tasked with transporting \#vaccines to a remote location, what would your preferred method of transport be?” (UNICEF Canada, 2021, 15:05 ET). A Tweet that is categorized as both conversation and appeal includes both a Retweet request as well as a call-to-action to visit the organization's website such as:

“\#DidYouKnow that Neglected Tropical Diseases (\#NTD) kill hundreds of thousands of people each year? RT to help us raise the profile of \#noma, and add your voice to the conversation below. Together we can \#EndTheNeglect and \#BeatNTDs. https://noma.msf.org \#zeronoma \#NTDday” (MSF Canada, 2021, 10:00 ET).

Tweets with an appeal frame can also include other functional frames such as informational, news dissemination, and conversation, however, they must include a link or request for action 
through prompts such as "read more", "click the link below", "watch”, "register here", “download", or an arrow or pointing emoji gesturing to click on a link. Conversation and appeal frames both evaluate the two-way communications tactics of organizations by encouraging dialogue and action. Conversation promotes Retweets and discussion on Twitter, while appeal looks at whether the Tweet content includes a call-to-action, namely leading to an action completed outside of Twitter. The final functional frame, storytelling, is tied to the organization's desire to draw on personal experiences and narration.

The sixth functional frame is storytelling, and posts with this frame tell a story by spotlighting stakeholders or community members, using testimonials or quotes, or by explaining someone's personal experience, or circumstance. This category is distinguished from informational, as storytelling uses the human element to present facts and educate the audience through personalization. Quotes can be classified as any quotation from either a beneficiary, community member, or someone who works for either UNICEF or MSF. An example of storytelling could be an organization's use of quotation in order to paint a picture of someone's experience with COVID-19: "I tested positive in July, I fell sick and had to quarantine. That is when I infected my sister, she passed away after 2 days" - Noncedo Xengeshe, from Nonzwakazi, De Aar” (UNICEF Southern Africa, 2021, 3:00 ET). By describing someone’s experience, the organization can showcase the human element through storytelling.

Informational, news dissemination and promotion convey one-way communication, whereas appeal and conversation emphasize two-way communication to promote engagement. The storytelling frame, however, includes both one-way and two-way communication, as the inclusion of storytelling can both convey information as well as promote action. In summary, a Tweet with the informational frame includes facts, numbers, or statistics related to the context in 
which each organization is working. While news dissemination also provides information to readers, it focuses on conveying breaking or recent news, including a reference to a date or time. The promotion frame refers to content that is related to the self-promotion of the organization's achievements, such as publishing information about an organization's completed projects or milestones. Posts that promote interaction on and off-Twitter are differentiated using the conversation and appeal frames. The conversation frame promotes audience interaction on Twitter, such as Retweet requests or prompts to reply to answer questions on the platform. On the other hand, the appeal frame includes a call-to-action that leads users off Twitter to pages such as an event registration page or website. The final functional frame is storytelling and Tweets using this frame tell a story, use testimonials or quotes, and overall include the human element to present facts and educate the audience through personalization. While all Tweets are categorized based on these six functional frames, they aim to provide a robust evaluation of how UNICEF and MSF are communicating across intraorganizational channels on Twitter. To further this study, a second component evaluates the persuasive appeal of each Tweet through three rhetorical devices. Taken together, these functional and rhetorical frames provide a thorough content evaluation when applied to MSF and UNICEF's intraorganizational channels in Canada and South Africa.

\section{Rhetorical Framing}

Rhetorical framing techniques are coded and included in the content evaluation to determine if the sampled Tweets employ Aristotle's modes of persuasion: ethos, building trust and credibility; pathos, using emotions and promoting values; or logos, using logic and reason (Auger, 2014). Each Tweet is coded to have one or more rhetorical frames or is marked "other" if no persuasion is identified. Examples of Tweets without any persuasive appeal include posts 
that wish users a happy new year, happy Sunday, or simply share links to their job vacancy page, among others. The following segments define each of these modes of persuasion: ethos, pathos, and $\log$ os.

Ethos is defined by Aristotle as proof that "the speaker sounds credible, [and notes that] true credibility results when the audience attributes three qualities to the speakers because of what is said; these virtues are good sense, virtue, and goodwill” (Braet, 1992, p. 311). Using this definition, ethos is evaluated based on how the Tweet demonstrates the organization's credibility or trustworthiness. This consists of Tweets that include personal qualifications, reviews or quotes from beneficiaries, or endorsements from reputable figures. It is also classified as ethos if the Tweet demonstrates project success, or denotes impact based on a stated need, such as treating the wounded after violent outbreaks, providing water and food kits to displaced persons, or offering mental health consultations following rising suicide attempts. An example of ethos highlights the success of a new operational model in Zimbabwe that was later implemented by the Ministry of Health:

“In this week's \#FieldworkerFriday post we recognise the achievements of our nurses in Manicaland, Zimbabwe, who successfully rolled out a nurse-led model of care for noncommunicable diseases. The project was handed over to $\mathrm{MoH}$ last month. http://bit.ly/3nuzvBn" (MSF South Africa, 2021, 7:00 ET). As the use of ethos draws on personal qualifications or endorsements to showcase the organization's credibility and trustworthiness, pathos conveys feelings and sentiments to impact the audience's perception or opinion.

Pathos draws on emotions to persuade audiences, and to influence them "into a certain frame of mind" (Braet, 1992, p. 314). Aristotle notes that while emotions emerge based on "1) 
the condition of the persons who suffer the emotion, 2) the persons about whom one feels the emotion and 3) the motive" (Braet, 1992, p. 314), framing with pathos can influence how audiences experience emotion. This study looks at how pathos is employed as a communications strategy in Tweets by determining if the Tweet content triggers emotion. The Tweet is coded as pathos if it includes personal stories or antidotes, experiences from beneficiaries, or speaks to sensitive topics such as suicide, death, or crises. For example, UNICEF South Africa informs audiences of the seriousness of COVID-19 by Tweeting "My husband was infected with \#COVID19, and my test was negative. When I heard he passed away, it was so hard" - Ellen from Retswelele, Kimberley.” (UNICEF Southern Africa, 2021, 2:00 ET). This example shares potentially alarming information and demonstrates the use of pathos, since it could trigger an emotional response or persuade action. By contrast, the final rhetorical frame uses logic as a mode of persuasion.

The logos rhetorical frame applies logic and reason to communicate to audiences. This is explained by Aristotle as "logical proof" (Braet, 1992, p. 309) that can persuade audiences towards the motive of the speaker. In this study, Tweets are categorized with the logos frame if they present a logical argument, incorporate facts and statistics, as well as present information with a clear rationale. For example, an MSF Tweet promotes the need for transparency by first explaining the background information, followed by the issue, and the proposed solution: "Pharma corporations cite R\&D costs when justifying high prices for medicines. But no one knows the true costs of drugs because this information isn't disclosed. We need transparency! Pharma should open their books \& disclose costs of Pill Syringe Microscope” (MSF Canada, 2021, 10:36 ET). 
Tweets that hold this type of logical argument and presentation of facts are considered to have a logos frame.

Overall, the study analyzes 163 Tweets from MSF Canada, MSF South Africa, UNICEF Canada and UNICEF South Africa accounts to determine if there are similarities or differences in communications between or within organizational channels. The pilot study compares each channel using six functional frames and three rhetorical frames through coding, while also referencing existing literature to point to possible trends or differences. The definitions of these functional and rhetorical frames are developed based on Lovejoy and Saxon's (2012) hierarchy of engagement, Campbell and Lambright's (2020) sub-categories within the hierarchy of engagement functions, as well as Aristotle's three modes of persuasion. The six functional frames are defined as informational, content providing facts and statistics; news dissemination, content conveying breaking or recent news; conversation, posts promoting audience interaction on Twitter; appeal, content containing a call-to-action; storytelling, posts telling a story through testimonials or explaining someone's personal experience, or circumstance, and promotion, information related to the self-promotion of the organization's achievements. The examination of persuasive appeal looks at three rhetorical frames: ethos, building trust and credibility; pathos, using emotions and promoting values; or logos, using logic and reason (Auger, 2014). The study therefore employs a two-pronged framing evaluation to evaluate how NPOs communicate across intraorganizational channels. 


\section{Findings and Discussion}

This section presents findings from coding 163 Tweets from UNICEF and MSF's Canada and South Africa accounts, including evaluating six functional frames and three rhetorical frames. The overall prominence of functional frames is first identified by looking at the entire sample, UNICEF and MSF Tweet content, followed by an evaluation of differences between MSF and UNICEF's Tweets published to the organization's Canada and South Africa accounts. This is succeeded by an examination of how each organization uses ethos, pathos and logos rhetorical frames, as well as noting any differences between intraorganizational channels. By looking at how organizations frame their Tweets, this study aims to discover what strategies are used by NPOs to communicate across intraorganizational pages on the platform, and if this differs from patterns previously studied between interorganizational non-profit pages.

\section{Functional Frame Use by NPOs}

By using ratio scales, this study presents comparable data of UNICEF and MSF Tweet trends, despite each page publishing a different number of Tweets across the one-month time frame of this study. As seen in Table 1, the most widely used functional frames by UNICEF and MSF combined are appeal, promotion, and informational, followed by storytelling, news dissemination and conversation-focused posts.

\section{Table 1: Functional Frames Prominence Across Sample}

\begin{tabular}{|l|l|}
\hline Functional Frames & Percentage \\
\hline Appeal & $41.10 \%$ \\
\hline Promotion & $39.88 \%$ \\
\hline Informational & $39.26 \%$ \\
\hline Storytelling & $23.93 \%$ \\
\hline News Dissemination & $9.82 \%$ \\
\hline Conversation & $9.20 \%$ \\
\hline
\end{tabular}


The elevated inclusion of promotion and appeal frames compared to the other frames indicate that organizations may more often use the platform to promote themselves or encourage call-toaction related to their initiatives, than use news dissemination or conversation frames, which are only present in less than 10 percent of the entire sample. The data also show that NPOs are using Twitter to solicit a variety of actions from their followers, as seen in Table 1.2 showing examples of Tweets with the appeal frame. Combined with the informational frame present in $39.26 \%$ of Tweets, the data could suggest that Twitter is predominantly used by UNICEF and MSF to disseminate facts, promote organizational messaging, and request action.

\section{Table 1.2: Examples of Tweets with the Appeal Frame}

\begin{tabular}{|c|c|}
\hline Channel & Example \\
\hline MSF Canada & $\begin{array}{l}\text { Watch the trailer for 'Restoring Dignity' and register a \#virtual } \\
\text { screening by @UofTDentistry on Weds. \#January } 20 \text { at 6pm ET } \\
\text { Register here: https://bit.ly/3nIenrH (MSF Canada, 2021, 10:04 ET) }\end{array}$ \\
\hline MSF South Africa & $\begin{array}{l}\text { How is \#COVID-19 actually affecting healthcare? From Latin } \\
\text { America to Africa and from Asia to Europe, we are seeing disrupted } \\
\text { health systems as indirect effects of the pandemic. Click on the link } \\
\text { below to see the stories of the \#KnockOnEffect } \\
\text { http://bit.ly/3o4KpOT (MSF South Africa, 2021, 7:23 ET) }\end{array}$ \\
\hline UNICEF Canada & $\begin{array}{l}\text { UNICEF is calling for @ CanadaDev and other governments to } \\
\text { prioritize teachers and education workers to receive \#COVID_19 } \\
\text { \#vaccines after frontline health workers and other high-risk } \\
\text { populations. Join us. Add your voice now: } \\
\text { http://ow.ly/QEos50DhHuE (UNICEF Canada, 2021, 2:15 ET) }\end{array}$ \\
\hline UNICEF South Africa & 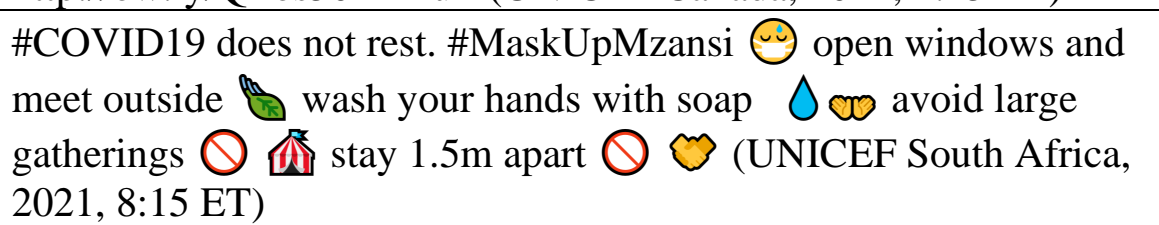 \\
\hline
\end{tabular}

As international humanitarian organizations, MSF and UNICEF both work in several countries around the world. While this study focuses on deciphering the differences between how each organization publishes information to their intraorganizational Twitter pages, Figure 1 presents the differences between the two organization's usage of the platform to help gauge 
possible overarching organizational Twitter strategies. It is noticeable in Figure 1 that informational, promotion, and appeal frames are consistently employed by MSF, however, only appeal and promotion are frequently used by UNICEF. These differences may indicate that promotion and appeal are the most popular functional frames between the two organizations, while news dissemination and conversation could be the least used. In addition, the use of the storytelling frame is relatively close between the two organizations, however, further examination into the storytelling frame use by each intraorganizational channel in a subsequent section shows possible discrepancies between Canada and South Africa accounts.

\section{Figure 1: Use of Functional Frames by Organization}

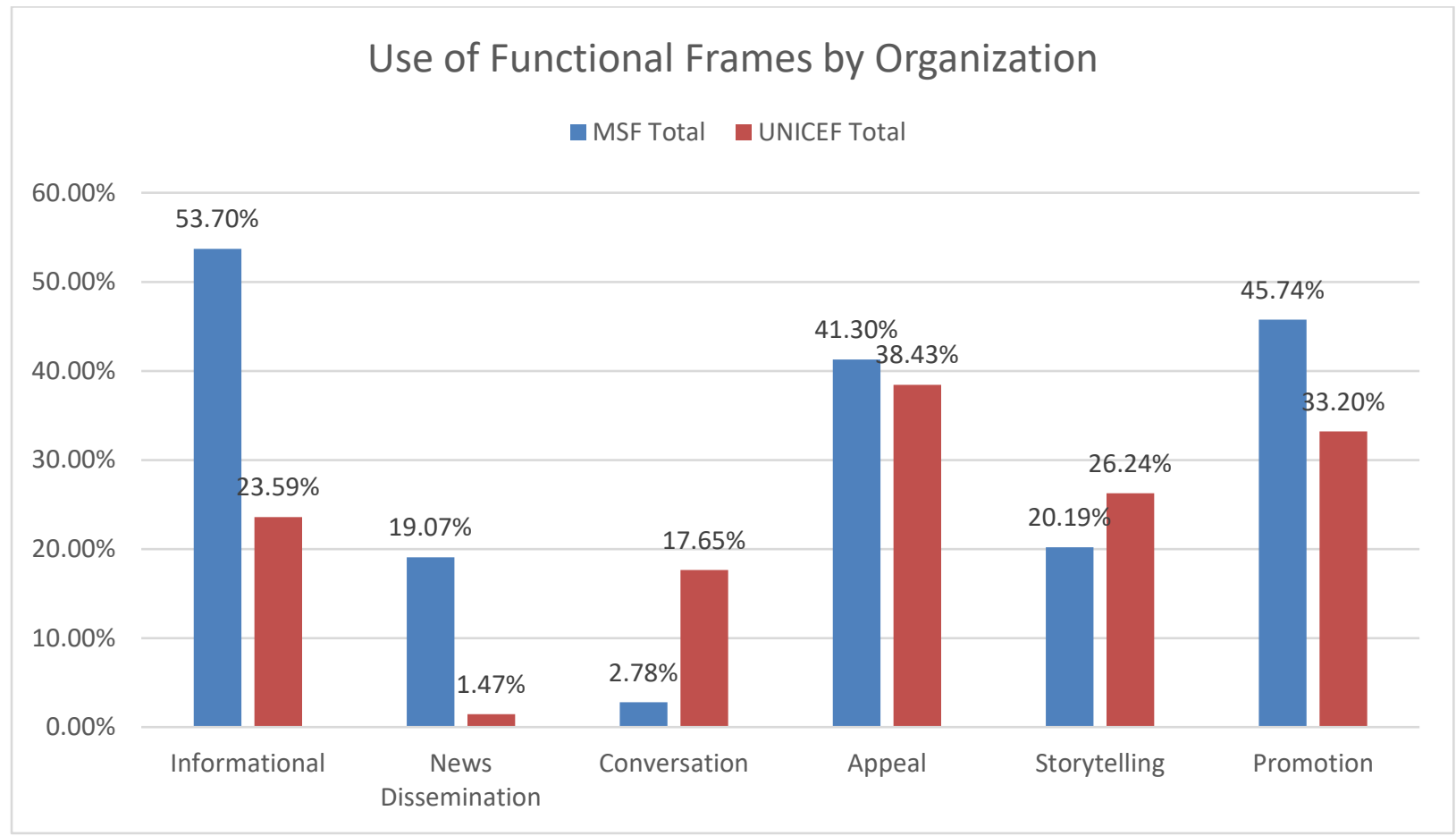

The findings could infer that informational and promotion-based frames are used more often than the other frames, which both aligns with, and challenges arguments presented in previous studies by Lovejoy and Saxon (2012) and Wang and Yang (2020). These authors find that NPOs focus on disseminating information on Twitter, rather than taking advantage of the 
two-way communication and engagement potential of the platform (Lovejoy \& Saxon, 2012; Wang \& Yang, 2020). Preliminary analysis may show that while one-way communication is dominant through the higher percentage of promotion and informational frame use, two-way communication is also frequently present using the appeal frame that seeks action from the audience.

In contrast to the aforementioned studies, the high percentage of appeal frame use by MSF and UNICEF compared to other frames such as news dissemination, conversation and storytelling may show that these NPOs are taking advantage of the two-way communication on the platform. This discrepancy could be due to differences in how two-way communication is defined since Lovejoy and Saxon's (2012) arguments do not consider the different forms of twoway communication that are examined in this study. Instead, Lovejoy and Saxon's (2012) framework identifies Tweets as being action-oriented without specifying any differences between action conducted on and off-Twitter. By omitting these breakdowns, the hierarchy of engagement framework could risk creating generalizations when it comes to action-oriented framing. On the other hand, in this pilot study, appeal is coded specifically as a request for action completed outside Twitter, such as clicking a link to read more, watching a video or registering for an event, whereas conversation refers to promoting action taken on Twitter, such as Retweeting, replying, or answering questions on the platform. Despite appeal being prominent, it is vital to look at how the conversation frame is used on Twitter to determine the extent of twoway communication tactics.

Although the percentage use of the conversation frame is overall lower than the other functional frames examined in this study, UNICEF Canada utilizes this conversation frame in $35.29 \%$ of its Tweets, as indicated in Figure 2. 
Figure 2: Use of Functional Frames by Twitter Account

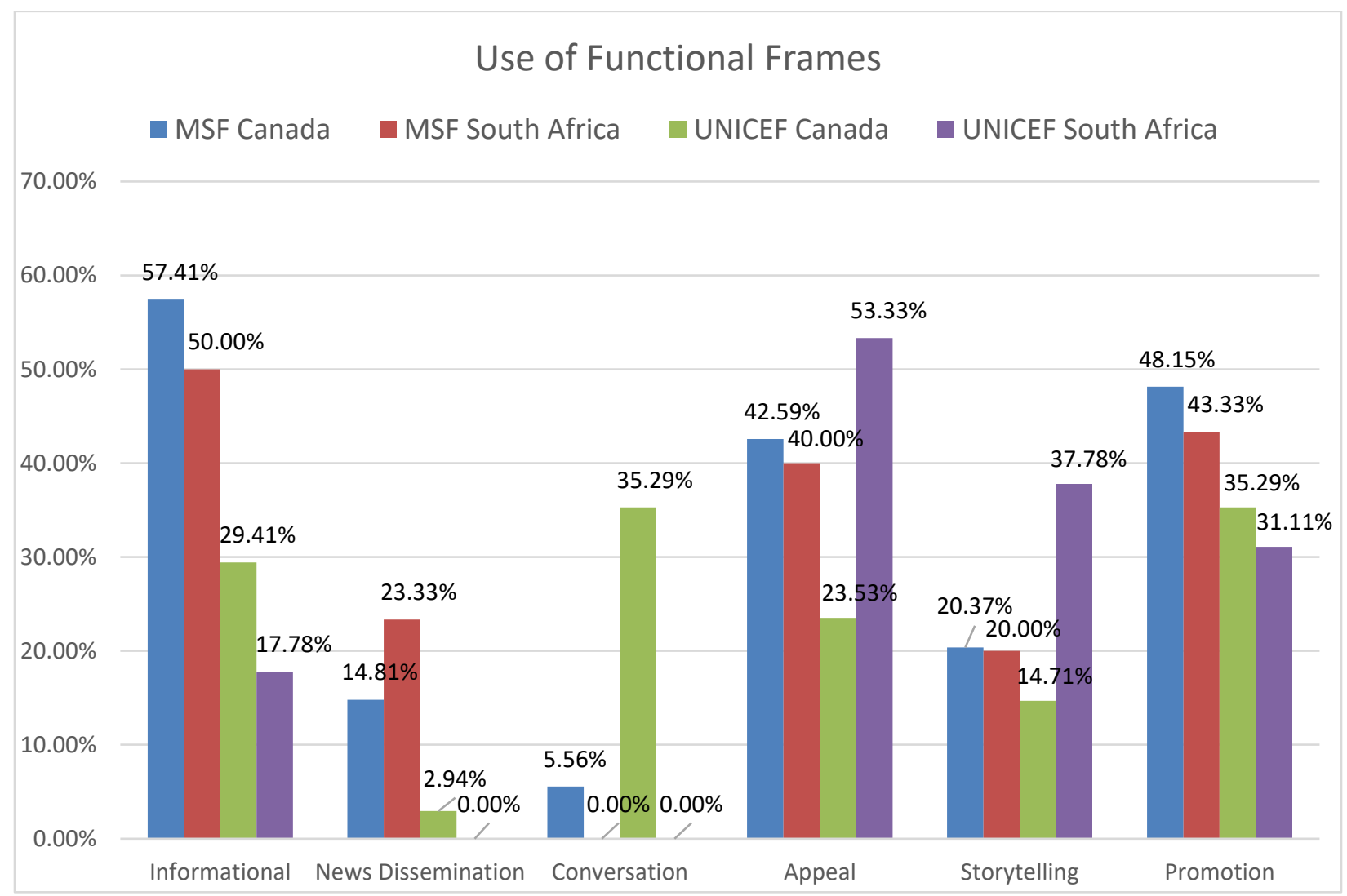

This data may challenge Waters and Jamal's (2011) argument that NPOs are unwilling to engage, and potentially infers that the use of the conversation frame may differ between intraorganizational pages. Based on this observation, it could be suggested that previous studies that compare interorganizational channels, or non-profits versus for-profits, are simplifying their arguments at the organizational level, without consideration for how there may be differences within each intraorganizational channel. The data also show that while MSF South Africa and UNICEF South Africa pages do not apply the conversation frame, both Canada channels are using it as part of their strategy, albeit to a varying degree as seen in Figure 2. This demonstrates that there is a potential geographic difference in the application of the conversation frame, showing that perhaps only the intraorganizational channels in Canada utilize it as part of their strategy. This is not the only difference found in this study. While the sample shows a dominance 
of promotion, appeal, and informational frame use by NPOs, Figure 2 shows variations between each of the four sampled channels. The next segments provide deeper analyses of functional frame use by MSF Canada, MSF South Africa, UNICEF Canada, and UNICEF South Africa Twitter channels.

\section{MSF Canada}

MSF Canada has the most variation of functional frame use in their content compared to the other three channels, and its Tweets predominantly include informational $(57.41 \%)$, promotion (48.15\%), and appeal (42.59\%) frames, as illustrated in Figure 3.

\section{Figure 3: Functional Frame Use in MSF Canada Tweets}

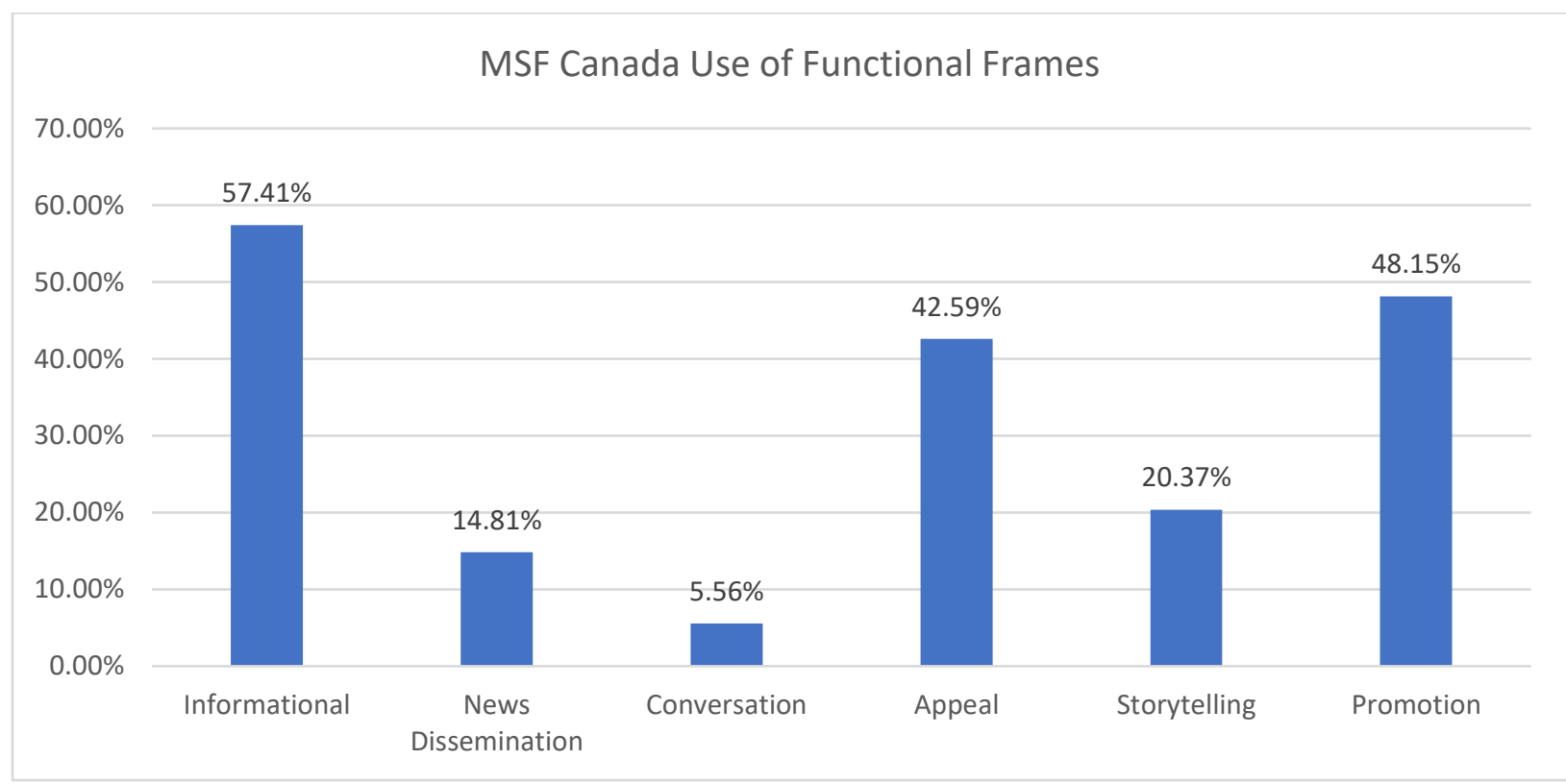

In addition, a third of MSF Canada's sampled Tweets include a combination of these dominant frames inside one Tweet. For example, a Tweet by MSF (see Figure B1 in Appendix B) includes a statistic, promotes the work of MSF, as well as invites the reader to click onwards to learn more as a call to action. This three-pronged strategy is multi-dimensional, aiming to both inform followers about an event, the organization's response to an emergency while also seeking action from the audience, leading users to the organization's website to learn more. 
Other Tweets only focus on one functional frame. For example, MSF Canada published a Tweet with an appeal frame directed at encouraging potential international donors to donate and learn more about work in Jonglei in South Sudan (see Figure B2). This is the sole Tweet in the sample that identifies international donors specifically as an audience on MSF Canada's Twitter account, however, it remains broad without specifically addressing any individual. This coincides with Guo and Saxon's (2014) study that argues that since Twitter audiences are often challenging to define; most organizations avoid targeting specific individuals. However, the data may counter Guo and Saxon's (2014) additional argument that NPOs avoid communicating action-based goals, given that MSF Canada employs the appeal frame in $42.59 \%$ of Tweets. In addition, as MSF Canada's most used functional frames are informational and promotion, its strategy could be classified as primarily utilizing one-way communication to inform its audiences about the situation in MSF-supported countries, their projects, as well as how MSF is responding to various emergencies.

\section{MSF South Africa}

MSF South Africa also primarily employs one-way communication strategies on Twitter, affirming previous studies by Lai et al. (2017), Lovejoy, Waters and Saxton (2012), and Waters and Jamal (2011) that argue NPOs prefer disseminating one-way communications. Similar to MSF Canada, MSF South Africa publishes significant content with informational (50.00\%), promotion (43.33\%), and appeal (40.00\%) frames, as indicated in Figure 4. However, it also utilizes $8.52 \%$ more news dissemination than MSF Canada. 
Figure 4: Functional Frame Use in MSF South Africa Tweets

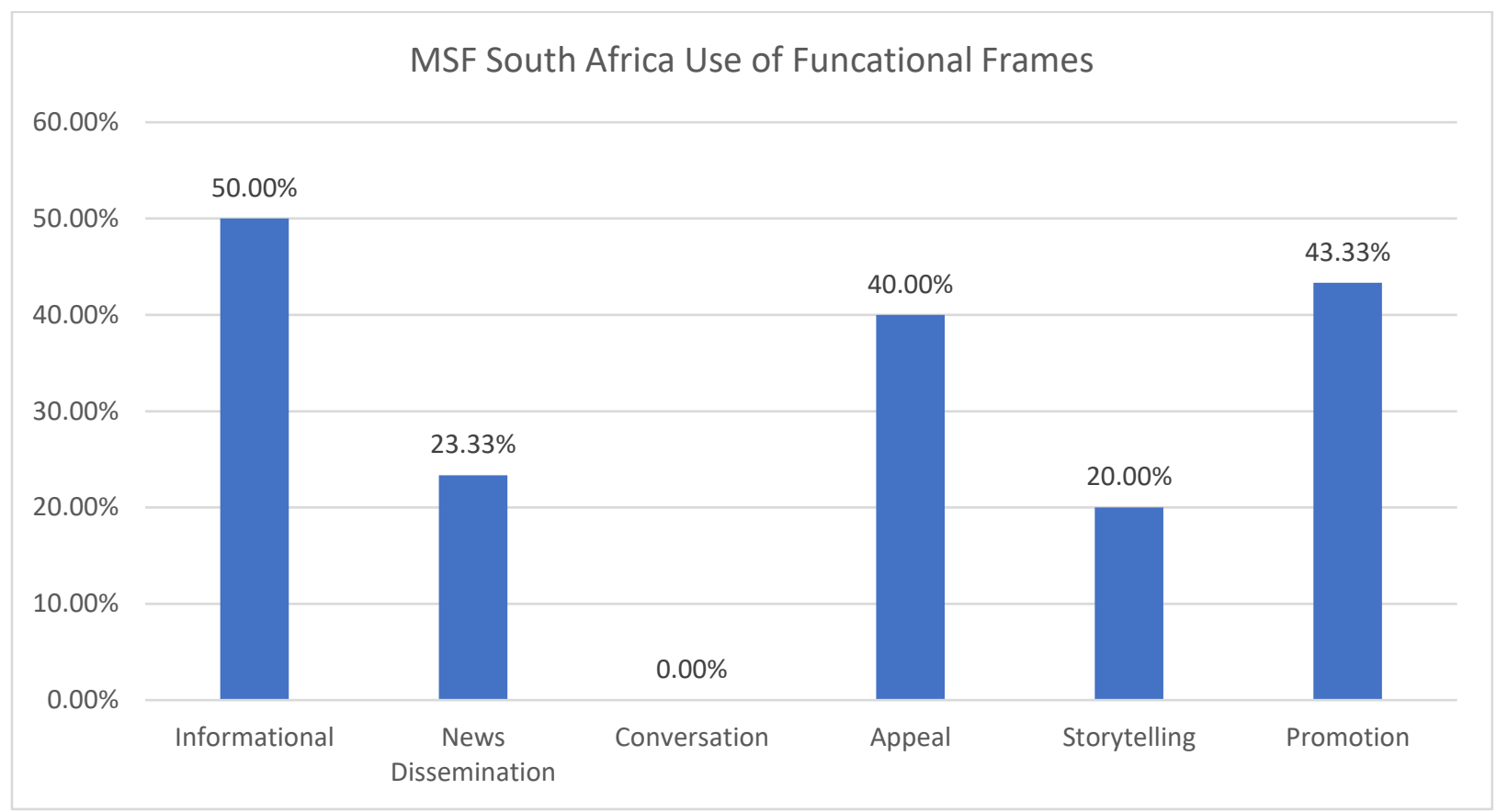

The greater prevalence of the news dissemination frame suggests a potential shift towards sharing more public education-oriented posts. For example, MSF South Africa published a news update about a cyclone in Sofala, Mozambique, as well as another post about ongoing violence in central Mali (see Figures B3 and B4). Through the news dissemination frame, these two posts both could showcase the severity of the ongoing crises and reinforce the context in which the organization works. In addition to news dissemination, the Tweet example in Figure B4 also uses the promotion and appeal frames to further reinforce organizational messaging. This coincides with Guo and Saxton's (2014) research arguing that organizations that engage in advocacy are more likely to use Twitter to encourage public education, conduct grassroots lobbying, and reinforce organizational messages. Thus, the data could illustrate that MSF South Africa employs one-way communication to encourage increased public education through news dissemination, compared to the MSF Canada page which only uses this frame in $14.81 \%$ of Tweets. An evaluation of MSF's use of two-way communication tactics on Twitter present different findings. 


\section{MSF's Intraorganizational Channels}

Overall, the findings suggest that MSF's Canada and South Africa pages employ the highest amount of promotion and informational frames. This showcases their potential preference to disseminate one-way communication messages to their audience, rather than using two-way communication methods to engage readers in a conversation on Twitter. The data thus align with previous studies that argue that organizations are more likely to utilize one-way messages to communicate with their stakeholders (Lai et al., 2017; Lovejoy, Waters \& Saxton, 2012; Waters \& Jamal, 2011). For MSF Canada and MSF South Africa, two-way communication is dominated by the appeal frame with $42.59 \%$ and $40.00 \%$ use, respectively. Since appeal is the third most used frame by both MSF channels, the data could imply that the organization favors requesting action from the audience while also sharing additional information outside of Twitter as one of their communication strategies. On the other hand, the conversation frame is not present in any of the sampled Tweets on MSF South Africa's account, potentially inferring that building a discourse online with their stakeholders may not be prioritized in the organization's digital strategy. Compared to MSF Canada, which includes the conversation frame in $5.56 \%$ of Tweets, MSF South Africa instead may prioritize other functional frames aimed at disseminating information to its audience. However, for each use of the conversation frame by MSF Canada, the Tweet content also includes either the informational or promotion frames to encourage further spread of their key messages (see Figure B5). This could infer that their strategy focuses on education versus discussion, despite using some conversational frames.

In addition, despite varying levels of functional frame use between MSF's Canada and South Africa channels, the prevalence of each frame demonstrates only a 3-8\% difference, as seen in Figures 3 and 4 above. The most prominent difference between the intraorganizational 
channels is in MSF South Africa's higher use of news dissemination, and MSF Canada's greater use of the conversation frame. Despite these differences, the two pages could have similar strategies in communicating to their audiences, since they focus on providing facts and statistics, promote the work and achievements of the organization, as well as call on their audiences to act. These findings could infer that MSF employs similar strategies between its Canada and South Africa intraorganizational channels. In contrast to MSF, UNICEF Canada and UNICEF South Africa have a higher prevalence of appeal and promotion frame use compared to the other frames in the sampled Tweets. To discover differences or similarities between how MSF and UNICEF communicate across intraorganizational channels, UNICEF's application of functional frames is further explored in the next segments.

\section{UNICEF Canada}

The prominent functional frames used by UNICEF Canada are conversation (35.29\%), promotion (35.29\%), and informational (29.41\%), followed by appeal (23.53\%), as demonstrated in Figure 5. UNICEF Canada also has a low percentage (2.94\%) of Tweets classified with the news dissemination frame compared to MSF's channels which corresponds to $15-23 \%$. Over $58 \%$ of Tweets demonstrate two-way communication through conversation and appeal frames, and nearly $65 \%$ use one-way communication tactics with informational and promotion frames. With this varied focus on sharing information about the organization's achievements, asking audience members to act, providing facts and statistics, and prompting conversation, the data could demonstrate that UNICEF Canada's strategy balances both one-way and two-way communication tactics. 
Figure 5: UNICEF Canada Use of Functional Frames

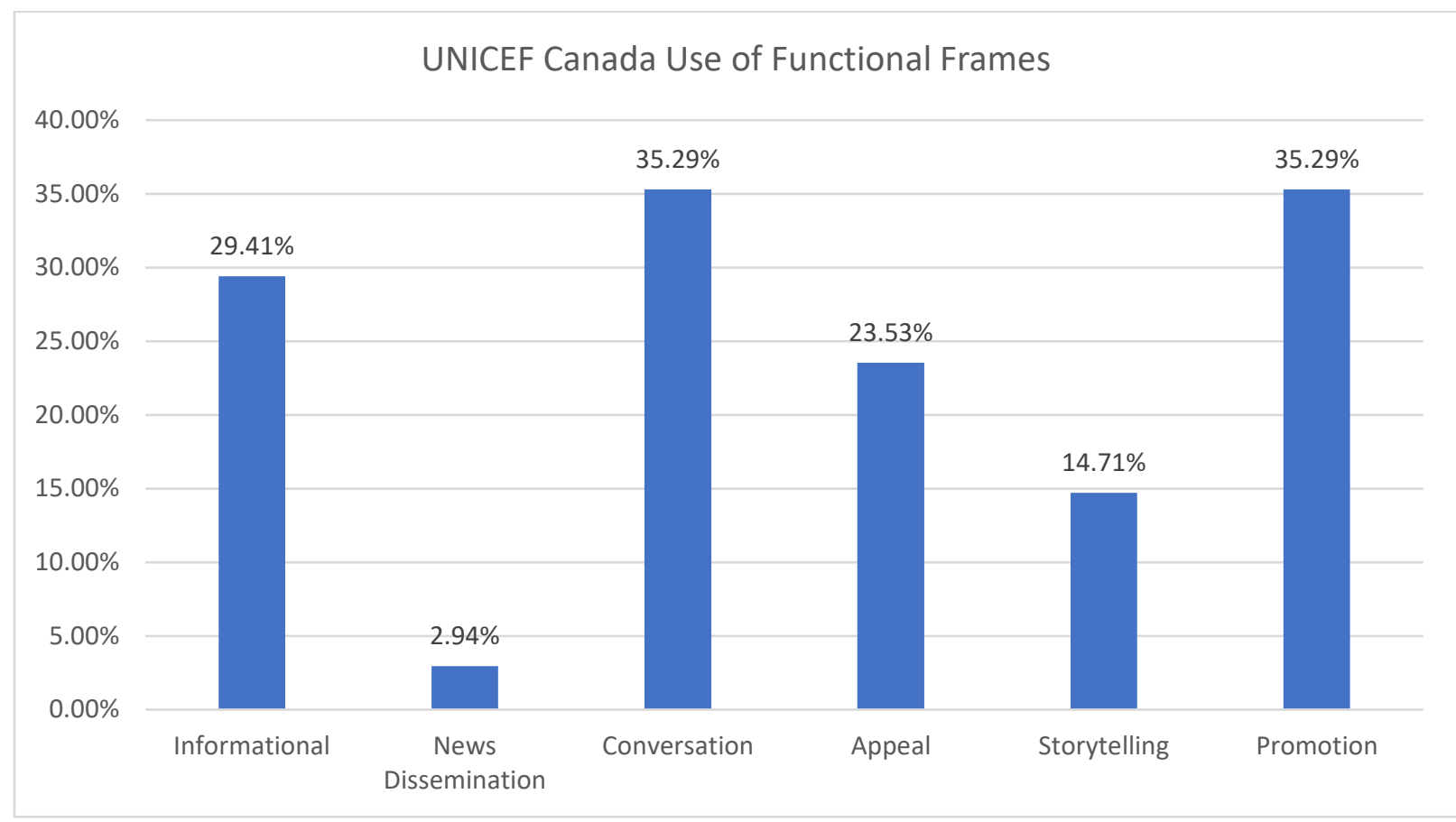

For example, in Figure B6 (see Appendix B) UNICEF Canada uses four functional frames in one Tweet by sparking a conversation through a question, providing information about the use of horses in Haiti, promoting an initiative conducted by UNICEF, as well as prompting audience members to watch a video on YouTube. In Figure B7 (see Appendix B), UNICEF Canada encourages engagement on Twitter, while also promoting UNICEF's achievements in providing access to healthcare to the community. These Tweets demonstrate UNICEF Canada's mixed use of one-way and two-way communications tactics within each Tweet, rather than solely focusing on sharing information versus sparking a conversation. This strategy may differ from the arguments presented in Lovejoy and Saxon's (2012) hierarchy of engagement, which considers Tweets to be categorized as either information, community, or action, rather than a combination of these frames. While Lovejoy and Saxon's (2012) study finds that the majority of NPOs employ information, followed by community and action-based functional frames, a more recent study by Campbell and Lambright (2020) discovers 51\% of sampled Tweets are action-related, 
" $29 \%$ of the Tweets [are] information related and $27 \%$ [are] community related" (p. 562). These differing results could imply that NPOs do not have a consistent strategy, may vary based on the sampled content, and ultimately require more in-depth study.

These methods by Lovejoy and Saxon (2012), and Campbell and Lambright (2020) are also not directly comparable to this study. While their studies assign one dominant mode of engagement per Tweet, this study looks at how each Tweet may include one or more of the six functional frames. However, while each Tweet includes different combinations of frames, the data from UNICEF Canada still does not show any dominance of either information, community, or action-related content. As UNICEF Canada has a more balanced approach, Tweets from UNICEF South Africa reveal a dominance of the appeal frame at 53.33\%. This coincides with Campbell and Lambright's (2020) argument that "the most common mode of engagement [is] to ask followers to take some sort of action" (p. 562). The differences between UNICEF's Canada and South Africa pages are further explored in the next segments, to determine if there are other discrepancies of frame use or Twitter strategies across intraorganizational channels.

\section{UNICEF South Africa}

UNICEF South Africa's functional frame use varies from UNICEF Canada's approach. As seen in Figure 6, UNICEF South Africa focuses on appeal (53.33\%), storytelling (37.78\%) and promotion (31.11\%), with minimal informational, and no Tweets using news dissemination or conversation frames. In addition, on MSF Canada, MSF South Africa and UNICEF Canada accounts, the storytelling frame is employed less than $20 \%$ of the time, whereas it is one of the most prevalent frames for UNICEF South Africa at $37.78 \%$. 
Figure 6: UNICEF South Africa Use of Functional Frames

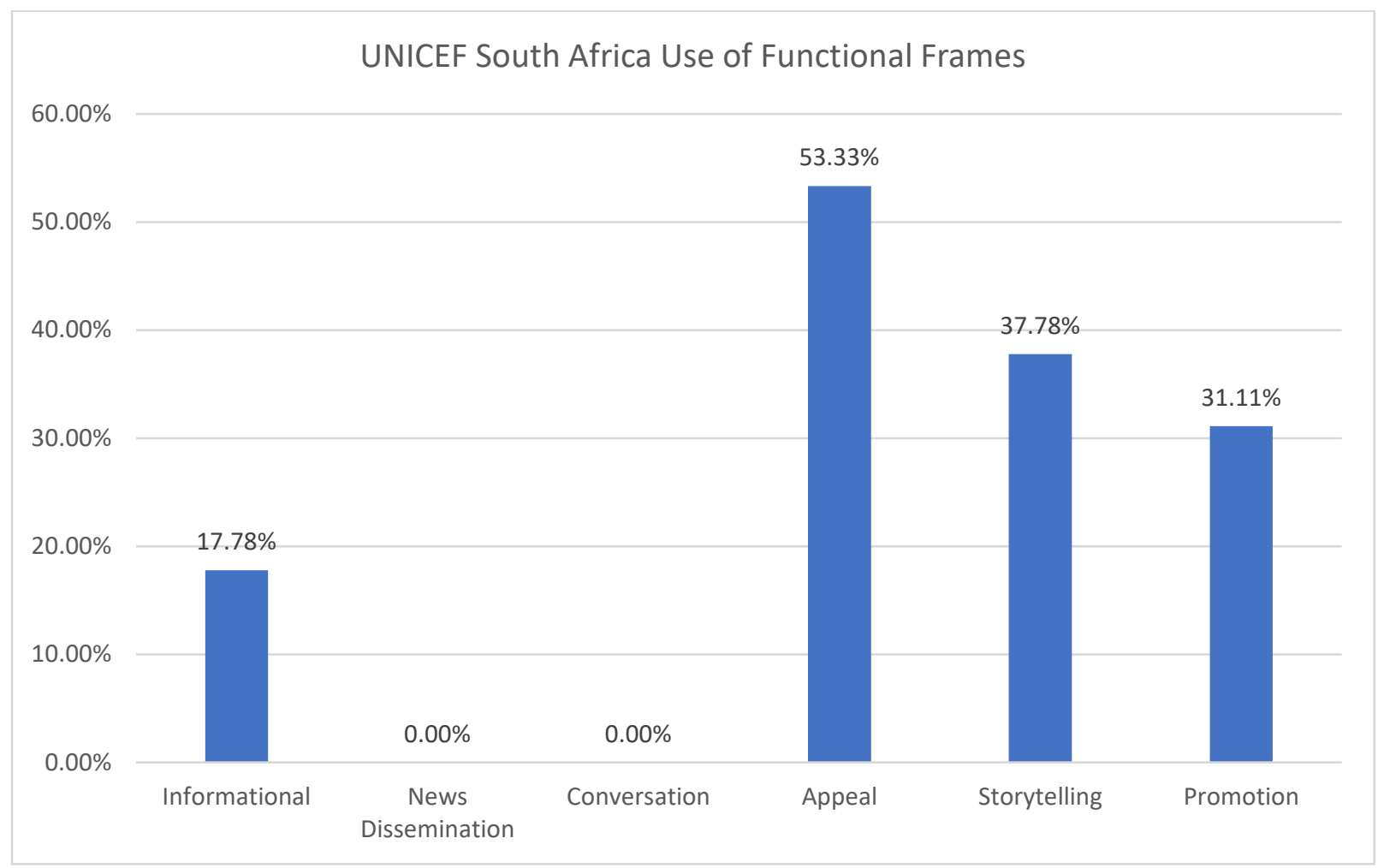

To demonstrate this frame, UNICEF South Africa tells stories of individuals by using quotations to explain someone's personal experience during the COVID-19 pandemic, as seen in Figures B8 and B9 (see Appendix B). Due to the personal nature of the quotes, the data may suggest that the quotes are used to share information about COVID-19, showcasing the human element.

To further examine how these channels are applying the storytelling frame, the frequency of quote use is evaluated. As seen in Figure 7, the data potentially infer that UNICEF South Africa employs quotations as the prime method of telling stories, while MSF Canada, MSF South Africa, and UNICEF Canada use quotes a smaller fraction of the time. These findings could suggest that only UNICEF South Africa include quotations as a significant tactic in storytelling, whereas the other channels publish more direct explanations of someone's circumstances, with minimal quotations. 
Figure 7: Quote Use versus Storytelling Frame Use

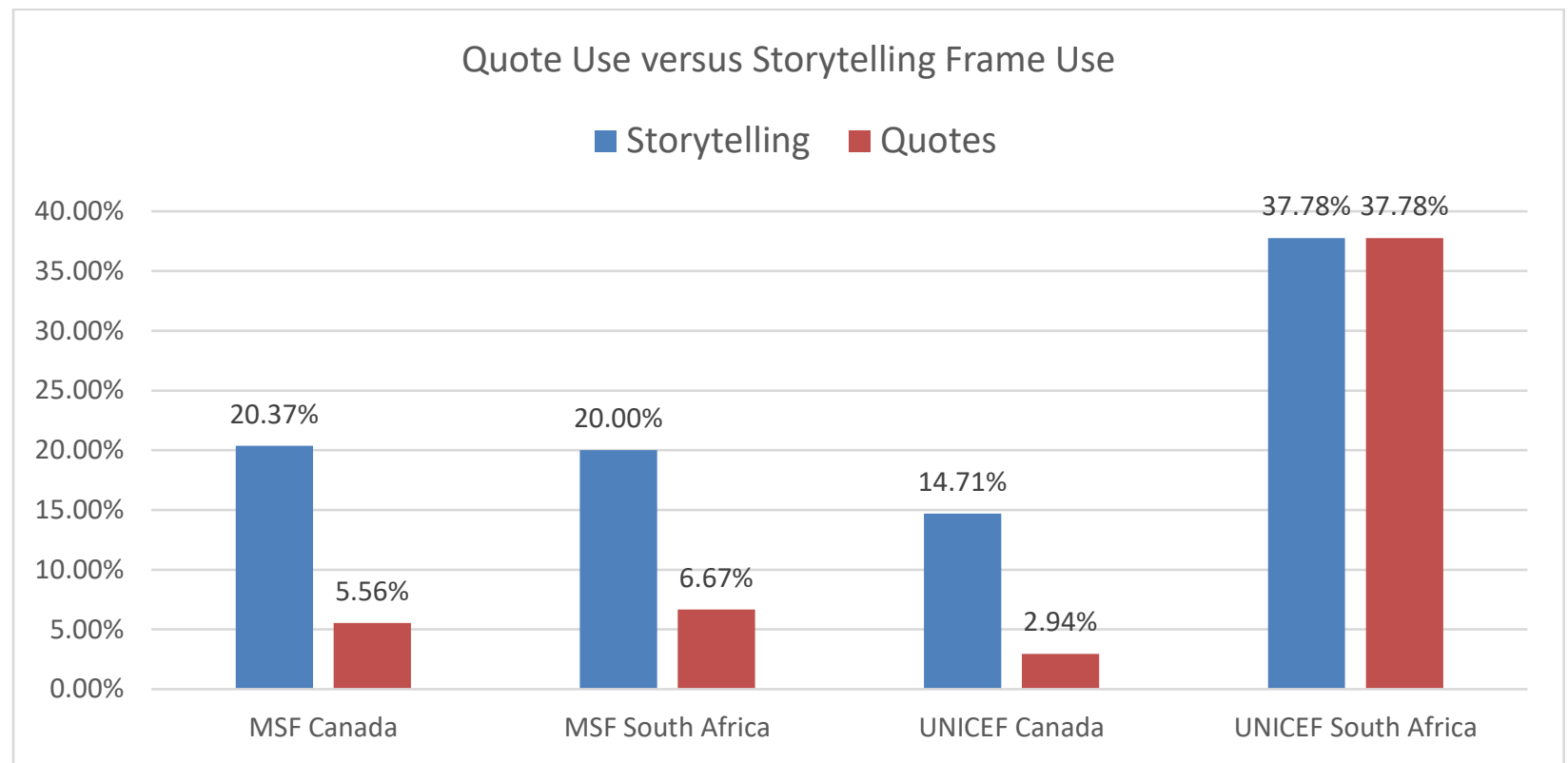

\section{UNICEF Intraorganizational Channels}

Overall, the data show that UNICEF's pages have the highest prevalence of appeal and promotion frames, however, when specifically analyzing each channel, UNICEF Canada and UNICEF South Africa pages use varying levels of each functional frame. For example, UNICEF Canada's most prevalent frames are conversation (35.29\%) and promotion (35.29\%), while UNICEF South Africa's are appeal (53.33\%) and storytelling (37.78\%). Although both channels employ two-way communication methods (conversation, appeal) as a dominant tactic, one focuses on building dialogue on Twitter, whereas the other aims to promote action, and link to content outside Twitter. The data also potentially reveal that the frame use of UNICEF Canada is more spread out between one-way and two-way communication tactics across all six functional frames. This differs from UNICEF South Africa, which employs only four of the six functional frames, and suggests a dominance of the appeal frame. In addition, the storytelling frame is the second most prevalent frame used on the UNICEF South Africa page, and the second least prevalent on the UNICEF Canada page, showcasing additional disparity between 
intraorganizational page strategies. Further, by looking at quotations in relation to the storytelling frame, the data may infer that only the UNICEF South Africa account includes quotations as a significant tactic in storytelling.

Largely the two UNICEF pages show different functional frame use, suggesting that unlike MSF which shows similar page trends, UNICEF's intraorganizational pages do not appear to have an overarching organizational strategy and utilize the platform differently for their Canada and South Africa accounts. This demonstrates that while previous studies focus on interorganizational comparison of how Twitter content is framed, it may not be accurate if organizations have more than one page for their organization. This broad comparison of functional frames between organizations is therefore potentially generalized and requires a deeper analysis to fully understand how NPOs utilize the platform across intraorganizational channels. To further examine how MSF and UNICEF's intraorganizational pages differ, the next section looks at how rhetorical frames are applied across these channels.

\section{Rhetorical Frame Use by NPOs}

By evaluating NPOs use of rhetorical frames, this study determines what modes of persuasion are employed in Tweets published by MSF Canada, MSF South Africa, UNICEF Canada, and UNCIEF South Africa over a one-month period. The results from the entire sample presented in Table 2 demonstrate that $\log$ os $(40.49 \%)$ and ethos (39.26\%) are the most common rhetorical frames used by the studied NPOs, followed by pathos (25.77\%).

\section{Table 2: Rhetorical Frames Prominence Across Sample}

\begin{tabular}{|l|l|}
\hline Functional Frames & Percentage \\
\hline Logos & $40.49 \%$ \\
\hline Ethos & $39.26 \%$ \\
\hline Pathos & $25.77 \%$ \\
\hline Other & $7.36 \%$ \\
\hline
\end{tabular}


On the other hand, when looking at MSF and UNICEF Tweets from both Canada and South Africa accounts, logos $(51.67 \%)$ is the dominant rhetorical frame for MSF, while ethos (36.54\%) is the most used frame by UNICEF (see Figure 8). Pathos (17.04\%) is also the least used frame by MSF, and for UNICEF, logos $(28.43 \%)$ has the lowest prevalence related to the other rhetorical frames, thereby showing that there could be no consistent strategy between the two organizations (see Figure 8).

\section{Figure 8: Use of Rhetorical Frames by Organization}

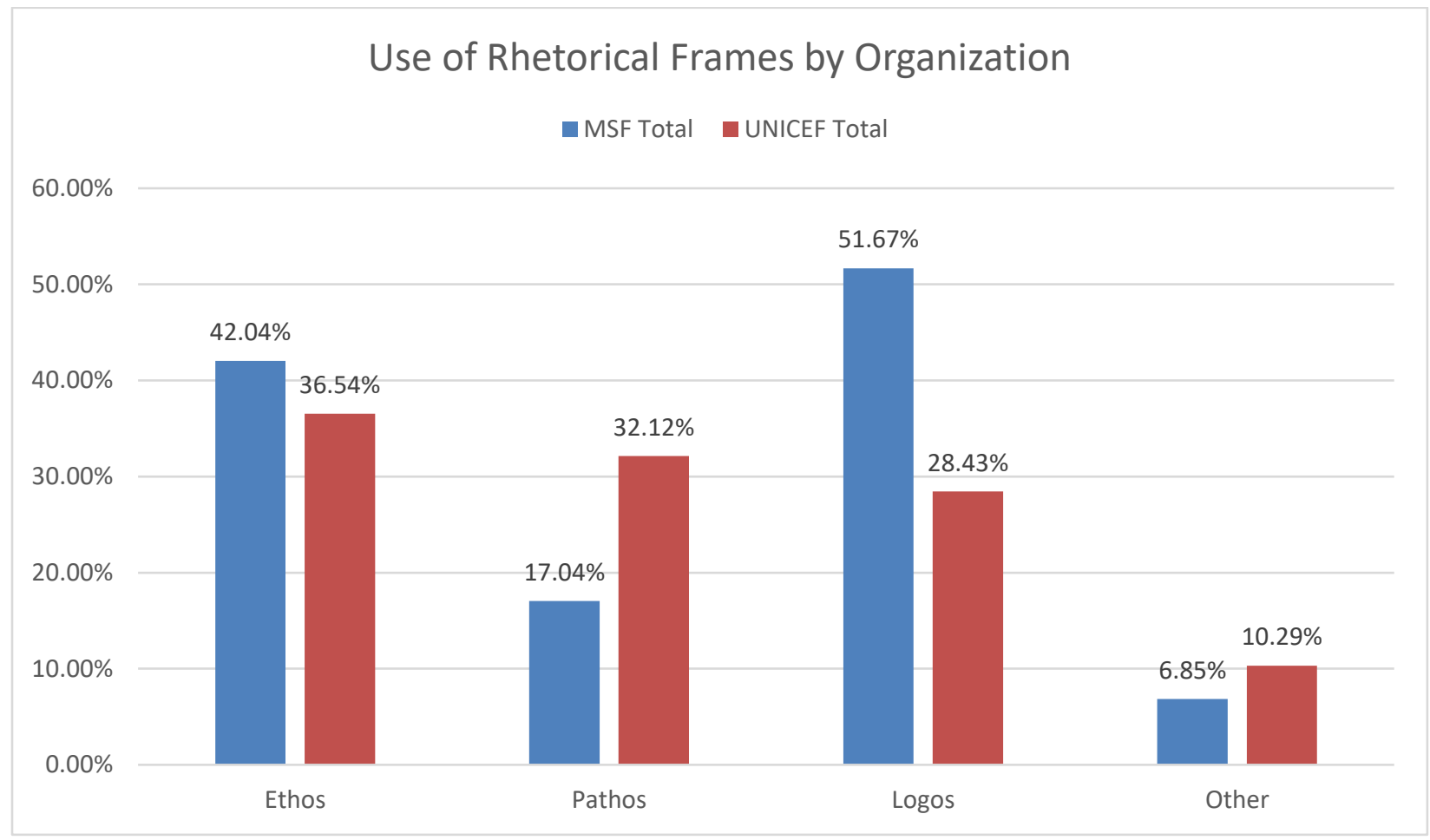

Given that the two organizations both run projects within the medical field abroad, these discrepancies align with McNeill and Briggs' (2014) argument that organizations produce different rhetoric frames for similar issues. The data from the entire sample and the data sorted by organization may suggest that deeper analysis is required to understand the full extent of differences. As seen in Figure 9, each of the sampled channels have a unique strategy as to what rhetorical devices are used or not used in their Tweets. 
Figure 9: Use of Rhetorical Frames by Twitter Account

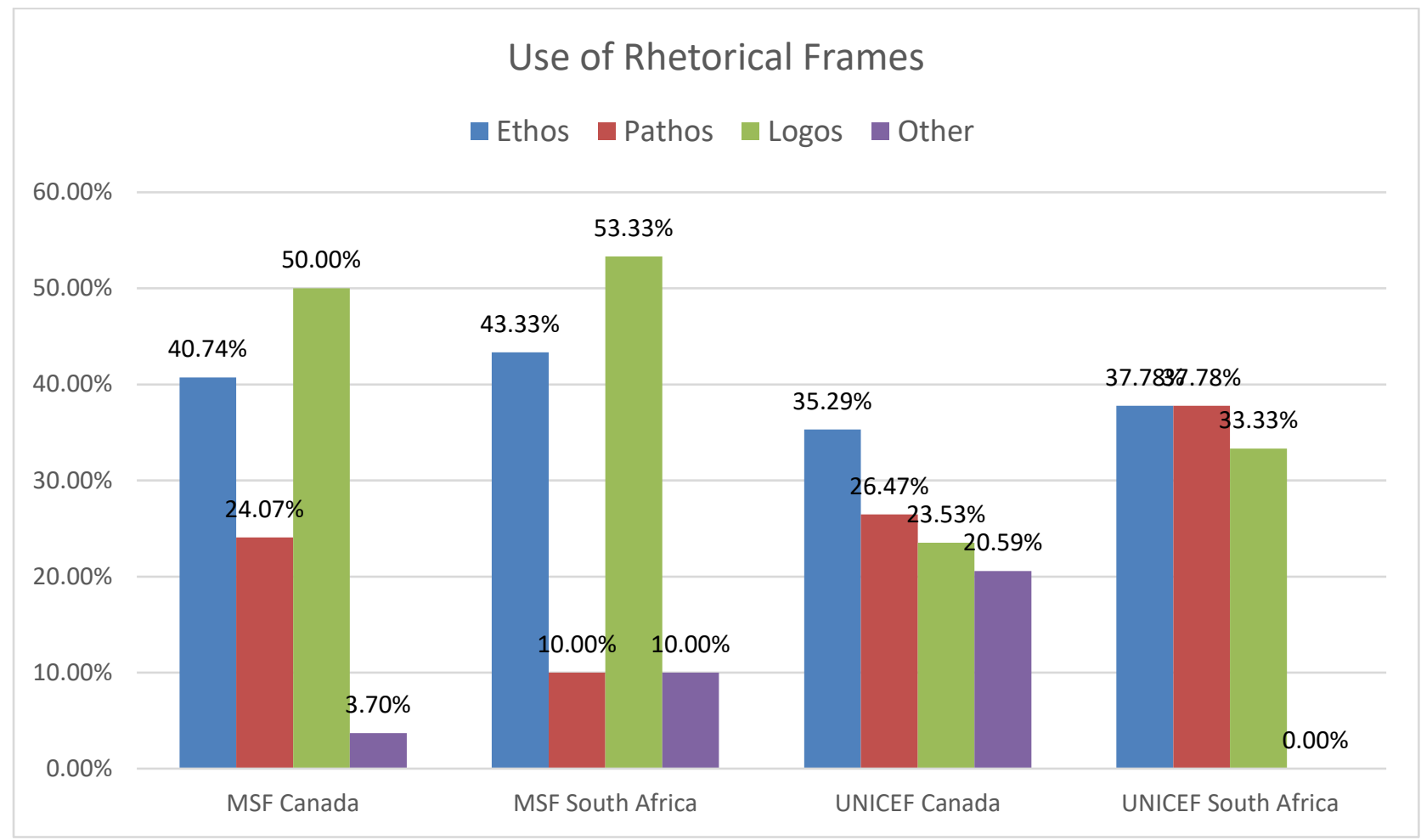

While this section covers which rhetorical devices are employed on each

intraorganizational channel, the data also point at trends in how they are not being used. A Tweet classified into the "other" category has no persuasive appeal present. The overall data (see Table 2) show that $92.64 \%$ of Tweets have at least one rhetorical frame, and when looking specifically at MSF and UNICEF, the findings show that under $10 \%$ of each organization's Tweets do not include a rhetorical frame (see Figure 8). Two previous studies analyzing NPOs indicate that organizations use varying levels of rhetorical frames (Auger, 2014; Smitko, 2012). A study by Auger (2014) concludes that rhetorical frames are used $60 \%$ of the time by NPOs, whereas an earlier study by Smitko (2012) provides evidence that $90 \%$ of analyzed NPO Tweets include at least one aspect of persuasive appeal. The findings in this study align with Smitko's (2012) analysis as three of the four pages analyzed include rhetorical frames over $90 \%$ of the time (see Figure 9). The outlier in this data is seen in UNICEF Canada's Tweets. While MSF Canada and 
MSF South Africa use rhetorical frames in 90.00-96.30\% of Tweets, UNICEF Canada and UNICEF South Africa have a larger discrepancy. UNICEF Canada uses persuasive appeal in $79.41 \%$ of Tweets, while UNICEF South Africa uses rhetorical frames in $100.00 \%$ of Tweets.

These findings could show that while MSF Canada and MSF South Africa accounts employ similar rhetorical framing strategies, UNICEF's Canada and South Africa accounts have different frame use across intraorganizational channels. This aligns with the previous section exploring functional framing trends for MSF and UNICEF, where MSF channels use similar strategies, and UNICEF channels employ different tactics. The next two segments further examine how rhetorical frames are utilized on MSF Canada, MSF South Africa, UNICEF Canada, and UNICEF South Africa accounts.

\section{MSF Canada and MSF South Africa}

For MSF Canada and MSF South Africa, logos is the dominant rhetorical frame at $50.00 \%$ and $53.33 \%$ respectively, and is followed by ethos and pathos, as seen in Figure 10. For logos and ethos, each page has only a 3.00\% difference between frame use, while MSF South Africa utilizes $14.07 \%$ less pathos frames in their Tweet content, compared to MSF Canada.

\section{Figure 10: Rhetorical Frame Use by MSF Canada and MSF South Africa}

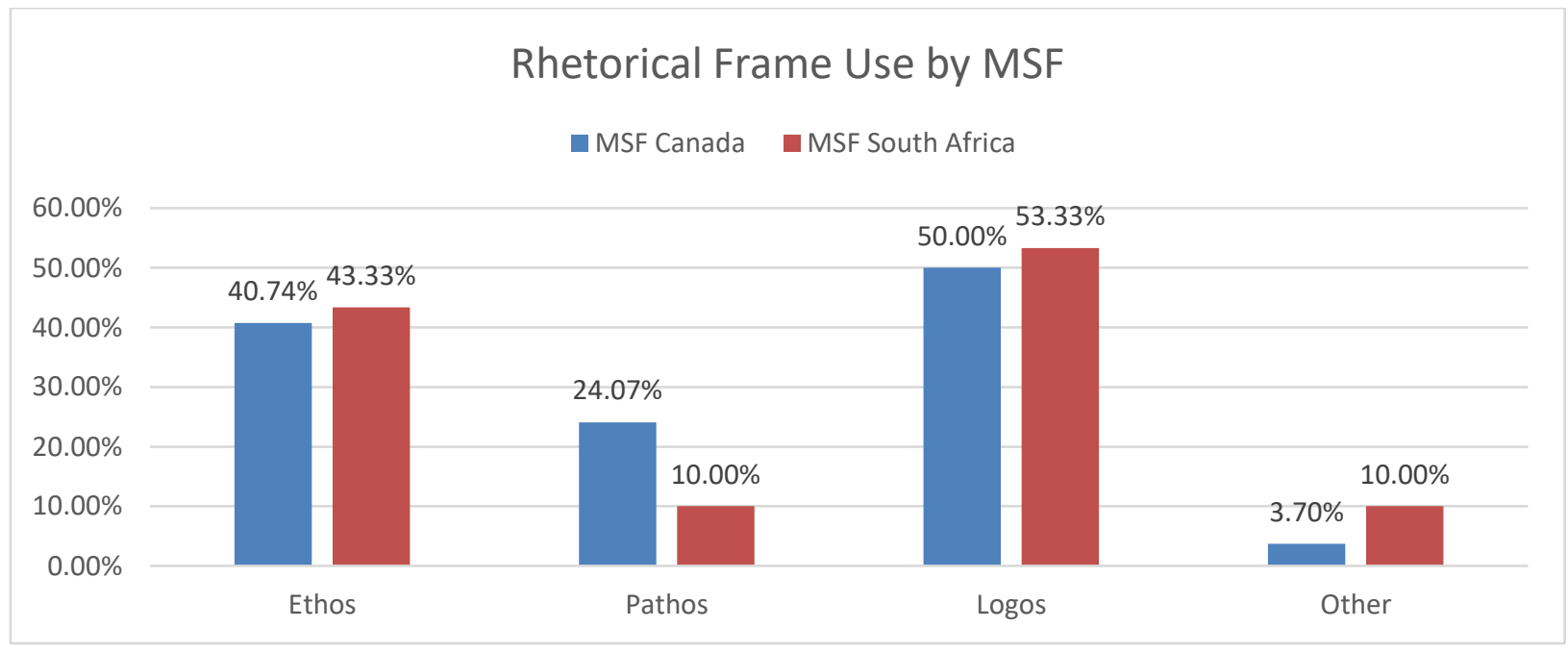


Tweets that use logos present a logical argument, incorporate facts and statistics, and demonstrate a clear rationale. For example, MSF Canada publishes a Tweet that describes the evolving crisis on the Ethiopian border, provides facts, and indicates the organization's rationale for providing assistance, as shown in Figure B10 (see Appendix B). MSF South Africa publishes posts with similar tactics as seen in Figure B11 (see Appendix B), where the post provides background information and facts about a conflict in Cabo Delgado, while also presenting a logical argument for implementing projects in this area.

While at least $50 \%$ of Tweets use the logos frame, some Tweets by MSF also employ a combination of logos and ethos rhetorical frames. For instance, in Figure B12 (see Appendix B) MSF Canada provides a logical explanation of the situation in Mozambique, while also demonstrating MSF's credibility by sharing information about their humanitarian response. This could infer that MSF has a mixed approach to framing their content, and may not only rely on one tactic. The significant use of the logos frame by MSF also potentially contradicts previous studies by Auger (2014) and Smitko (2012) who argue that pathos and ethos are the dominant rhetorical frames employed by NPOs, respectfully (Auger, 2014, Smitko, 2012). Further, while ethos is less common than pathos on both UNICEF accounts, pathos is the second most prevalent, covering $40.74 \%$ of MSF Canada, and $43.33 \%$ of MSF South Africa Tweets. The data thus show the opposite order compared to Smitko's (2012) study, which observes ethos as the most prominent rhetorical frame, followed by logos.

While logos is found in at least half of all published Tweets by both MSF Canada and MSF South Africa, pathos is used to a lesser degree. The pathos rhetorical frame is present when emotion is conveyed as a mode of persuasion. For example, in Figure B13 (see Appendix B) MSF Canada shares a story about a man and his young child who are unable to obtain healthcare 
due to the pandemic situation. As seen in Figure B14 (see Appendix B), MSF South Africa also tells personal stories. By including a personal antidote of someone's negative experience, it could trigger emotion and may be employed to persuade audiences.

According to Auger (2014), pathos is primarily utilized by NPOs to build and motivate audiences. Thus, based on prevalence of pathos in MSF content, it can be inferred that building or motivating audiences may not be the primary objective of MSF Canada and MSF South Africa pages. Instead, with MSF's higher use of logos and ethos, it could be argued that the organization may have a preference for using logic, presenting data, and facts, as well as demonstrating the organizations credibility and trustworthiness to persuade audiences. These findings potentially reveal that while both MSF channels use a similar strategy in terms of using rhetorical frames, their choice of using logos, ethos, or pathos frames, as well as using more than one frame in a Tweet, may not match general findings found in previous studies. This could infer that some NPOs, such as MSF, may have a common organizational strategy in terms of rhetorical framing, but the specific use of each rhetorical device may not be able to be generalized more widely for the non-profit industry due to different results across studies. The next segment covers how UNICEF Canada and UNICEF South Africa employ rhetorical devices in their Tweets.

\section{UNICEF Canada and UNICEF South Africa}

Unlike MSF Canada and MSF South Africa pages which have the most use of the logos frame, ethos is the most prevalent rhetorical frame employed by UNICEF Canada and UNICEF South Africa overall, as seen in Figure 11. 
Figure 11: Rhetorical Frame Use by UNICEF Canada and UNICEF South Africa

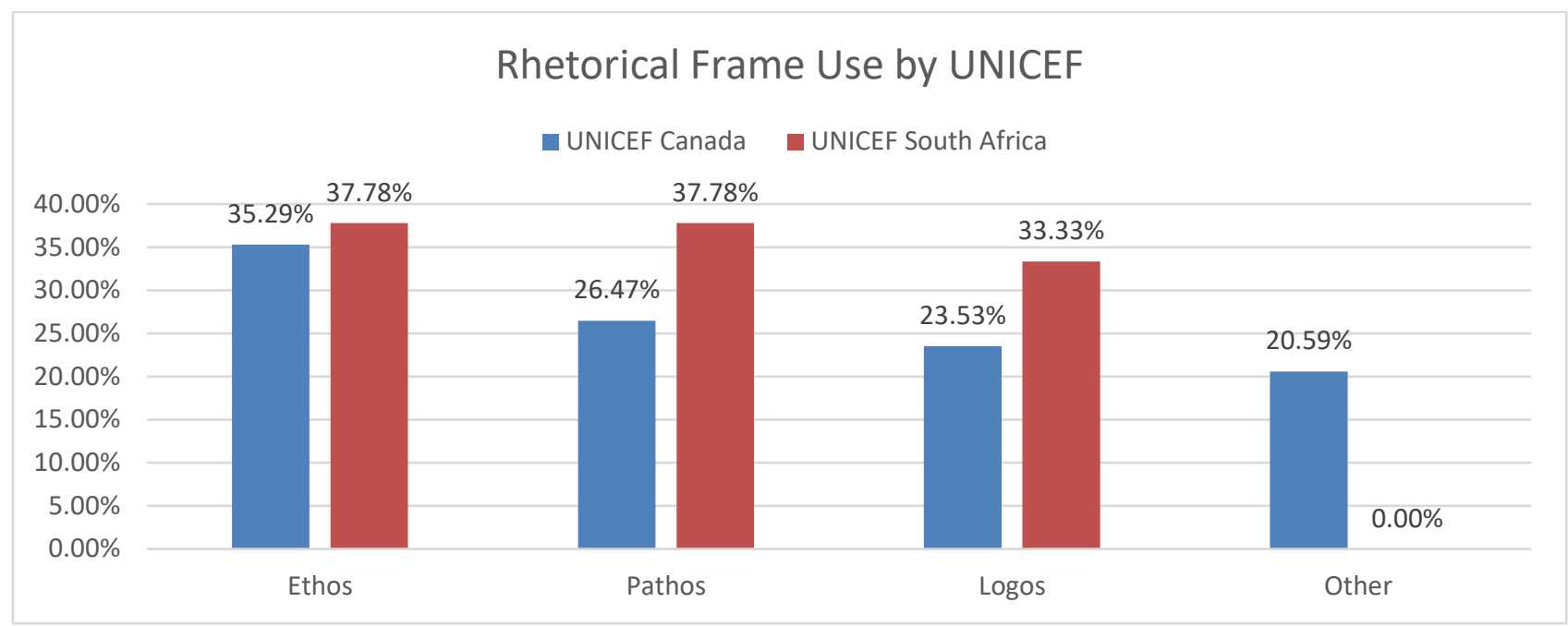

For UNICEF South Africa, the amount of ethos and pathos frames in the sampled Tweets are the same at $37.78 \%$, while UNICEF Canada has a lower prevalence of pathos (26.47\%). In contrast to some MSF Tweets that combine the two most prevalent rhetorical frames, neither UNICEF Canada or UNICEF South Africa pages include both ethos and pathos rhetorical framing within the same Tweets. Instead, UNICEF's account uses either pathos or ethos frames, or one of these in combination with the logos frame. For example, Figure B15 (see Appendix B) is classified with ethos as it demonstrates UNICEF Canada's credibility and trustworthiness by announcing a new partnership with India's National Service Scheme to deliver COVID-19 programming. Further, a Tweet by UNICEF South Africa includes only the pathos frame to communicate feelings to persuade audiences, as seen in Figure B16 (see Appendix B).

Another difference between UNICEF Canada and UNICEF South Africa is the varying levels of not using any rhetorical frames, as noted in the previous section. Over twenty percent of Tweets by UNICEF Canada exclude rhetorical devices, whereas all Tweets by UNICEF South Africa use them. An example of a Tweet without any rhetorical framing is shown in Figure B17 
(see Appendix B), which includes a question asked to the audience, without inclusion of emotion, facts, or information to demonstrate credibility or trustworthiness.

The higher prevalence of ethos and pathos by UNICEF's Canada and South Africa channels could therefore align with Auger (2014) and Smitko's (2012) research that identifies logos as the least common frame used by NPOs. However, for UNICEF South Africa, there are minimal differences between each of the three frames, as the prevalence of the logos frame is only $5 \%$ less than the ethos and pathos. This contrasts with UNICEF Canada's use of rhetorical devices, which demonstrates a dominance of ethos (35.29\%) followed by pathos (26.47\%) and $\log \operatorname{los}(23.53 \%)$ which are only $2 \%$ apart. These findings could infer that while both UNICEF pages may demonstrate their credibility and trustworthiness and persuade audiences using the ethos frame, they also might rely on communicating with emotion, and logic as part of their strategy.

\section{MSF and UNICEF Rhetorical Framing}

The findings may suggest that overall MSF and UNICEF have no consistent use of rhetorical frames on their intraorganizational channels, however, rhetorical framing is found in the majority (92.64\%) of the sampled Tweet content. Logos is found to be the most prevalent in MSF Tweets and ethos is dominant in UNICEF Tweets, however, a closer look at the intraorganizational channels may suggest certain differences. MSF channels have similar levels of ethos and logos, while MSF South Africa has less pathos than MSF Canada. This could suggest that MSF South Africa has more of a preference to using logic, facts, and building credibility and trustworthiness to persuade audiences, rather than emotion.

MSF's Tweets also point at a consistent use of more than one rhetorical frame within each Tweet across all three frames. This contrasts with UNICEF's pages, which only include a 
combination of logos with either ethos or pathos. An analysis of UNICEF's pages also could show that UNICEF Canada uses the most ethos, followed by pathos and logos, whereas UNICEF South Africa sees minimal differences between all three rhetorical frames. UNICEF Canada also has the lowest prevalence of rhetorical frames at $79.41 \%$ compared to UNICEF South Africa, which uses rhetorical framing in $100.00 \%$ of its posts. These findings may suggest that while UNICEF Canada includes different amounts of each rhetorical frame, UNICEF South Africa has more balanced levels of each frame. As seen in Figures 10 and 11, UNICEF's intraorganizational channels follow the same order of prevalence between each rhetorical frame, whereas MSF's intraorganizational channels take different approaches. These findings could validate the argument that some non-profit organizations use similar framing strategies across intraorganizational channels, while others do not. While previous studies have examined how NPOs frame their content on Twitter, this study takes a deeper look at how NPOs communicate across different branches of their organization. This study finds several similarities and differences between MSF and UNICEF's framing strategies, which potentially reveals an overall inconsistency between frame use by NPOs across interorganizational and intraorganizational channels. The next section summarizes the findings from this pilot study on content framing across intraorganizational channels, and shares considerations for future studies. 


\section{Conclusion}

MSF and UNICEF use Twitter to disseminate content to their audiences, yet they are utilizing different functional and rhetorical framing strategies across their intraorganizational channels in Canada and South Africa. This pilot study questions the differences between MSF and UNICEF's use of functional frames within text communication across intraorganizational channels on Twitter, as well as identifies what rhetorical framing strategies are presented in MSF's and UNICEF's Canada and South Africa channels. This section presents considerations for future research, describes some limitations of the study, and shares final conclusions related to functional and rhetorical framing by MSF's and UNICEF's intraorganizational channels.

\section{Considerations for Future Research \& Limitations}

This pilot study overall demonstrates the need for further evaluation into how NPOs communicate across intraorganizational channels. While previous studies provide general findings for NPOs, this study expands Lovejoy and Saxon's (2012) hierarchy of engagement to include six functional frames designed to extract insights at the intraorganizational level. It also considers rhetorical framing tactics, and whether NPOs are using rhetorical frames in their content on Twitter. This study evaluates two NPOs and two intraorganizational channels across a one-month period. Future research can incorporate this framework of functional and rhetorical frames across more NPOs and expand the evaluation to more than one intraorganizational channel per examined NPO. Evaluating additional NPOs can help provide more meaningful insights to see if these findings are similar or different to MSF and UNICEF's results.

The methodology of this study also employs manual coding, and therefore creates some limitations in retrieving historical data. While a detailed codebook is developed, the results may present some subjectivity regarding how each Tweet is categorized. Future studies could 
incorporate multiple coders to ensure inter-coder reliability, as well as possibly introduce social media analysis software such as NVivo when dealing with larger amounts of data. The study is also limited to more recent timeline, and future studies could explore using APIs to obtain historical data and analyze if any framing differences are found pre- and post-COVID across the same channels evaluated in this study. The next segments summarize the key findings of this pilot study related to functional and rhetorical framing.

\section{Functional Framing}

The data may suggest that one-way communication is dominant as seen through the high prevalence of promotion and informational frames across both MSF and UNICEF pages. This aligns with several studies that state NPOs prefer to publish one-way communication messages (Waters \& Jamal, 2011, Lovejoy \& Saxon, 2012, Auger, 2014). At the page level, while MSF Canada and MSF South Africa both publish mostly one-way communication messages, UNICEF Canada and UNICEF South Africa employ more two-way communication tactics including using conversation and appeal frames as a dominant strategy. These findings may not be aligned with previous studies since the study shows that not all intraorganizational channels are publishing the same type of content.

Despite varying levels of functional frame use between MSF Canada and MSF South Africa channels, the prevalence of each frame demonstrates only a 3-8\% variation. The main difference between MSF's channels is MSF South Africa's higher use of the news dissemination frame, and MSF Canada's greater use of the conversation frame. For instance, the conversation frame is used in 5.56\% of Tweets by MSF Canada, whereas it is not present in any of MSF South Africa's Tweets. Despite minor variations, the study may suggest that MSF employs parallel strategies between its Canada and South Africa intraorganizational channels. 
On the other hand, the functional frames used by UNICEF Canada and UNICEF South Africa are overall inconsistent, with a wider discrepancy rate of frame use ranging from $2.94 \%$ to $35.29 \%$. The most significant variation is seen through the conversation frame with $35.29 \%$ of UNICEF Canada Tweets using the conversation frame compared to zero by UNICEF South Africa. Another major difference in functional framing includes UNICEF South Africa using storytelling in $37.78 \%$ of Tweets compared to $14.71 \%$ in UNICEF Canada. In addition, UNICEF South Africa uses the appeal frame in 53.33\% of Tweets compared to $23.53 \%$ in UNICEF Canada. These discrepancies show that while UNICEF South Africa uses appeal and storytelling as a prominent strategy, UNICEF Canada instead has a higher use of the conversation and promotion frames. These differences could infer that NPOs do not all have similar strategies for how they choose to engage with their audiences in different locations.

The data not only reveal potential differences between intraorganizational channels, but also may suggest that findings do not align with previous studies evaluating how Twitter content is framed by NPOs. While some results reach similar conclusions to previous research, each of the four analyzed pages point at different trends, often potentially contradicting these studies. For example, when considering the entire sample, the appeal frame is the most frequently utilized frame, followed by promotion and information frames at slightly less prevalent rates. When looking at each individual channel, appeal is also consistently found within the top three or four functional frames, further emphasizing its prominence compared to other frames such as the news dissemination and conversation frames. However, this high level of appeal is not aligned with several studies which claim that NPOs are unwilling to engage, and that they avoid communicating action-based goals (Waters \& Jamal, 2011; Guo \& Saxon, 2014). In addition, it also potentially contradicts a study by Lovejoy and Saxon (2012) that identifies the lowest 
percentage of Tweets as action-based. While the overall statistics show NPOs having slight differences between the top three frames (appeal, promotion, and informational), the data from each intraorganizational channel suggest their unique strategies.

Overall, previous studies are presenting data in a way that generalizes how NPOs are communicating on Twitter, such as stating that most NPOs communicate informational content. However, these generalizations may not consider the growing international nature of NPOs who have multiple accounts in different areas of the world, which limits the depth of research, and may create inaccurate assumptions on how NPOs communicate on Twitter. Considering these potential generalizations on how NPOs are communicating, the next segment covers how modes of persuasion are utilized in MSF and UNICEF's Twitter channels.

\section{Rhetorical Framing}

In addition to analyzing functional framing trends for NPOs, this pilot study also reviews how MSF and UNICEF employs rhetorical framing into their intraorganizational channels. Rhetorical framing is found in $92.64 \%$ of Tweets in the sample, which coincides with a study by Smitko (2012) that finds at least $90 \%$ of NPO Tweets including one aspect of persuasive appeal. Generally, the study finds that MSF Canada and MSF South Africa accounts employ similar rhetorical frame use strategies. For example, the dominant rhetorical frame of both MSF channels is logos, followed by ethos and pathos. On the other hand, UNICEF Canada and UNICEF South Africa have different frame use across intraorganizational channels. For instance, $100 \%$ of Tweets by UNICEF South Africa use rhetorical devices, whereas $20 \%$ of Tweets by UNICEF Canada exclude rhetorical devices. Also, while UNICEF South Africa has similar levels of ethos and pathos rhetorical frames, and the logos frame is only $5 \%$ less than the ethos 
and pathos, UNICEF Canada has the greatest number of Tweets using ethos, followed by pathos and logos at greater variations.

While the logos frame is the most used by MSF channels, this is not aligned with previous studies by Auger (2014), and Smitko (2012) who observe that ethos and pathos are the dominant rhetorical frames used by NPOs. In contrast, data from UNICEF support Smitko's (2012) research as UNICEF Canada and UNICEF South Africa have the highest prevalence of the ethos frame compared to logos and pathos. These potentially conflicting findings support McNeill and Briggs's (2014) argument that different organizations are producing different rhetorical frames for similar issues. This study thus expands this argument to intraorganizational channels since rhetorical framing techniques are also different for each of the sampled Twitter accounts.

Considering the research questions, the study finds that when looking at the functional framing techniques by both organizations, MSF overall employs similar strategies between its Canada and South Africa pages, whereas UNICEF has different tactics depending on which page they are posting to. On the other side, UNICEF's intraorganizational channels follow the same order of prevalence between each rhetorical frame, whereas MSF's intraorganizational channels take different approaches with more variations in the data. These discrepancies demonstrate that NPOs do not all have parallel strategies for how they choose to engage with their audiences across intraorganizational channels. Ultimately when looking at both functional and rhetorical framing, one organization has similar strategies for each of their pages, while the other has divergent strategies. These inconsistencies both support and contradict previous studies, suggesting that not all non-profits have the same strategy when communicating on Twitter. This study therefore concludes that while existing literature provides generalizations on how NPOs 
use Twitter, trends or differences across intraorganizational channels should also be considered to find more accurate insights about how NPOs use the platform. 


\section{Appendix A}

Coding Results

Table A1. Coding Results: Functional Frames by Twitter Account

\begin{tabular}{|l|l|l|l|l|}
\hline Category & $\begin{array}{l}\text { MSF Canada } \\
(\%)\end{array}$ & $\begin{array}{l}\text { MSF South } \\
\text { Africa }(\%)\end{array}$ & $\begin{array}{l}\text { UNICEF } \\
\text { Canada (\%) }\end{array}$ & $\begin{array}{l}\text { UNICEF South } \\
\text { Africa (\%) }\end{array}$ \\
\hline Informational & 57.41 & 50.00 & 29.41 & 17.78 \\
\hline $\begin{array}{l}\text { News } \\
\text { Dissemination }\end{array}$ & 14.18 & 23.33 & 2.94 & 0.00 \\
\hline Conversation & 5.56 & 0.00 & 35.29 & 0.00 \\
\hline Appeal & 42.59 & 40.00 & 23.53 & 53.33 \\
\hline Storytelling & 20.37 & 20.00 & 14.17 & 37.78 \\
\hline Promotion & 48.15 & 43.33 & 35.29 & 31.11 \\
\hline
\end{tabular}

Table A2. Coding Results: Functional Frames by Organization

\begin{tabular}{|l|l|l|}
\hline Category & MSF $(\%)$ & UNICEF $(\%)$ \\
\hline Informational & 53.70 & 23.59 \\
\hline $\begin{array}{l}\text { News } \\
\text { Dissemination }\end{array}$ & 19.07 & 1.47 \\
\hline Conversation & 2.78 & 17.65 \\
\hline Appeal & 41.30 & 38.43 \\
\hline Storytelling & 20.19 & 26.24 \\
\hline Promotion & 45.74 & 33.20 \\
\hline
\end{tabular}

Table A3. Coding Results: Rhetorical Frames by Twitter Account

\begin{tabular}{|l|l|l|l|l|}
\hline Category & $\begin{array}{l}\text { MSF Canada } \\
(\%)\end{array}$ & $\begin{array}{l}\text { MSF South } \\
\text { Africa }(\%)\end{array}$ & $\begin{array}{l}\text { UNICEF Canada } \\
(\%)\end{array}$ & $\begin{array}{l}\text { UNICEF South } \\
\text { Africa (\%) }\end{array}$ \\
\hline Ethos & 40.74 & 43.33 & 35.29 & 37.78 \\
\hline Pathos & 24.07 & 10.00 & 26.47 & 36.78 \\
\hline Logos & 50.00 & 53.33 & 23.53 & 33.33 \\
\hline Other & 3.70 & 10.00 & 20.59 & 0.00 \\
\hline
\end{tabular}

Table A4. Coding Results: Rhetorical Frames by Organization

\begin{tabular}{|l|l|l|}
\hline Category & MSF $(\%)$ & UNICEF $(\%)$ \\
\hline Ethos & 42.04 & 36.54 \\
\hline Pathos & 17.04 & 32.12 \\
\hline Logos & 51.67 & 28.43 \\
\hline Other & 6.85 & 10.29 \\
\hline
\end{tabular}




\section{Appendix B}

Screenshots of Select Sampled Tweets

Figure B1: MSF Canada Tweet with Informational, Promotional and Appeal Frames

MSF Canada

@MSF_canada

Since November, over 55,00 \#refugees and arrivals

from \#Ethiopia are in \#Sudan. Hear about MSF's

response from Karline Kleijer, MSF Head of Emergency:

bit.ly/3i5ZbUa

(MSF Canada, 2021, 11:30 ET)

\section{Figure B2: MSF Canada Tweet with Functional Frame}

MSF Canada

\#MSF is calling on international donors to ensure funding continues for other health organizations working in \#Jonglei state so that they can provide healthcare and urgent humanitarian assistance, including food, water, and latrines. Read more below

(MSF Canada, 2021, 12:43 ET)

\section{Figure B3: MSF South Africa Tweet with News Dissemination Frame}

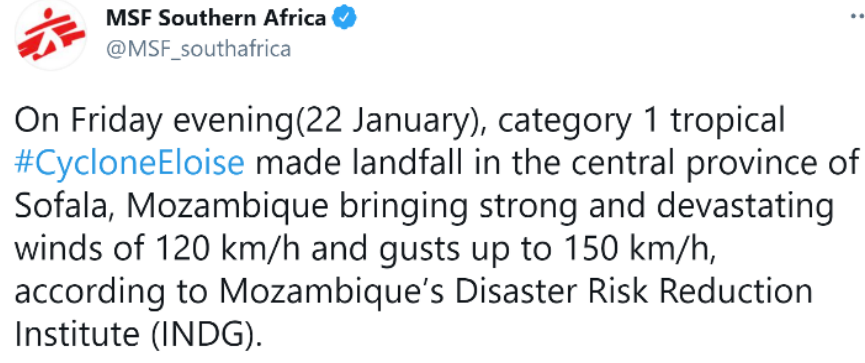

On Friday evening(22 January), category 1 tropical \#CycloneEloise made landfall in the central province of Sofala, Mozambique bringing strong and devastating winds of $120 \mathrm{~km} / \mathrm{h}$ and gusts up to $150 \mathrm{~km} / \mathrm{h}$, according to Mozambique's Disaster Risk Reduction Institute (INDG).

(MSF Southern Africa, 2021, 3:02 ET)

Figure B4: MSF South Africa Tweet with News Dissemination, Promotion, Appeal Frames

$$
\text { MSF Southern Africa }
$$

@MSF_southafrica

Our teams treated eight people who were seriously injured in attacks on the villages of Bounty and Kikara, in central \#Mali on Sunday 3 January 2021. Violence has continued to intensify making living conditions difficult for residents. Read: bit.ly/3oorUpl

(MSF Southern Africa, 2021, 6:18 ET) 
Figure B5: MSF Canada Tweet with Conversation and Informational Frames

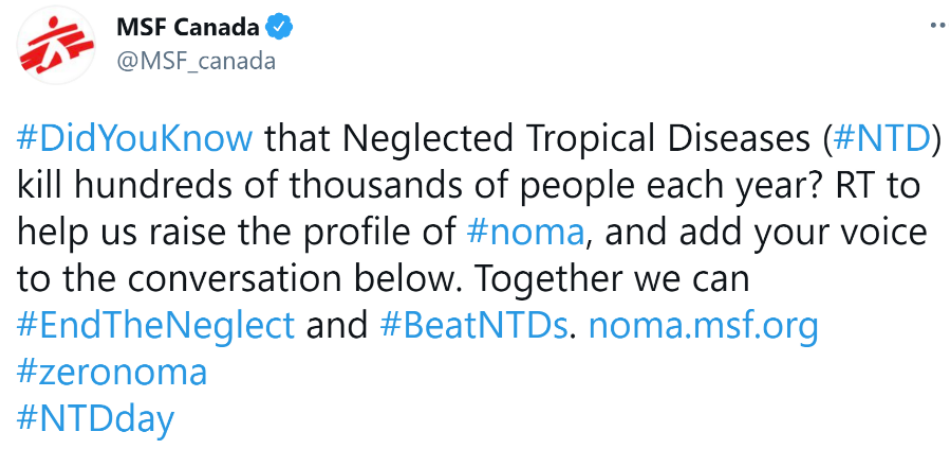

(MSF Canada, 2021, 10:00 ET)

Figure B6: UNICEF Canada Tweet with Informational, Promotion, Conversation, and

\section{Appeal Frames}

UNICEF Canada $\$$

@UNICEFCanada

You've heard of travel by car, motorbike and boat but how about by horse? To raise awareness of \#COVID_19, UNICEF has been working with community educators, some of whom in \#Haiti use horses to reach rural communities with life-saving information: youtube.com/watch?v=dlF4ul...

(UNICEF Canada, 2021, 12:05 ET)

Figure B7: UNICEF Canada Tweet with Promotion and Appeal Frames

\section{UNICEF Canada}

@UNICEFCanada

How far is too far to deliver essential \#vaccines? If you ask UNICEF staff and field workers, there's no such thing. Click through the gallery and check out all the different methods UNICEF staff use to ensure every child - and community - has access to healthcare.

(UNICEF Canada, 2021, 13:45 ET) 
Figure B8: UNICEF South Africa Tweet with Storytelling Frame using Quotations

UNICEF South Africa

@UNICEF_SA

"I tested positive in July, I fell sick and had to quarantine. That is when I infected my sister, she passed away after 2 days" - Noncedo Xengeshe, from Nonzwakazi, De Aar.

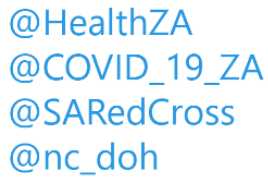

\section{Figure B9: UNICEF South Africa Tweet with Storytelling Frame using Quotations}

"When my brother tested positive, he struggled a lot to get a bed at the hospital, and we were really worried that he would die" - Louisa Williams | Reservoir Hills, Despatch.

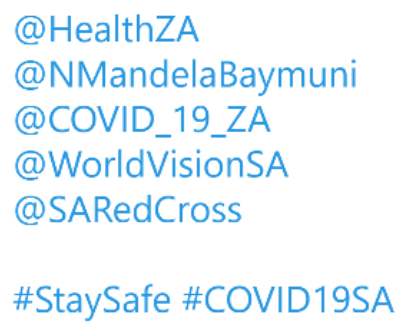

\section{Figure B10: MSF Canada Tweet using Logos}

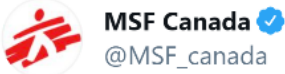

The evolving crisis on the \#Ethiopian border: MSF is providing medical care in \#Sudan, where more than 55,000 people have fled the fighting in \#Tigray.

Rapid assistance is needed to address the needs of \#refugees from \#Tigray region. See where we're responding $\boldsymbol{v}$ 


\section{Figure B11: MSF South Africa Tweet using Logos}

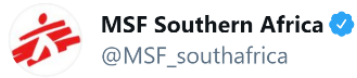

Our team in Montepuez estimates that 1,200 displaced people have arrived every week for the past 4 weeks. Since November 2020, we have been supporting displaced people in the area. Since 2017, half a million people have been displaced by the conflict in Cabo Delgado

(UNICEF Southern Africa, 2021, 4:59 ET)

\section{Figure B12: MSF Canada Tweet using Logos and Ethos}

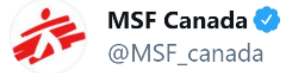

Over half a million people have been displaced by the \#conflict in \#CaboDelgado, \#Mozambique.

Thousands of people arrive every month in \#Montepuez, the second largest city in the province. @MSF provides here \#medical assistance to \#IDPs \& local \#communities.

(MSF Canada, 2021, 12:31 ET)

\section{Figure B13: MSF Canada Tweet using Pathos}

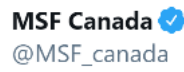

Alberto took his 4-year-old son to two different hospitals in \#Caracas, \#Venezuela, but he could not get him admitted in any of them, because \#Covid19 patients are the priority.

The \#KnockOnEffect of the \#pandemic has become a real threat to accessing healthcare.

(MSF Canada, 2021, 10:00 ET)

\section{Figure B14: MSF South Africa Tweet using Pathos}

\section{MSF Southern Africa}

@MSF_southafrica

\#DisplacedinMozambique This is Fiel. He and his family arrived in Mapupulo three months ago, after fleeing their home in Muidumbe. "They burned our houses and all of our belongings. We have nothing left. We arrived here with nothing".

(MSF South Africa, 2021, 3:11 ET) 


\section{Figure B15: UNICEF Tweet using Ethos}

To address issues of access to essential services and information during \#COVID_19 UNICEF \#India partnered with the NSS to create the 'Blue Brigade' - a team of community volunteers who assist with immunization efforts, remote learning and provide key messaging around COVID-19.

(UNICEF Canada, 2021, 14:30 ET)

Figure B16: UNICEF South Africa Tweet using Pathos

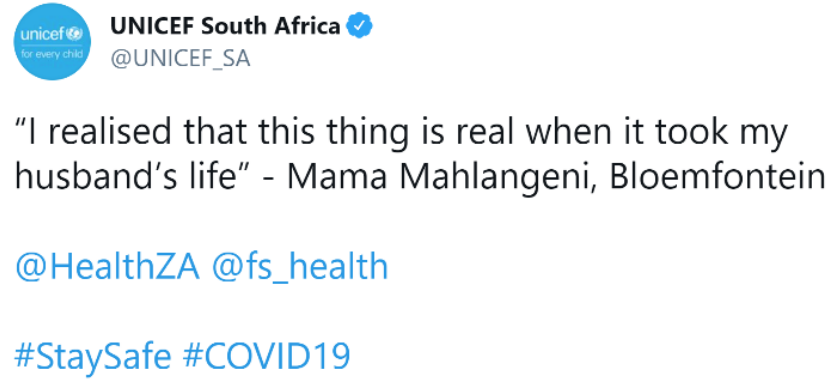

Figure B17: UNICEF Canada Tweet without Rhetorical Device Use

UNICEF Canada

@UNICEFCanada

If you were tasked with transporting \#vaccines to a remote location, what would your preferred method of transport be?

(UNICEF Canada, 2021, 15:05 ET) 


\section{References}

Auger, G. A. (2014). Rhetorical framing: examining the message structure of nonprofit organizations on Twitter. International Journal of Nonprofit and Voluntary Sector Marketing, 19(4), 239-249. https://doi.org/10.1002/nvsm.1499

Budree, A., Fietkiewicz, K., \& Lins, E. (2019). Investigating usage of social media platforms in South Africa. The African Journal of Information Systems, 11(4). https://digitalcommons.kennesaw.edu/ajis/vol11/iss4/1

Campbell, D. A., \& Lambright, K. T. (2020). Terms of engagement: Facebook and Twitter use among nonprofit human service organizations. Nonprofit Management and Leadership, 30(4), 545-568. https://doi.org/10.1002/nml.21403

Doctors without Borders (2020). MSF COVID-19 Operations in Canada 2020. https://www.doctorswithoutborders.ca/sites/default/files/528_msf_covid_ops_public_repo rt_final.pdf

Dong, C., \& Rim, H. (2019). Exploring nonprofit-business partnerships on Twitter from a network perspective. Public Relations Review, 45(1), 104-118. https://doi.org/10.1016/j.pubrev.2018.11.001

Galvez-Rodriguez, M. D. M., Caba-Pérez, C., \& Lopez, M. (2016). Drivers of Twitter as a strategic communication tool for non-profit organizations. Internet Research, 26(5), 1052-1071. https://doi.org/10.1108/IntR-07-2014-0188

Garcia-Gavilanes, R., Mejova, Y., \& Quercia, D. (2014). Twitter ain't without frontiers: Economic, social, and cultural boundaries in international communication. Proceedings of the ACM Conference on Computer Supported Cooperative Work, 1511-1522. https://doi.org/10.1145/2531602.2531725 
Greenberg, J., \& MacAulay, M. (2009). NPO 2.0? Exploring the Web Presence of Environmental Nonprofit Organizations in Canada. Global Media Journal: Canadian Edition, 2(1), 63-88.

Gruzd, A, \& Mai, P. (2020). The State of Social Media in Canada 2020 (Version 6.) [Data set]. Scholars Portal Dataverse. https://doi.org/10.5683/SP2/XIW8EW

Guidry, J. P. D., Jin, Y., Orr, C. A., Messner, M., \& Meganck, S. (2017). Ebola on Instagram and Twitter: How health organizations address the health crisis in their social media engagement. Public Relations Review, 43(3), 477-486. https://doi.org/10.1016/j.pubrev.2017.04.009

Guo, C., \& Saxton, G. D. (2014). Tweeting Social Change: How Social Media Are Changing Nonprofit Advocacy. Nonprofit and Voluntary Sector Quarterly, 43(1), 57-79. https://doi.org/10.1177/0899764012471585

Guo, C., \& Saxton, G. D. (2018). Speaking and Being Heard: How Nonprofit Advocacy Organizations Gain Attention on Social Media. Nonprofit and Voluntary Sector Quarterly, 47(1), 5-26. https://doi.org/10.1177/0899764017713724

Java, A., Song, X., Finin, T., \& Tseng, B. (2009). Why We Twitter: An Analysis of a Microblogging Community. In H. Zhang, M. Spiliopoulou, B. Mobasher, C. L. Giles, A. McCallum, O. Nasraoui, J. Srivastava, \& J. Yen (Eds.), Advances in Web Mining and Web Usage Analysis (p. 118-138). Springer. https://doi.org/10.1007/978-3-642-00528$\underline{2 \_7}$

Kubheka, B. Z., Carter, V., \& Mwaura, J. (2020). Social media health promotion in South Africa: Opportunities and challenges. African Journal of Primary Health Care \& Family Medicine, 12(1). https://doi.org/10.4102/phcfm.v12i1.2389 
Kulshrestha, J., Kooti, F., Nikravesh, A., \& Gummadi, K. (2012). Geographic Dissection of the Twitter Network. Proceedings of the International AAAI Conference on Web and Social Media, 6(1), 202-209. https://ojs.aaai.org/index.php/ICWSM/article/view/14280

Lai, C.-H., She, B., \& Tao, C.-C. (2017). Connecting the dots: A longitudinal observation of relief organizations' representational networks on social media. Computers in Human Behavior, 74, 224-234. https://doi.org/10.1016/j.chb.2017.04.037

Li, Z., \& Li, C. (2014). Tweet or "re-tweet"? An experiment of message strategy and interactivity on Twitter. Internet Research, 24(5), 648-667. https://doi.org/10.1108/IntR$\underline{11-2013-0233}$

Lovejoy, K., \& Saxton, G. D. (2012). Information, Community, and Action: How Nonprofit Organizations Use Social Media. Journal of Computer-Mediated Communication, 17(3), 337-353. https://doi.org/10.1111/j.1083-6101.2012.01576.x

Lovejoy, K., Waters, R. D., \& Saxton, G. D. (2012). Engaging stakeholders through Twitter: How nonprofit organizations are getting more out of 140 characters or less. Public Relations Review, 38(2), 313-318. https://doi.org/10.1016/j.pubrev.2012.01.005

McNeill, A. R., \& Briggs, P. (2014). Understanding Twitter influence in the health domain: A social-psychological contribution. Proceedings of the 23rd International Conference on World Wide Web, 673-678. https://doi.org/10.1145/2567948.2579280

Messner, M., Jin, Y., Medina-Messner, V., Meganck, S., Quarforth, S. C., \& Norton, S. K. (2013). 140 Characters for Better Health: An Exploration of the Twitter Engagement of Leading Nonprofit Organizations. In H. S. N. Al-Deen \& J. A. Hendricks (Eds.), Social Media and Strategic Communications (pp. 119-136). Palgrave Macmillan UK. https://doi.org/10.1057/9781137287052_7 
MSF Canada [@MSF_Canada]. (2021, January 30, 10:30 ET). \#DidYouKnow that today is \#NeglectedTropicalDiseases (NTDs) day!? Not sure what that means? Check out the pics below! At \#MSF we [Tweet; images; link to article]. Twitter. https://twitter.com/MSF_canada/status/1355538762076315653

MSF Canada [@MSF_Canada]. (2021, January 29, 15:30 ET).\#ICYMI - You can see this week's \#FeelGood Friday highlighting Dr Abhishek Agarwal, a \#paediatrician from Rajasthan, \#India. Find our [Tweet; image; link to Facebook post]. Twitter. https://twitter.com/MSF_canada/status/1355251872701972481

MSF Canada [@MSF_Canada]. (2021, January 29, 13:00 ET). \#DidYouKnow Neglected Tropical Diseases (\#NTDs) affect over 1.5 billion people worldwide? \#Covid19 was probably the most talked-about disease of 2020. [Tweet; image; link to article]. Twitter. https://twitter.com/MSF_canada/status/1355214130458685440

MSF Canada [@MSF_Canada]. (2021, January 29, 11:30 ET). How is \#COVID19 actually affecting \#healthcare? From \#Latin America to \#Africa and from \#Asia to \#Europe, we are seeing disrupted [Tweet; video; link to webpage]. Twitter. https://twitter.com/MSF_canada/status/1355191476322324481

MSF Canada [@MSF_Canada]. (2021, January 29, 10:00 ET). \#CARcrisis - In \#Bouar, MSF teams provide 20,000 litres of \#water per day, have carried out 672 consultations in all the [Tweet; images; link to article]. Twitter. https://twitter.com/MSF_canada/status/1355168829060558852

MSF Canada [@MSF_Canada]. (2021, January 28, 11:00 ET). \#BellLetsTalkDay: We've seen the \#COVID19 \#pandemic amplify uncertainty and instability affecting \#mentalhealth. In Dadaab, MSF saw an increase in suicide [Tweet; images; link to article]. Twitter. 
https://twitter.com/MSF_canada/status/1354821542430052352

MSF Canada [@MSF_Canada]. (2021, January 28, 10:00 ET). \#DidYouKnow that Neglected Tropical Diseases (\#NTD) kill hundreds of thousands of people each year? RT to help us raise the [Tweet; image; link to webpage]. Twitter.

https://twitter.com/MSF_canada/status/1354806449294041092

MSF Canada [@MSF_Canada]. (2021, January 28, 9:07 ET). \#BellLetsTalk: \#MentalHealth support is an essential part of MSF's medical response around the world. \#Refugees, \#Frontline workers, civilians and people [Tweet; image]. Twitter. https://twitter.com/MSF_canada/status/1354793103195074562

MSF Canada [@MSF_Canada]. (2021, January 27, 13:15 ET). \#CARcrisis - following violent attacks in \#Bouar in the previous two weeks, about 8,000 \#IDPs took refuge in different makeshift camps [Tweet; image; link to article]. Twitter. https://twitter.com/MSF_canada/status/1354493122106056704

MSF Canada [@MSF_Canada]. (2021, January 27, 10:00 ET). The \#Rohingya \#refugees have now been in \#Bangladesh for three years. What does this mean about their long-term future? Their

[Tweet; video]. Twitter. https://twitter.com/MSF_canada/status/1354444055334313986

MSF Canada [@MSF_Canada]. (2021, January 26, 13:00 ET). \#CARcrisis - many villages, including health centres, located south and east of \#Bossembele are currently deserted and have been looted [Tweet; image]. Twitter.

https://twitter.com/MSF_canada/status/1354127076736065537 
MSF Canada [@MSF_Canada]. (2021, January 26, 11:35 ET). \#Thread on MSF's response to the \#Covid_19 \#pandemic in \#Brazil. The health system in \#Manaus, the capital of the Brazilian [Tweet; image]. Twitter. https://twitter.com/MSF_canada/status/1354105723681124352

MSF Canada [@MSF_Canada]. (2021, January 26, 10:00 ET). Alberto took his 4-year-old son to two different hospitals in \#Caracas, \#Venezuela, but he could not get him admitted in [Tweet; video]. Twitter. https://twitter.com/MSF_canada/status/1354081661378469888

MSF Canada [@MSF_Canada]. (2021, January 25, 12:31 ET). On the evening of \#January 22, category 1 \#TropicalCycloneEloise made landfall in the central province of \#Sofala, \#Mozambique bringing strong [Tweet; image]. Twitter. https://twitter.com/MSF_canada/status/1353757504933662725

MSF Canada [@MSF_Canada]. (2021, January 25, 9:30 ET). Yamilette has to cope with strong pains that prevent her from going to work. We met her while she waited [Tweet; video]. Twitter. https://twitter.com/MSF_canada/status/1353711723656536065

MSF Canada [@MSF_Canada]. (2021, January 22, 13:15 ET). Have you seen this week's \#FeelGoodFriday?! We're highlighting Hannah Samba, MSF Outreach \#Nurse working in \#SierraLeone! Check out her story [Tweet; image; link to Facebook post]. Twitter. $\underline{\text { https://twitter.com/MSF_canada/status/1352681182887092226 }}$

MSF Canada [@MSF_Canada]. (2021, January 21, 14:37 ET). 1/3 Dulce explains how \#COVID19 affected her team's capacity to respond to sexual violence in \#Caracas, \#Venezuela, and what is [Tweet; video]. Twitter. https://twitter.com/MSF_canada/status/1352339532306382849 
MSF Canada [@MSF_Canada]. (2021, January 21, 13:15 ET). The evolving crisis on the \#Ethiopian border: MSF is providing medical care in \#Sudan, where more than 55,000 people have [Tweet; image]. Twitter. https://twitter.com/MSF_canada/status/1352318794908237827

MSF Canada [@MSF_Canada]. (2021, January 21, 9:00 ET). \#CAR - For the past weeks, \#MSF teams across the country have been treating the wounded and responding to people's [Tweet; image' link to article]. Twitter. https://twitter.com/MSF_canada/status/1352254628767776768

MSF Canada [@MSF_Canada]. (2021, January 20, 21:00 ET).\#CAR - Tens of thousands of people have been \#displaced from their homes by the latest cycle of \#violence. More [Tweet; image; link to article]. Twitter. https://twitter.com/MSF_canada/status/1352073431777333250

MSF Canada [@MSF_Canada]. (2021, January 20, 14:15 ET). A severe lack of access to \#healthcare in Riang, \#SouthSudan is promoted by protracted \#flooding, ongoing \#violence in the region [Tweet; image]. Twitter. https://twitter.com/MSF_canada/status/1351971506587381760

MSF Canada [@MSF_Canada]. (2021, January 20, 12:31 ET). Over half a million people have been displaced by the \#conflict in \#CaboDelgado, \#Mozambique. Thousands of people arrive every month [Tweet; image]. Twitter. https://twitter.com/MSF_canada/status/1351945387586813952

MSF Canada [@MSF_Canada].(2021, January 20, 11:00 ET).MSF Canada's @jwnickerson says he's worried wealthy countries such as \#Canada will \#vaccinate people who are at lower risk of [Tweet; link]. Twitter. 
https://twitter.com/MSF_canada/status/1351922441677795328

MSF Canada [@MSF_Canada].(2021, January 20, 10:00 ET).\#ICYMI: Karline Kleijer, MSF Head of \#Emergency discusses the \#crisis in \#Tigray, \#Ethiopia causing thousands of \#refugees crossing borders to [Tweet; video]. Twitter. https://twitter.com/MSF_canada/status/1351907341982068738

MSF Canada [@MSF_Canada]. (2021, January 19, 12:43 ET). \#MSF is calling on international donors to ensure funding continues for other health organizations working in \#Jonglei state so that [Tweet; video]. Twitter.

https://twitter.com/MSF_canada/status/1351586142022463488

MSF Canada [@MSF_Canada].(2021, January 19, 21:25 ET).\#CARcrisis - “The number of medical consultations has exploded, mainly women and children suffering from for malaria, diarrhoea and respiratory [Tweet; image; link to article]. Twitter. https://twitter.com/MSF_canada/status/1351536137890889729

MSF Canada [@MSF_Canada]. (2021, January 19, 21:00 ET). MSF staff is transporting \#medicines and \#water purification materials to the Bondeko \#Health Centre, northern \#DRC, where thousands of people [Tweet; image; link to article]. Twitter. https://twitter.com/MSF_canada/status/1351348654167101444

MSF Canada [@MSF_Canada]. (2021, January 18, 15:35 ET). \#Yemen \#update: 1/2 The \#UnitedStates government has moved to designate Ansar Allah, the \#Yemeni group that controls Sana'a and much [Tweet; image]. Twitter.

https://twitter.com/MSF_canada/status/1351269463702835210 
MSF Canada [@MSF_Canada]. (2021, January 18, 10:04 ET). Watch the trailer for 'Restoring Dignity' and register a \#virtual screening by @UofTDentistry on Weds. \#January 20 at 6pm ET [Tweet; video; link to webpage]. Twitter.

https://twitter.com/MSF_canada/status/1351183565145452544

MSF Canada [@MSF_Canada]. (2021, January 15, 10:30 ET). MSF in \#CentralAfricanRepublic: Teams have installed a \#water purification system with river water treated to make it safe for drinking [Tweet; image; link to article]. Twitter. https://twitter.com/MSF_canada/status/1350103103069163520

MSF Canada [@MSF_Canada]. (2021, January 14, 10:00 ET). The @UofT \#Dental \#Student's Society (DSS) is proud to present the official \#Canadian \#premiere and virtual screening of the documentary [Tweet; image; link to eventbrite]. Twitter. https://twitter.com/MSF_canada/status/1349733007326789633

MSF Canada [@MSF_Canada]. (2021, January 13, 13:45 ET). "The importance of \#psychotherapy is to transform the way people see themselves, to give new significance to life, to develop [Tweet; image; link to article]. Twitter.

https://twitter.com/MSF_canada/status/1349427241680207872

MSF Canada [@MSF_Canada]. (2021, January 13, 10:01 ET). 100Ks of people have been forced to leave their homes in the \#Tigray region of northern \#Ethiopia after fighting broke [Tweet; image]. Twitter. https://twitter.com/MSF_canada/status/1349371034609340416

MSF Canada [@MSF_Canada]. (2021, January 12, 21:00 ET). \#ICYMI: Have you checked MSF \#Canada out on \#Facebook ?! You can like us for more content at http://facebook.com/doctorswithoutborderscanada $\_$[Tweet; image]. Twitter. https://twitter.com/MSF_canada/status/1349174328336773123 
MSF Canada [@MSF_Canada]. (2021, January 12, 14:46 ET). MSF stands with \#maternalhealthequity! This clip takes you \#behindthemask in \#SierraLeone for a front seat to our incredible \#frontliners and [Tweet; image]. Twitter.

https://twitter.com/MSF_canada/status/1349080428808970241

MSF Canada [@MSF_Canada]. (2021, January 12, 11:00 ET). What does MSF do in \#Mali? Here's a quick overview \& [Tweet; image]. Twitter. https://twitter.com/MSF_canada/status/1349023331685552128

MSF Canada [@MSF_Canada]. (2021, January 11, 13:45 ET). A study led by MSF and the World Health Organization (@WHO) proves that increasing \#yellowfever prevention is possible in order [Tweet; image; link to article]. Twitter. https://twitter.com/MSF_canada/status/1348702466129473539

MSF Canada [@MSF_Canada]. (2021, January 11, 11:30 ET). Since November, over 55,00 \#refugees and arrivals from \#Ethiopia are in \#Sudan. Hear about MSF's response from Karline Kleijer, MSF [Tweet; image; link to article]. Twitter. https://twitter.com/MSF_canada/status/1348668494750101506

MSF Canada [@MSF_Canada]. (2021, January 8, 13:45 ET). In response to the \#COVID19 pandemic in \#Canada, MSF ran a modest \#COVID19 operational response in \#Canada that partnered with [Tweet; link to webpage]. Twitter. https://twitter.com/MSF_canada/status/1347615302738038784

MSF Canada [@MSF_Canada]. (2021, January 8, 11:50 ET). Update from \#Mali: An @MSF ambulance transporting patients between Douentza and Sévaré, in central Mali, was violently stopped by \#armed [Tweet; link to webpage]. Twitter. https://twitter.com/MSF_canada/status/1347586444852940800 
MSF Canada [@MSF_Canada]. (2021, January 8, 10:00 ET). Check out our new \#TikTok featuring our 2021 wish list! @MSF_access https://bit.ly/35bjTN9 [Tweet; link to TikTok]. Twitter. https://twitter.com/MSF_canada/status/1347558685078286337

MSF Canada [@MSF_Canada]. (2021, January 7, 13:30 ET). \#ThursdayThoughts from Emmanuelle Privat, @msf Deputy Country Director in \#Kenya shares her experience via The National on why \#refugees need [Tweet; image; link to news site]. Twitter. https://twitter.com/MSF_canada/status/1347249139529043970

MSF Canada [@MSF_Canada]. (2021, January 7, 10:54 ET). 1/4 E⿰氵 unprecedentedly began operations in \#Canada due to the \#COVID19 \#pandemic.

People experiencing \#homelessness, \#longtermcare homes [Tweet; image]. Twitter. https://twitter.com/MSF_canada/status/1347209933029257216

MSF Canada [@MSF_Canada]. (2021, January 7, 10:30 ET). "The region of central \#Mali has become the deadliest in the country for the \#civilian population," said Juan Carlos Cano, [Tweet; image; link to article]. Twitter.

https://twitter.com/MSF_canada/status/1347203841385766913

MSF Canada [@MSF_Canada]. (2021, January 6. 13:05 ET). MSF in \#Palestine ? Approx. 300,000 \#Palestinians are lacking access to medical care. Since November, MSF has been regularly visiting [Tweet; image; link to article]. Twitter. https://twitter.com/MSF_canada/status/1346880460794654722

MSF Canada [@MSF_Canada]. (2021, January 6, 10:39 ET). \#Wishlist2021 约Today, decisions about people's \#health around the world are largely made by a small group of people in wealthy [Tweet; image]. Twitter. https://twitter.com/MSF_canada/status/1346843718263910406 
MSF Canada [@MSF_Canada]. (2021, January 5, 14:00 ET).MSF denounces the killing of one of its \#medical staff members following a shooting incident on a public transport truck [Tweet; link to article]. Twitter. https://twitter.com/MSF_canada/status/1346531917357838336

MSF Canada [@MSF_Canada]. (2021, January 5, 13:00 ET). Who is ready for some \#NewYearsEve babies?! These little humans were born in various MSF-supported wards around the globe [Tweet; images]. Twitter. https://twitter.com/MSF_canada/status/1346516821239877633

MSF Canada [@MSF_Canada]. (2021, January 5, 10:38 ET). \#Wishlist2021 嗮 Billions of public \& private $\$$ are poured into the development of new medicines every year-without any conditions [Tweet; image]. Twitter. https://twitter.com/MSF_canada/status/1346481078618513408

MSF Canada [@MSF_Canada]. (2021, January 4, 10:36 ET). \#Wishlist2021 约Pharma corporations cite $R \& D$ costs when justifying high prices for medicines. But no one knows the true costs of drugs [Tweet; image]. Twitter. https://twitter.com/MSF_canada/status/1346118187641921536

MSF Canada [@MSF_Canada]. (2021, January 3, 10:34 ET). \#Wishlist2021 \#pharma corporations \& other institutions don't allow others to use their data and know-how. This wastes opportunities to make [Tweet; image]. Twitter. https://twitter.com/MSF_canada/status/1345755296417918998 
MSF Canada [@MSF_Canada]. (2021, January 2, 10:30 ET).\#Wishlist2021 Nearly two billion people 100 don't have access to the \#medicines they need to stay healthy, largely due to [Tweet; image]. Twitter. https://twitter.com/MSF_canada/status/1345391903341162497

MSF Canada [@MSF_Canada]. (2021, January 1, 11:00 ET). As 2020 was the \#yearofthenurseandmidwife, in 2021, we'd like you to meet Rebecca Morante, MSF \#nurse from \#Canada! She works [Tweet; image]. Twitter.

https://twitter.com/MSF_canada/status/1345037068527874049

MSF Canada [@MSF_Canada]. (2021, January 1, 10:00 ET). Happy New Year! 2020 was a year like no other, bringing with it the biggest global health challenge in [Tweet; image]. Twitter. https://twitter.com/MSF_canada/status/1345021973596930050

MSF Southern Africa [@MSF_southafrica]. (2021, January 31, 3:00 ET). Zara works in the MSF \#COVID19 triage unit in Bambari, Central African Republic. Her main concern is the fragility [Tweet; images]. Twitter. https://twitter.com/MSF_southafrica/status/1355787915150811141

MSF Southern Africa [@MSF_southafrica]. (2021, January 30, 2:47 ET). Since October 2020, South Africa together with India have been leading a proposal at the World Trade Organization (@wto)for [Tweet; image; link to article]. Twitter. https://twitter.com/MSF_southafrica/status/1355422494065364993

MSF Southern Africa [@MSF_southafrica]. (2021, January 29, 6:17 ET). At \#MSF we care about Neglected Tropical Diseases! $\square$ http://bit.ly/2NIIROp \#EndTheNeglect \#BeatNTDs [Tweet, image, link to article]. Twitter. https://twitter.com/MSF_southafrica/status/1355112921349685249 
MSF Southern Africa [@MSF_southafrica]. (2021, January 29, 3:10 ET). \#Malawi was relatively spared by the first wave of the \#COVID19 in 2020, but, the second wave has overwhelmed the [Tweet; image; link to article]. Twitter. https://twitter.com/MSF_southafrica/status/1355065803096338432

MSF Southern Africa [@MSF_southafrica]. (2021, January 27, 7:30 ET). As @ POTUS starts to roll back some of the Trump administration's most harmful migration policies, we call for urgent action [Tweet; image; link to article]. Twitter. https://twitter.com/MSF_southafrica/status/1354406410369388544

MSF Southern Africa [@MSF_southafrica]. (2021, January 25, 7:30 ET). It' been 4 years since \#Rohingya refugees have lived in overcrowded shelters within a temporary camp in the \#Bangladesh. \#COVID19 [Tweet; image; link to article]. Twitter. https://twitter.com/MSF_southafrica/status/1353681534281125888

MSF Southern Africa [@MSF_southafrica]. (2021, January 25, 3:02 ET). On Friday evening(22 January), category 1 tropical \#CycloneEloise made landfall in the central province of Sofala, Mozambique bringing strong and [Tweet; image]. Twitter. https://twitter.com/MSF_southafrica/status/1353614319544627202

MSF Southern Africa [@MSF_southafrica]. (2021, January 23,3:00 ET). Alberto took his 4-yearold son to two different hospitals in Caracas, Venezuela, but he could not get him admitted in [Tweet; image; link to article]. Twitter. https://twitter.com/MSF_southafrica/status/1352888809592037377

MSF Southern Africa [@MSF_southafrica]. (2021, January 22, 7:00 ET). This week's \#FieldworkerFriday is Hanri Rust, a paediatric nurse supervisor from Cape Town. She shares highlights from her 9-month assignment [Tweet; image; link to video]. Twitter. 
https://twitter.com/MSF_southafrica/status/1352586835495538691

MSF Southern Africa [@MSF_southafrica]. (2021, January 21, 7:23 ET). How is \#COVID-19 actually affecting healthcare? From Latin America to Africa and from Asia to Europe, we are seeing disrupted [Tweet; image; link to article]. Twitter.

https://twitter.com/MSF_southafrica/status/1352230383740354560

MSF Southern Africa [@MSF_southafrica]. (2021, January 20, 3:27 ET). We are \#recruiting for these positions, please apply online and share with your connections: Physiotherapist (COVID-19 Response), KwaZulu-Natal: http://bit.ly/3is7gCC Radiographer [Tweet; image; links to articles]. Twitter.

https://twitter.com/MSF_southafrica/status/1351808516357550081

MSF Southern Africa [@MSF_southafrica]. (2021, January 19, 3:04 ET). \#CARcrisis - “The number of medical consultations has exploded, mainly women and children suffering from for malaria, diarrhoea and respiratory [Tweet; image; link to article]. Twitter. https://twitter.com/MSF_southafrica/status/1351440397675978752

MSF Southern Africa [@MSF_southafrica]. (2021, January 17, 4:59 ET).Our team in Montepuez estimates that 1,200 displaced people have arrived every week for the past 4 weeks. Since November [Tweet; images]. Twitter.

https://twitter.com/MSF_southafrica/status/1350744429053689856

MSF Southern Africa [@MSF_southafrica]. (2021, January 17, 3:11 ET). \#DisplacedinMozambique This is Fiel. He and his family arrived in Mapupulo three months ago, after fleeing their home in Muidumbe. [Tweet; image]. Twitter.

https://twitter.com/MSF_southafrica/status/1350717249733103618 
MSF Southern Africa [@MSF_southafrica]. (2021, January 16, 3:36 ET). Hundreds of thousands of people have been forced to leave their homes in the Tigray region of northern Ethiopia after [Tweet; image; link to video]. Twitter. https://twitter.com/MSF_southafrica/status/1350361387675996162

MSF Southern Africa [@MSF_southafrica]. (2021, January 15, 7:30 ET). Our \#FieldworkerFriday this week is logistician Yusuf Goddard who set off to Pemba to initiate a WATSAN project in March [Tweet; image; link to article]. Twitter. https://twitter.com/MSF_southafrica/status/1350057651003035648

MSF Southern Africa [@ MSF_southafrica]. (2021, January 15, 5:14 ET). We are \#recruiting for the following positions, apply and share with your connections: Media Database Officer: https://bit.ly/3q7lL1a International Privacy [Tweet; image; links to articles]. Twitter. https://twitter.com/MSF_southafrica/status/1350023619280318465

MSF Southern Africa [@MSF_southafrica]. (2021, January 14, 8:02 ET).In 2010, @MSF set up the Centro de Referência do Alto Maé (CRAM) in Mozambique to provide better access to [Tweet; image; link to article]. Twitter.

https://twitter.com/MSF_southafrica/status/1349703331409756164

MSF Southern Africa [@MSF_southafrica]. (2021, January 13, 3:11 ET). A group of international humanitarian organisations led by @WHO announced the creation of the first global stockpile of the Ervebo [Tweet; image; link to article]. Twitter. https://twitter.com/MSF_southafrica/status/1349267919075684361

MSF Southern Africa [@MSF_southafrica]. (2021, January $11, \quad 12: 30 \quad$ ET). \#Wishlist2021 Billions of public \& private $\$$ are poured into the development of new medicines every year- without any conditions [Tweet; image]. Twitter. 


\section{https://twitter.com/MSF_southafrica/status/1348502467730944000}

MSF Southern Africa [@MSF_southafrica]. (2021, January 11, 10:53 ET). Nearly half a million people have been displaced in \#CaboDelgado Mozambique $\mathrm{Mz}$, multiple times, and their basic needs remain [Tweet; image; link to article]. Twitter.

https://twitter.com/MSF_southafrica/status/1348659303004205064

MSF Southern Africa [@MSF_southafrica]. (2021, January 8, 7:00 ET). In this week's \#FieldworkerFriday post we recognise the achievements of our nurses in Manicaland, Zimbabwe, who successfully rolled out a [Tweet; images; link to article]. Twitter. https://twitter.com/MSF_southafrica/status/1347513460616089605

MSF Southern Africa [@MSF_southafrica]. (2021, January 7, 6:18 ET). Our teams treated eight people who were seriously injured in attacks on the villages of Bounty and Kikara, in central [Tweet; image; link to article]. Twitter.

https://twitter.com/MSF_southafrica/status/1347140665868746752

MSF Southern Africa [@MSF_southafrica].(2021, January 7, 8:35 ET).\#Wishlist2021 嗮Pharma corporations cite $R \& D$ costs when justifying high prices for medicines. But no one knows the true costs of [Tweet, image]. Twitter. https://twitter.com/MSF_southafrica/status/1347175081248624640

MSF Southern Africa [@MSF_southafrica]. (2021, January 6, 8:38 ET).\#Wishlist2021 邹Pharma corporations \& other institutions don't allow others to use their data and know-how. This wastes opportunities to make [Tweet; image]. Twitter. https://twitter.com/MSF_southafrica/status/1346813423011524608 
MSF Southern Africa [@MSF_southafrica]. (2021, January 6, 4:58 ET). Following an attack on the town of Bangassou in Central African Republic, this Sunday, 12 patients were taken care of [Tweet; image; link to article]. Twitter. https://twitter.com/MSF_southafrica/status/1346757957674029056

MSF Southern Africa [@MSF_southafrica]. (2021, January 5, 8:35 ET).\#Wishlist2021 Nearly two billion people 000 don't have access to the medicines they need to stay healthy, largely due to [Tweet; image]. Twitter. https://twitter.com/MSF_southafrica/status/1346450204430458880

MSF Southern Africa [@MSF_southafrica]. (2021, January 4, 8:30 ET). Happy New Year! 2020 was a year like no other, bringing with it the biggest global health challenge [Tweet; image]. Twitter. https://twitter.com/MSF_southafrica/status/1346086716134760448

MSF Southern Africa [@MSF_southafrica]. (2021, January 4, 8:02 ET). Join our teams responding to the \#COVID19 pandemic in Kwa-Zulu Natal. https://bit.ly/389X9yI [Tweet; image; link to article]. Twitter. https://twitter.com/MSF_southafrica/status/1346079521729032192

MSF Southern Africa [@MSF_southafrica]. (2021, January 1, 8:20 ET). Every year MSF teams provide lifesaving medical assistance to people who would otherwise be denied access to basic health care. [Tweet; images; link to article]. Twitter. https://twitter.com/MSF_southafrica/status/1344996808175415297

MSF. (n.d.). Médecins Sans Frontières (MSF) International. https://www.msf.org

MSF South Africa (n.d.) South Africa. https://www.msf.org.za/our-work/where-we-work/southafrica 
Obar, J. A. (2014). Canadian Advocacy 2.0: An Analysis of Social Media Adoption and Perceived Affordances by Advocacy Groups Looking to Advance Activism in Canada. Canadian Journal of Communication, 39(2), 211-233. https://doi.org/10.22230/cjc.2014v39n2a2678

Park, J., Baek, Y. M., \& Cha, M. (2014). Cross-Cultural Comparison of Nonverbal Cues in Emoticons on Twitter: Evidence from Big Data Analysis. Journal of Communication, 64(2), 333-354. https://doi.org/10.1111/jcom.12086

Saffer, A. J., Sommerfeldt, E. J., \& Taylor, M. (2013). The effects of organizational Twitter interactivity on organization-public relationships. Public Relations Review, 39(3), 213215. https://doi.org/10.1016/j.pubrev.2013.02.005

Saxton, G. D., Niyirora, J. N., Guo, C., \& Waters, R. D. (2015). \#AdvocatingForChange: The Strategic Use of Hashtags in Social Media Advocacy. Advances in Social Work, 16(1), 154-169. https://doi.org/10.18060/17952

Shahin, S., \& Dai, Z. (2019). Understanding Public Engagement With Global Aid Agencies on Twitter: A Technosocial Framework. American Behavioral Scientist, 63(12), 1684-1707. https://doi.org/10.1177/0002764219835248

Smitko, K. (2012). Donor engagement through Twitter. Public Relations Review, 38(4), 633635. https://doi.org/10.1016/j.pubrev.2012.05.012

Taylor, K. \& Silver, L. (2019, February 5). Smartphone Ownership Is Growing Rapidly Around the World, but Not Always Equally. Pew Research Center's Global Attitudes Project. https://www.pewresearch.org/global/2019/02/05/smartphone-ownership-is-growingrapidly-around-the-world-but-not-always-equally 
Tully, M., Dalrymple, K. E., \& Young, R. (2019). Contextualizing Nonprofits' Use of Links on Twitter During the West African Ebola Virus Epidemic. Communication Studies, 70(3), 313-331. https://doi.org/10.1080/10510974.2018.1539021

UNICEF Canada. (n.d.) About Us. https://www.unicef.ca/en/about-unicef

UNICEF Canada (n.d.). UNICEF Canada: Children's Charity - For Every Child. https://www.unicef.ca/en/home-page

UNICEF. (n.d.) About UNICEF. https://www.unicef.org/about-unicef

UNICEF. (n.d.) Frequently Asked Questions. https://www.unicef.org/about-unicef/frequently$\underline{\text { asked-questions }}$

UNICEF. (n.d.). What we do. https://www.unicef.org/southafrica/what-we-do

UNICEF Canada [@UNICEFCanada]. (2021, January 31, 12:15 ET). Sunday \#trivia time! \#DYK that UNICEF works in over 190 different countries? That way we can ensure that we're where [Tweet; image]. Twitter.

https://twitter.com/UNICEFCanada/status/1355927614406483970

UNICEF Canada [@UNICEFCanada]. (2021, January 30, 12:30 ET). What is a cold chain and why is it important in the delivery of \#COVID_19 \#vaccines? In supporting the global [Tweet; video]. Twitter.

https://twitter.com/UNICEFCanada/status/1355569000038752256

UNICEF Canada [@UNICEFCanada]. (2021, January 29, 14:15 ET). UNICEF is calling for @ CanadaDev and other governments to prioritize teachers and education workers to receive \#COVID_19 \#vaccines after frontline [Tweet; image]. Twitter. https://twitter.com/UNICEFCanada/status/1355233053824659457 
UNICEF Canada [@UNICEFCanada]. (2021, January 29, 13:35 ET). UNICEF Canada's For Every Child podcast is back for 2021! This episode our President and CEO @DMorleyUNICEF tackles tough questions [Tweet; image]. Twitter. https://twitter.com/UNICEFCanada/status/1355223129434558468

UNICEF Canada [@UNICEFCanada]. (2021, January 28, 11:35 ET). Emergencies don't stop for \#COVID_19. In fact, around the world \#COVID_19 is worsening many existing health and \#nutrition crises - [Tweet; video]. Twitter. https://twitter.com/UNICEFCanada/status/1354830345246543886

UNICEF Canada [@UNICEFCanada]. (2021, January 27, 15:05 ET). If you were tasked with transporting \#vaccines to a remote location, what would your preferred method of transport be? [Tweet; poll]. Twitter. https://twitter.com/UNICEFCanada/status/1354520874209202177

UNICEF Canada [@UNICEFCanada]. (2021, January 27, 13:45 ET). How far is too far to deliver essential \#vaccines? If you ask UNICEF staff and field workers, there's no such [Tweet; images]. Twitter. https://twitter.com/UNICEFCanada/status/1354500731286540290

UNICEF Canada [@UNICEFCanada]. (2021, January 26, 14:25 ET). The sudden onset of \#winter storms mean that even more children in \#Syria are in need of emergency aid. Give [Tweet; image, link to webpage]. Twitter. https://twitter.com/UNICEFCanada/status/1354148378062577669

UNICEF Canada [@UNICEFCanada]. (2021, January 25, 13:10 ET). How is UNICEF helping to support education around the $\bigcirc$ during \#COVID_19? In \#Venezuela Fernando, 17, and his younger brother [Tweet; video]. Twitter. https://twitter.com/UNICEFCanada/status/1353767126914523137 
UNICEF Canada [@UNICEFCanada]. (2021, January 24, 12:10 ET). For many children, a teacher is so much more than just an educator. For \#InternationalEducationDay we're sharing stories of teachers [Tweet; image; link to article]. Twitter. https://twitter.com/UNICEFCanada/status/1353389632692527104

UNICEF Canada [@UNICEFCanada]. (2021, January 23, 12:30 ET). \#DYK that over 370,000 children were born worldwide on New Year's Day 2021? For every child, a happy and healthy [Tweet; image; link to article]. Twitter. https://twitter.com/UNICEFCanada/status/1353032349160714242

UNICEF Canada [@UNICEFCanada]. (2021, January 22, 14:30 ET). To address issues of access to essential services and information during \#COVID_19 UNICEF \#India partnered with the NSS to create [Tweet; image]. Twitter. https://twitter.com/UNICEFCanada/status/1352700185449799681

UNICEF Canada [@UNICEFCanada]. (2021, January 21, 11:30 ET). \#TBT to 1946; SerbianCroatian children at a refugee camp in \#Egypt practice their writing in sand. 1946 was the same [Tweet; image]. Twitter. https://twitter.com/UNICEFCanada/status/1352292534819684353

UNICEF Canada [@UNICEFCanada]. (2021, January 20, 14:15 ET). In \#Pakistan, a young girl proudly shows off the mark she received after getting a \#polio \#vaccine. Pakistan's first national [Tweet; image]. Twitter. https://twitter.com/UNICEFCanada/status/1351971564628160522

UNICEF Canada [@UNICEFCanada]. (2021, January 19, 13:15 ET). What is the \#COVAX Facility and what role is UNICEF playing in it? We've got your answers right here with our FAQ video [Tweet; video]. Twitter. 
https://twitter.com/UNICEFCanada/status/1351594078350278672

UNICEF Canada [@UNICEFCanada]. (2021, January 18, 11:45 ET). “The time is always right to do what is right." RT and tag a world leader or someone you know who exemplifies doing the right thing. \#MLKDay \#MLKDay2021 [Tweet; image]. Twitter. https://twitter.com/UNICEFCanada/status/1351209039502442506

UNICEF Canada [@UNICEFCanada]. (2021, January 17, 12:30 ET). Happy Sunday! We hope you all can spend some time with someone you love today - even if it's from [Tweet; image]. Twitter. https://twitter.com/UNICEFCanada/status/1350857994540560389

UNICEF Canada [@UNICEFCanada]. (2021, January 16, 12:05 ET). You've heard of travel by car, motorbike and boat but how about by horse? To raise awareness of \#COVID_19, UNICEF [Tweet; link to video]. Twitter. https://twitter.com/UNICEFCanada/status/1350489291676332039

UNICEF Canada [@UNICEFCanada]. (2021, January 15, 14:25 ET). Does this look familiar? With many schools closed due to \#COVID_19, teachers around the world are finding innovative ways to [Tweet; images]. Twitter. https://twitter.com/UNICEFCanada/status/1350162107522834433

UNICEF Canada [@UNICEFCanada]. (2021, January 14, 11:10 ET). How is UNICEF supporting unaccompanied minors in the USA? For every child, the right to a family and community: https://youtube.com/watch? $v=z$ ZpDOLXEXXQ $\quad[$ Tweet; link to video]. Twitter. https://twitter.com/UNICEFCanada/status/1349750770615382016

UNICEF Canada [@UNICEFCanada]. (2021, January 13, 14:15 ET). No matter the challenges posed by \#COVID_19, healthcare workers and UNICEF staff are determined to be there for children. In [Tweet; images]. Twitter. 
https://twitter.com/UNICEFCanada/status/1349434849346678794

UNICEF Canada [@UNICEFCanada]. (2021, January 12, 13:35 ET). On January 12, 2010 a 7.0 magnitude earthquake struck \#Haiti, killing an estimated 300,000 people and injuring and displacing thousands [Tweet; link to video]. Twitter.

https://twitter.com/UNICEFCanada/status/1349062361957629952

UNICEF Canada [@UNICEFCanada]. (2021, January 11, 11:45 ET). \#DYK playing can help stimulate a baby's brain? At UNICEF-supported nutrition centres in \#SouthSudan play areas have been set up, [Tweet; images]. Twitter.

https://twitter.com/UNICEFCanada/status/1348672318164381698

UNICEF Canada [@UNICEFCanada]. (2021, January 10, 12:01 ET). Happy Sunday! [Tweet; image]. Twitter. https://twitter.com/UNICEFCanada/status/1348314005446795264

UNICEF Canada [@UNICEFCanada]. (2021, January 9, 12:20 ET). How can you help combat misinformation around \#vaccines? To help you out, UNICEF has put together a guide for determining [Tweet; image]. Twitter.

https://twitter.com/UNICEFCanada/status/1347956338433925122

UNICEF Canada [@UNICEFCanada]. (2021, January 8, 13:40). Young people around the world are speaking up and speaking out on their right to a healthy climate and planet. [Tweet; video]. Twitter. https://twitter.com/UNICEFCanada/status/1347614074524282883

UNICEF Canada [@UNICEFCanada]. (2021, January 7, 11:05 ET). What does school during \#COVID_19 look like for children around the world? RT and let us know what school looks [Tweet; images]. Twitter.

https://twitter.com/UNICEFCanada/status/1347212705111932931 
UNICEF Canada [@UNICEFCanada]. (2021, January 6, 11:25 ET). In \#Nicaragua, Rouss receives a therapeutic massage from her mother Heisell, while her father watches. Throughout \#COVID_19 Rouss and her [Tweet; image]. Twitter. https://twitter.com/UNICEFCanada/status/1346855326117736450

UNICEF Canada [@UNICEFCanada]. (2021, January 5, 14:50 ET). Around the world, UNICEF staff are hard at work to defend every child's right to a childhood. In the \#Philipines [Tweet; images]. Twitter. https://twitter.com/UNICEFCanada/status/1346544530250719235

UNICEF Canada [@UNICEFCanada]. (2021, January 4, 13:15 ET). How can we use the power of lived experience to educate and inform others? Richard, 60, is a \#polio survivor [Tweet; video]. Twitter. https://twitter.com/UNICEFCanada/status/1346158281799118851

UNICEF Canada [@UNICEFCanada]. (2021, January 3, 11:35 ET). Happy Sunday! Hope you all started your day with a nutritious and delicious meal like these little ones from Côte [Tweet; image]. Twitter. https://twitter.com/UNICEFCanada/status/1345770666226835456

UNICEF Canada [@UNICEFCanada]. (2021, January 2, 12:10 ET). 2020 was a hard year for everyone - including children. For 2021, let's reimagine a better world together, for everyone. [Tweet; video]. Twitter. https://twitter.com/UNICEFCanada/status/1345417102866444290

UNICEF Canada [@UNICEFCanada]. (2021, January 1, 12:07 ET). Every baby born in 2021 and beyond - deserves the right to a childhood. Congratulations to the first babies [Tweet; link to article]. Twitter. https://twitter.com/UNICEFCanada/status/1345054161159774208 
UNICEF Canada [@UNICEFCanada]. (2021, January 1, 10:30 ET). Happy 2021 from all of us (and with assistance from some of 2020's first newborns). Thank you for all your [Tweet; images]. Twitter. https://twitter.com/UNICEFCanada/status/1345029658627231747

UNICEF South Africa [@UNICEF_SA]. (2021, January 31, 9:05 ET). Parents and Caregivers 】 Knowing how to protect your children from the affects of \#COVID19 is very important. This guide is. [Tweet; image; link to webpage]. Twitter. https://twitter.com/UNICEF_SA/status/1355879773478776835

UNICEF South Africa [@UNICEF_SA]. (2021, January 30, 3:05 ET). "Me and my mother tested positive. She went to the hospital - I wanted to cry" - Bokang | Bloemfontein. [Tweet; video]. Twitter. https://twitter.com/UNICEF_SA/status/1355426794711736321

UNICEF South Africa [@UNICEF_SA]. (2021, January 30, 9:05 ET). Our partners @ WorldVisionSA took on the \#TippyTapChallenge together with residents of Silver Town and Old Hostel informal settlement in Soweto. [Tweet; images]. Twitter. https://twitter.com/UNICEF_SA/status/1355517392781266947

UNICEF South Africa [@UNICEF_SA]. (2021, January 29, 3:05 ET). “There are thousands of people who are dying from this disease, so you should ask yourself - 'what makes you so. [Tweet; videos]. Twitter. https://twitter.com/UNICEF_SA/status/1355064462173200385 UNICEF South Africa [@UNICEF_SA]. (2021, January 29, 8:45 ET). We must \#reimagine a Ofit \#ForEveryChild as we respond to this global health, economic, and social crisis. Thanks to @LouisVuitton’s [Tweet; image]. Twitter. https://twitter.com/UNICEF_SA/status/1355149986527379456 
UNICEF South Africa [@UNICEF_SA]. (2021, January 28, 3:05 ET). “To be honest, I was ignorant and said, 'no, there is no \#COVID19'- until I realised that it does exist". [Tweet; video]. Twitter. https://twitter.com/UNICEF_SA/status/1354702059879215105

UNICEF South Africa [@UNICEF_SA]. (2021, January 28, 8:20 ET). More than 39 billion inschool meals have been missed globally since the start of the \#COVID19 pandemic due to school [Tweet; image; link to report]. Twitter. https://twitter.com/UNICEF_SA/status/1354781421198602242

UNICEF South Africa [@UNICEF_SA]. (2021, January 26, 3:05 ET). “We must take safety measures [...] for the protection of the person sitting next to you-that is all we. [Tweet; video]. Twitter. https://twitter.com/UNICEF_SA/status/1353977240657211393

UNICEF South Africa [@UNICEF_SA]. (2021, January 26, 7:45 ET). Hand washing with soap and water is STILL one of the best ways to protect yourself, and those around you, from \#COVID19sa. [Tweet; image]. Twitter.

https://twitter.com/UNICEF_SA/status/1354047709649502208

UNICEF South Africa [@UNICEF_SA]. (2021, January 25, 3:05 ET). “It's really terrifying what's going on. Young people are contracting COVID-19 and bringing it to the elderly and the elderly. [Tweet; video]. Twitter. https://twitter.com/UNICEF_SA/status/1353614851076222976

UNICEF South Africa [@UNICEF_SA]. (2021, January 24, 3:05 ET). “My friend, she got sick and then I couldn't play with her. I was afraid" - Neishay | Despatch. @ HealthZA @NMandelaBaymuni. [Tweet; video]. Twitter. https://twitter.com/UNICEF_SA/status/1353252507703779328 
UNICEF South Africa [@UNICEF_SA]. (2021, January 23, 8:15 ET). \#COVID19 does not rest. \#MaskUpMzansi $\bigcirc$ open windows and meet outside wash your hands with soap Oco avoid large. [Tweet; image]. Twitter. https://twitter.com/UNICEF_SA/status/1352968095577550848

UNICEF South Africa [@UNICEF_SA]. (2021, January 23, 3:05 ET). “You are isolated from your loved ones, you cannot be visited and you can't go visit others" - Mziwoxolo Nxele. [Tweet; video]. Twitter. https://twitter.com/UNICEF_SA/status/1352890099915247617

UNICEF South Africa [@UNICEF_SA]. (2021, January 22, 3:05 ET). “When my brother tested positive, he struggled a lot to get a bed at the hospital, and we were really. [Tweet; video]. Twitter. https://twitter.com/UNICEF_SA/status/1352527732001927168

UNICEF South Africa [@UNICEF_SA]. (2021, January 22, 7:25 ET). To \#reimagine and \#rebuild a better world for children, UNICEF South Africa has put forward a clear agenda for action. [Tweet; image; link to webpage]. Twitter. https://twitter.com/UNICEF_SA/status/1352595649729077248

UNICEF South Africa [@UNICEF_SA]. (2021, January 21, 3:05 ET). “That's when we realised that this virus is not only for certain people, it is dangerous to everyone" - Yanelisa Mhambi. [Tweet; video]. Twitter. https://twitter.com/UNICEF_SA/status/1352165301773807617

UNICEF South Africa [@UNICEF_SA]. (2021, January 21, 8:00 ET). Tips and guidance for early learning at home \& 8 htps://uni.cf/3p2Yrlm. [Tweet; image; link to webpage]. Twitter. https://twitter.com/UNICEF_SA/status/1352239633632002048 
UNICEF South Africa [@UNICEF_SA]. (2021, January 20, 8:40 ET). ICYMI "On the road to slowing COVID-19 in South Africa" with @tobyfricker and @C_Muhigana Fhttps://uni.cf/3bG96yw. [Tweet; image; link to article] Twitter. https://twitter.com/UNICEF_SA/status/1351887214758801411

UNICEF South Africa [@UNICEF_SA]. (2021, January 19, 9:30 ET).Through the \#TippyTapChallenge, UNICEF and @ WorldVisionSA teams assisted with 80 Tippy Tap activations in Khayelitsha. Tippy Taps continue to be a. [Tweet; images; link to webpage]. Twitter. https://twitter.com/UNICEF_SA/status/1351537491887665156

UNICEF South Africa [@UNICEF_SA]. (2021, January 18, 3:05 ET). "I realised that this thing is real when it took my husband's life” - Mama Mahlangeni, Bloemfontein @ HealthZA $@ f s \_$health \#StaySafe. [Tweet; video]. Twitter. https://twitter.com/UNICEF_SA/status/1351078141041774593

UNICEF South Africa [@UNICEF_SA]. (2021, January 17, 3:05 ET). "We must take safety measures [...] for the protection of the person sitting next to you - that is all we. [Tweet; video]. Twitter. https://twitter.com/UNICEF_SA/status/1350715778035814400

UNICEF South Africa [@UNICEF_SA]. (2021, January 16, 3:00 ET). “I tested positive in July, I fell sick and had to quarantine. That is when I infected my sister, she. [Tweet; video]. Twitter. https://twitter.com/UNICEF_SA/status/1350352097523466240

UNICEF South Africa [@UNICEF_SA]. (2021, January 16, 9:15 ET). For \#COVID19 news, resources as well as tips on protecting you and your family from the virus, visit: https://uni.cf/2K62RZi. [Tweet; image; link to webpage]. Twitter. https://twitter.com/UNICEF_SA/status/1350446476992901120 
UNICEF South Africa [@UNICEF_SA]. (2021, January 15, 3:00 ET). “Any visitor that come to your home, sanitize; even if it sounds to them like the same old story" - [Tweet; video]. Twitter. https://twitter.com/UNICEF_SA/status/1349989777999847425

UNICEF South Africa [@UNICEF_SA]. (2021, January 15, 7:35 ET). As a second \#COVID19 wave hits \#SouthAfrica, community awareness raising via \#TheTruck is vital to \#FlattenTheCurve. @tobyfricker reflects on a. [Tweet; image; link to article]. Twitter. https://twitter.com/UNICEF_SA/status/1350056398684631040

UNICEF South Africa [@UNICEF_SA]. (2021, January 15, 9:30 ET). Myths, conspiracies, rumours and misinformation - we're all hearing them, but need to listen to this: Watch Prof Salim. [Tweet; link to video]. Twitter.

https://twitter.com/UNICEF_SA/status/1350087877728854016

UNICEF South Africa [@UNICEF_SA]. (2021, January 15, 7:01 ET). Over the \#FestiveSeasontogetherwith @WorldVisionSA and the Impact Resource Centre-4,925 home visits in \#Khayelitsha in the Western Cape. [Tweet; image]. Twitter.

https://twitter.com/UNICEF_SA/status/1350050350292676608

UNICEF South Africa [@UNICEF_SA]. (2021, January 14, 9:00 ET). \#TheTruck and @NokoMashaba were at Carousel plaza toll gate earlier today broadcasting \#COVID19 prevention messaging before visiting Hammanskraal taxi rank [Tweet; images]. Twitter. https://twitter.com/UNICEF_SA/status/1349718006239211521

UNICEF South Africa [@UNICEF_SA]. (2021, January 14, 3:00 ET). “When I contracted the virus, and I had those symptoms, I started to realise how serious it is" - Anthony, Northern Cape. [Tweet; video]. Twitter.

https://twitter.com/UNICEF_SA/status/1349627429413933056 
UNICEF South Africa [@UNICEF_SA]. (2021, January 14, 7:18 ET). Free Download $\downarrow$ https://uni.cf/3oLdRu7. [Tweet; image; link to webpage]. Twitter. https://twitter.com/UNICEF_SA/status/1349692453239009280

UNICEF South Africa [@UNICEF_SA]. (2021, January 13, 9:36 ET). "Can I have a word with you?" - \#TheTruck and @ NokoMashaba at the Grasmere toll plaza earlier today after a [Tweet; images]. Twitter. https://twitter.com/UNICEF_SA/status/1349364809989574658

UNICEF South Africa [@UNICEF_SA]. (2021, January 12, 7:45 ET). UNICEF's \#TheTruck is in Sedibeng today sharing \#COVID19 prevention messages. As South Africa's health system continues to take strain from. [Tweet; images]. Twitter. https://twitter.com/UNICEF_SA/status/1348974272140730368

UNICEF South Africa [@UNICEF_SA]. (2021, January 11, 9:10 ET). \#COVID19 has reminded us that we can't look away when our neighbours' are in need. Today we celebrate \#UN75 for. [Tweet; video]. Twitter. https://twitter.com/UNICEF_SA/status/1348633402036129792

UNICEF South Africa [@UNICEF_SA]. (2021, January 11, 1:05 ET).UNICEF's \#TheTruck and Community Health Workers from West Rand District were joined in Randfontein today by @ SAPoliceService Here, Malome Dons. [Tweet; images]. Twitter. https://twitter.com/UNICEF_SA/status/1348692418565173250

UNICEF South Africa [@UNICEF_SA]. (2021, January 10, 3:00 ET). Sunday at home with the family? Build a Tippy Tap! Washing hands with soap and water is one of the. [Tweet; image; link to webpage]. Twitter. https://twitter.com/UNICEF_SA/status/1348177854463414273 
UNICEF South Africa [@UNICEF_SA]. (2021, January 8, 8:55 ET). Thank you Springbok and Namaqualand! A hot day for the community engagement teams broadcasting the \#StaySafe message. Lets continue to. [Tweet; images]. Twitter. https://twitter.com/UNICEF_SA/status/1347542336734113798

UNICEF South Africa [@UNICEF_SA]. (2021, January 7, 9:30 ET). The @nc_doh and @SARedCross community engagement teams are in Upington today, spreading key \#COVID19 prevention messages $₫$ \#Springbok, see you. [Tweet; images]. Twitter. https://twitter.com/UNICEF_SA/status/1347188773138870275

UNICEF South Africa [@UNICEF_SA]. (2021, January 6, 2:00 ET). “My husband was infected with \#COVID19, and my test was negative. When I heard he passed away, it was so hard" [Tweet; video]. Twitter. https://twitter.com/UNICEF_SA/status/1346713219990245378

UNICEF South Africa [@UNICEF_SA]. (2021, January 6, 10:15 ET). UNICEF's \#TheTruck, the @nc_doh and @SARedCross teams are wrapping up community engagement in Galeshewe, Kimberley this afternoon. Next stop: Upington. [Tweet; images]. Twitter. https://twitter.com/UNICEF_SA/status/1346837697630003203

UNICEF South Africa [@UNICEF_SA]. (2021, January 6, 5:00 ET). Washing our hands with soap and water is one of the best defences against \#COVID19SA. But not everyone has access. [Tweet; image; link to report]. Twitter. https://twitter.com/UNICEF_SA/status/1346758473560838146

UNICEF South Africa [@UNICEF_SA]. (2021, January 5, 4:00 ET). “I so wish that everyone out there, they take this virus seriously" - Dumelo Notsiki, Kimberley. Look out for UNICEF's \#TheTruck. [Tweet; video]. Twitter. https://twitter.com/UNICEF_SA/status/1346381041666240512 
UNICEF South Africa [@UNICEF_SA]. (2021, January 4, 8:35 ET).\#2021 has begun. Let's all continue to do our part to slow the spread of \#COVID19SA. - Wear your mask. [Tweet; image]. Twitter. https://twitter.com/UNICEF_SA/status/1346087755626000385

UNICEF South Africa [@UNICEF_SA]. (2021, January 4, 4:00 ET). Let's Stop \#COVID19 WATCH: https://uni.cf/2M101Wb@HealthZA@NMandelaBaymuni @COVID_19_ZA @WorldVisionSA @SARedCross \#StaySafe. [Tweet; image; link to video]. Twitter. https://twitter.com/UNICEF_SA/status/1346018698524561408

UNICEF South Africa [@UNICEF_SA]. (2021, January 4, 12:00 ET). Northern Cape we see you! UNICEF's \#TheTruck was in \#Hanover today sharing crucial \#COVID19 prevention messaging with the amazing community. [Tweet; images]. Twitter. https://twitter.com/UNICEF_SA/status/1346139419435290625

UNICEF South Africa [@UNICEF_SA]. (2021, January 2, 8:00 ET). A fairer and safer world for children is possible. As we enter \#2021, UNICEF South Africa is committed to building. [Tweet; image; link to article]. Twitter. https://twitter.com/UNICEF_SA/status/1345354290890760195

Vafeiadis, M., Bortree, D. S., Buckley, C., Diddi, P., \& Xiao, A. (2019). Refuting fake news on social media: Nonprofits, crisis response strategies and issue involvement. Journal of Product \& Brand Management, 29(2), 209-222. https://doi.org/10.1108/JPBM-12-2018$\underline{2146}$

Valenzuela, S., Piña, M., \& Ramírez, J. (2017). Behavioral Effects of Framing on Social Media Users: How Conflict, Economic, Human Interest, and Morality Frames Drive News Sharing. Journal of Communication, 67(5), 803-826. https://doi.org/10.1111/jcom.12325 
Viljoen K, L., Dube L., \& Murisi T. (2016). Facebook versus Twitter: Which one is more credible in a South African context? South African Journal of Information Management, 18(1), 1-7. https://doi.org/10.4102/sajim.v18i1.718

Wang, Y., \& Yang, Y. (2020). Dialogic communication on social media: How organizations use Twitter to build dialogic relationships with their publics. Computers in Human Behavior, 104, 1-3. https://doi.org/10.1016/j.chb.2019.106183

Waters, R. D., \& Jamal, J. Y. (2011). Tweet, tweet, tweet: A content analysis of nonprofit organizations' Twitter updates. Public Relations Review, 37(3), 321-324.

https://doi.org/10.1016/j.pubrev.2011.03.002 